University of Louisville

ThinkIR: The University of Louisville's Institutional Repository

Electronic Theses and Dissertations

$5-2011$

\title{
The Texas $10 \%$ law and its impact on admitted students.
}

C. J. Woods

University of Louisville

Follow this and additional works at: https://ir.library.louisville.edu/etd

\section{Recommended Citation}

Woods, C. J., "The Texas 10\% law and its impact on admitted students." (2011). Electronic Theses and Dissertations. Paper 1590.

https://doi.org/10.18297/etd/1590

This Doctoral Dissertation is brought to you for free and open access by ThinkIR: The University of Louisville's Institutional Repository. It has been accepted for inclusion in Electronic Theses and Dissertations by an authorized administrator of ThinkIR: The University of Louisville's Institutional Repository. This title appears here courtesy of the author, who has retained all other copyrights. For more information, please contact thinkir@louisville.edu. 


\author{
By \\ C. J. Woods \\ B.S., University of Southern Mississippi, 1993 \\ M.A., George Mason University, 1995 \\ A Dissertation Proposal \\ Submitted to the Faculty of the \\ Graduate School of the University of Louisville \\ and \\ Graduate Studies and Research at Western Kentucky University \\ in Partial Fulfillment of the Requirements \\ for the Degree of
}

\begin{abstract}
Doctor of Philosophy
Department of Leadership, Foundation, and Human Resource Education University of Louisville and

College of Education and Behavioral Sciences

Western Kentucky University
\end{abstract}

May 2011 
Copyright 2011 by C. J. Woods

All rights reserved 


\title{
THE TEXAS 10\% LAW AND ITS IMPACT ON ADMITTED STUDENTS
}

\author{
By
}

C.J. Woods

B.S., University of Southern Mississippi, 1993

M.A., George Mason University, 1995

A Dissertation Approved on

March 31, 2011

by the following Dissertation Committee:

Dissertation Director

Bill C. Miller 


\begin{abstract}
THE TEXAS 10\% LAW AND ITS IMPACT ON ADMITTED STUDENTS

C. J. Woods

May 1, 2011
\end{abstract}

This qualitative case study explored the experiences of 10 Top $10 \%$ African American and Hispanic students at Texas A\&M University. The purpose of the study was to examine how the Texas Top 10\% Law influenced underrepresented students' perceptions of the law, application to universities under the law's provisions, and feelings of acceptance at a Texas flagship institution. Critical race theory (CRT) served as the theoretical framework for the study.

The data were collected using semistructured interviews and focus groups. The study confirmed linkages with CRT research on underrepresented students' experiences with Affirmative Action policy through exploration of social construction, differential racialization, and intersectionality. Findings indicated that (a) race and diversity on college campuses are still prevalent issues for African American and Hispanic students, (b) high-achieving African American and Hispanic students emphasize their merit rather than Affirmative Action policy for their presence at predominantly White institutions, PWIs, (c) family expectations and financial support for Top 10\% African American and Hispanic students are miniscule, and (d) there is limited understanding and knowledge of the Top 10\% Law in African American and Hispanic communities. 
These findings are meaningful to higher education officials, elected leaders, and policy makers in several ways. First, results clearly indicate that the Top 10\% Law is working, as reflected in the demographic composition of racially isolated schools. Second, the emphasis of the Top $10 \%$ law is on undergraduate admissions; the law does not impact enrollments or diversity goals for graduate and professional schools. Third, communication and dissemination of information between $\mathrm{K}-12$ schools and postsecondary institutions lack consistency.

Stories and statements from study participants validated much of the research on college choice and access. Using CRT as a framework, this study provided an alternative perspective on how African American and Hispanic students perceived, related to, and applied the Top $10 \%$ Law. 


\section{TABLE OF CONTENTS}

PAGE

\section{CHAPTER}

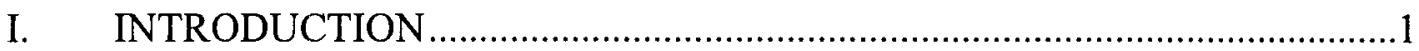

Statement of the Problem.............................................................................

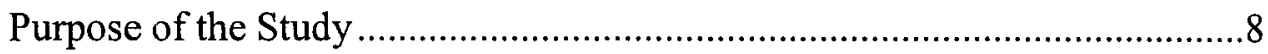

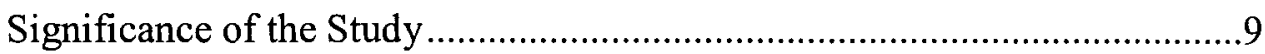

Researcher's Positionality...................................................................11

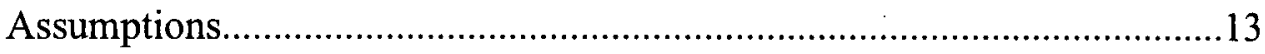

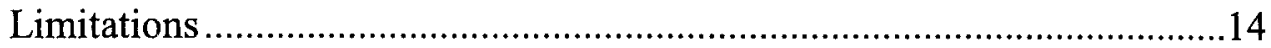

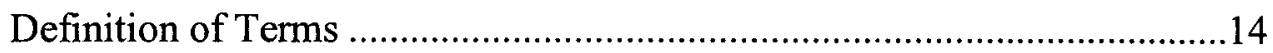

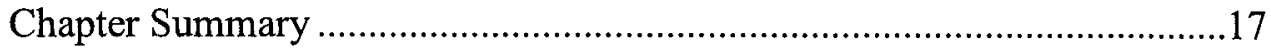

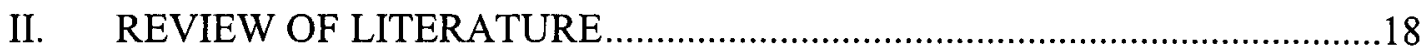

Civil Rights and Affirmative Action …………………….......................18

Integration in Higher Education ..........................................................19

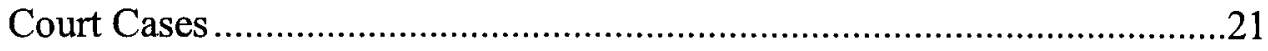

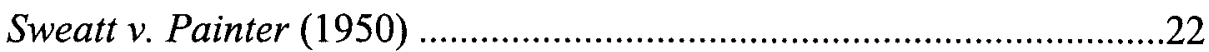

Brown v. Board of Education of Topeka (1954) ....................................23

Regents of the University of California v. Bakke (1978) .......................24

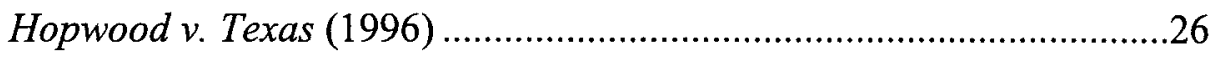

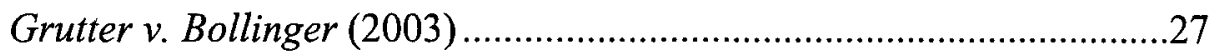




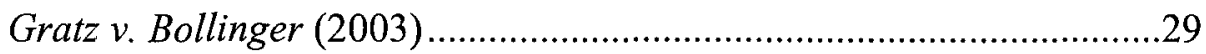

Societal Attitudes on Affirmative Action in Hiring......................................30

Attitudes on Affirmative Action, Admissions, and Higher Education..........38

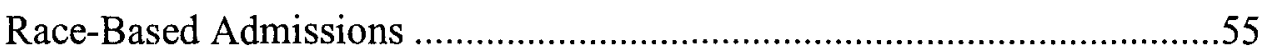

Alternative Strategies (State Policies) ………………………………........56

California Higher Education Affirmative Action Policy .........................57

Florida Higher Education Affirmative Action Policy .............................58

Texas Higher Education Affirmative Action Policy...............................60

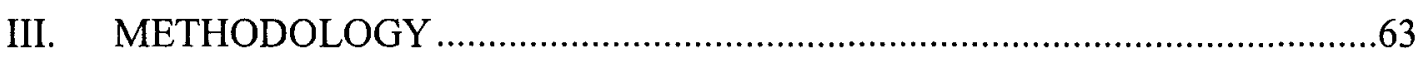

Statement of the Research Questions.............................................................64

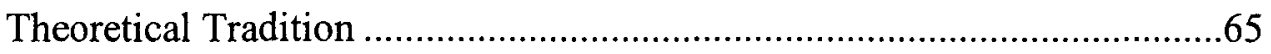

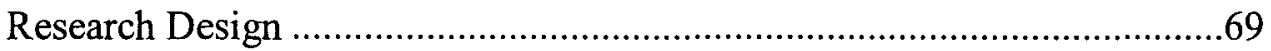

Site and Sample Selection........................................................................

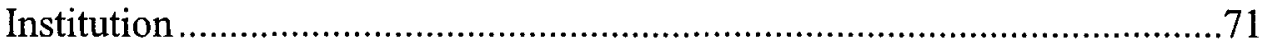

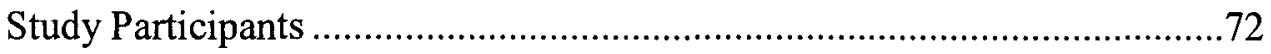

Researcher's Role Management .................................................................73

Entry

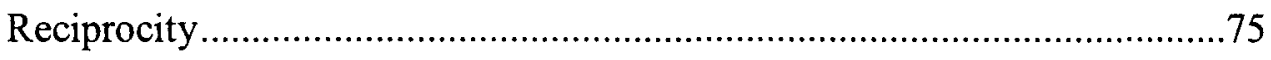

Ethics

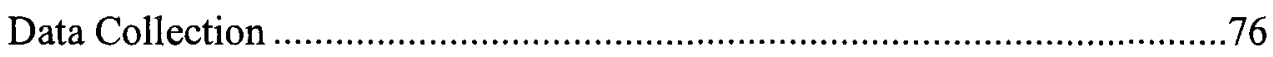

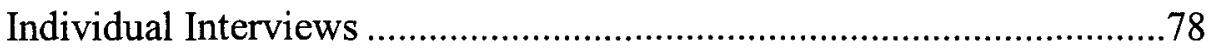

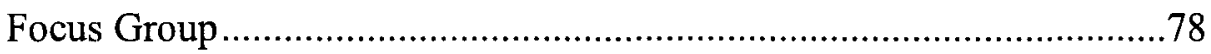

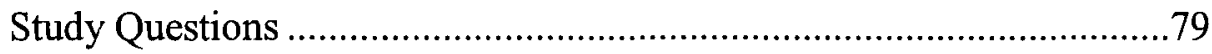




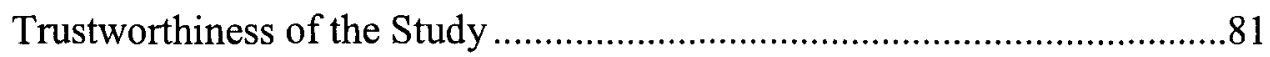

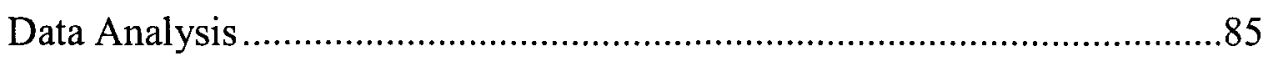

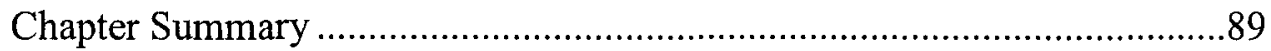

IV. DATA PRESENTATION AND ANALYSIS ................................................

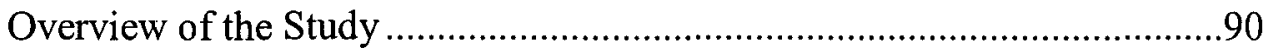

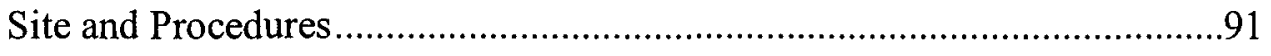

Study Participants' Characteristics ............................................................92

Focus Group Participants .....................................................................93

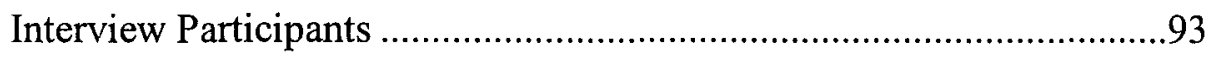

Summary of Reviewed Documents ...........................................................95

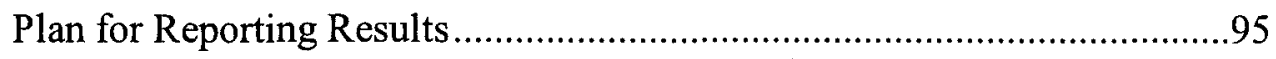

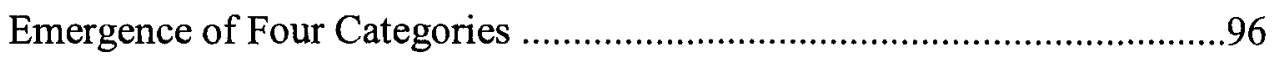

Results Produced by the Focus Group ......................................................100

Category 1: Importance of Diversity and Race.....................................100

Category 2: Personal Success and Rewards...........................................105

Category 3: Family Expectations and Support ……………………......108

Category 4: Knowledge of the Law ...................................................111

Results Produced in the Individual Interviews ..........................................113

Category 1: Importance of Diversity and Race....................................113

Category 2: Personal Success and Rewards..........................................117

Category 3: Family Expectations and Support ......................................120

Category 4: Knowledge of the Law ....................................................122 
Researcher's Log

Researcher's Log for the Focus Group Session..................................124

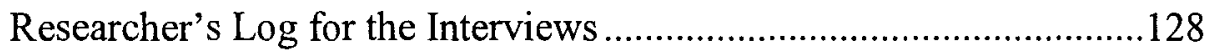

Results of the Review of Supporting Documents......................................130

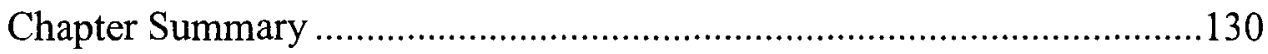

V. CONCLUSIONS AND RECOMMENDATIONS .........................................132

Relation to Theoretical Framework …………........................................132

Relation to Research Questions ................................................................134

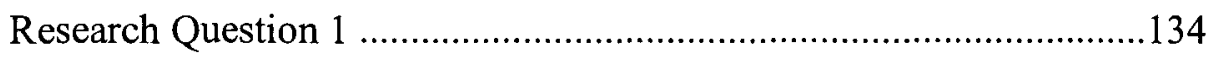

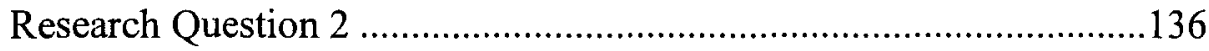

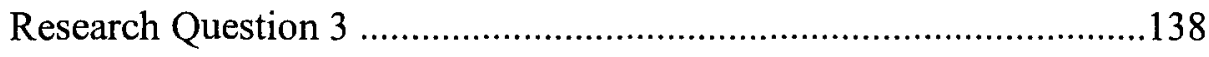

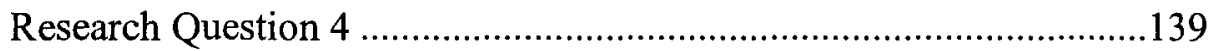

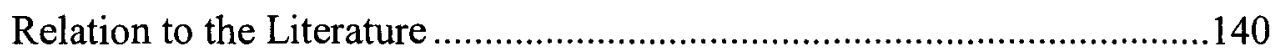

Recommendations for Practice ..............................................................143

Implications for Further Research ...........................................................

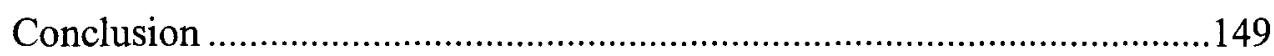

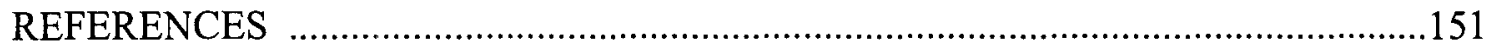

APPENDICES

A: Legislative Documents Reviewed .......................................................168

B: Focus Group Interview Protocol ..........................................................183

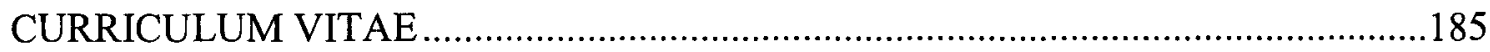




\section{LIST OF TABLES}

TABLE

PAGE

1. Demographic Characteristics of Focus Group Participants ..................................94

2. Demographic Characteristics of the Interview Participants...................................94

3. Conceptually Clustered Matrix for Individual Interviews .......................................98

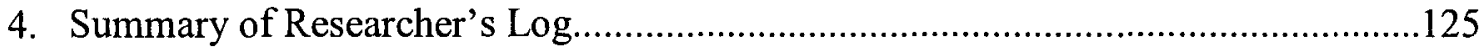




\section{LIST OF FIGURES}

FIGURE

PAGE

1. Summary of the percentage admissions plans in Texas, California, and Florida ........62

2. Conceptual illustration of the current study research questions and case.....................66

3. Linkage of the current study research questions to theory and current literature........69

4. Yin's chain of evidence model, with elements in ascending order..............................84

5. Summary of the Glaser and Strauss constant comparative method...............................86

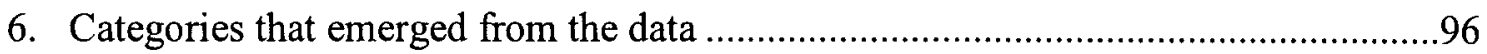




\section{CHAPTER I}

\section{NTRODUCTION}

The past two decades have witnessed broad swings in the legality of using affirmative action (AA) in university admissions and in the strategies used to boost minority enrollment (Long, M. C., \& Tienda, 2009). Members of the Supreme Court have disagreed on the educational value and effects of diversity in educational settings. In companion cases from the University of Michigan the Supreme Court reflected its own ambivalence in this regard, upholding the use of race-conscious AA admissions policies in its law school in the 2003 Grutter v. Bollinger case but striking down its application in its undergraduate programs in the 2003 Gratz v. Bollinger case (Russo \& Mawdsley, 2003).

AA policies aimed at equalizing access to higher education are under increased scrutiny due to a litany of complaints regarding institutional admissions practices and claims of reverse discrimination. Opponents of AA have often characterized AA as unfair, claiming that it violates a cherished system of meritocracy in the United States by basing selection decisions on demographic characteristics at the expense of ability and achievement (Crosby, Iyer, \& Sincharoen, 2006). Shaw (as cited in Watson, 2007) argued that minority students are the ones most affected by the rulings, not the plaintiffs or the institutions that are sued. 
AA has the goal of equal opportunity but differs from the policy of equal opportunity in being proactive. Equal opportunity assumes that, when there is not overt discrimination, equal opportunity exists for members of all groups. In contrast, AA is an active policy calling for action to ensure that equal opportunity actually exists (Crosby, Iyer, Clayton, \& Downing, 2003). AA thus involves proactive examination of whether equality of opportunity exists and, if it does not, a plan for taking concrete measures to eliminate barriers and to establish true equality (Crosby \& Cordova, 1996).

Harper and Reskin (2005) asserted that "AA in education resulted from the initiative of institutions of higher education whose leaders recognized that AA was a necessary part of their mission, and it relied primarily on race-conscious preferences" (p. 358). Maccabe (2004) asserted, "Many universities, especially those that were risk averse, were justifiably concerned about considering any dimension of race or ethnicity in admissions for fear that they would be subject to expensive lawsuits" (p. 423).

The first state to outlaw AA in the application process was California in 1995. The state passed a law banning AA in the state's higher education system, an action that was affirmed in 1996 in the passage of Proposition 209 (Rotthoff, 2008). Washington state voters passed Initiative 200 in 1998 to ban AA in state and local government hiring, contracting, and education. Simultaneously, federal courts began to consider lawsuits from White students claiming reverse discrimination based on universities' admissions policies. Meanwhile, various federal district and appellate courts have rendered different, even conflicting, opinions about the legality of AA plans at the University of Washington, the University of Texas, the University of Maryland, the University of Georgia, and, most recently and noticeably, the University of Michigan (Hebel, 2001). 
Faced with legal and political prohibitions against race-sensitive admissions, leaders in higher education began to devise alternative strategies to maintain their hard-earned campus diversity (Tienda, Leicht, Sullivan, Maltese, \& Lloyd, 2003).

According to Horn, Flores, and Orfield (2003),

When institutions say that they have ended AA, they are almost always talking about one part of an interrelated process, while continuing affirmative policies on other fronts, either through direct action or by adopting "race-attentive" recruitment policies focused on largely minority communities and schools. (p. 9).

Dickson (2006) asserted that the 5th Circuit Court decision in Hopwood v. Texas (1996) ended the use of consideration in college admissions in Texas and immediately impacted the application behavior of minority students.

As the two selective public institutions that practiced affirmative action prior to Hopwood, the University of Texas at Austin (UT) and Texas A\&M University (TAMU), witnessed significant declines in minority student enrollment. In response to mounting public concern regarding the ensuing drop in minority students at both public flagships, then Governor George W. Bush signed House Bill 588 (Uniform Admission Policy), which guarantees admission to all high school seniors with grades in the Top $10 \%$ of their own high school classes.

(Long, M. C., \& Tienda, 2009, p. 48)

"As public and judicial support for AA has waned, employers and educators have increasingly turned to diversity as a rationale for including underrepresented groups" (Harper \& Reskin, 2005, p. 357). Horn et al. (2003) argued, "In states where AA is comprehensively outlawed, campuses and states are actively pursuing a variety of 
outreach strategies that are focused on schools and areas with predominantly Black and Hispanic populations" (p. 9). The principal issue for predominantly White colleges and universities is how to restrict race-based preferences in admissions while taking AA to increase the diversity of the student body (Asagba \& Antwi-Boasiako, 2004). Methods for achieving campus diversity vary from state to state, with no continuity. Kain, O'Brien, and Jargowsky (2005) contended, Even though Hopwood v. Texas applied to colleges and universities in only three states (Texas, Louisiana, and Mississippi), the decision sent a shock wave through higher education, particularly causing concern at selective colleges and universities that had considered race in their admissions decisions and believed that their selection procedures were legal. (p. 3)

\section{Statement of the Problem}

"Dating back as far as 1862 with the passage of the Morrill Act" (Stefkovich \& Leas, 1994, p. 407), desegregating and providing equal access to education has been a thorny problem for the judiciary and higher education. Although the Morrill Act of 1862 (which extended federal financial support for the nation's land grant universities to provide the masses with scientific and practical training) did not directly address the educational inequalities for African Americans, the Morrill Act of 1862 is significant because it established separate land grant colleges for African Americans in South Carolina, Virginia, and Kentucky (Stefkovich \& Leas, 1994). Brown and Patterson (2004) noted that the Morrill Act of 1890 led to a proliferation of public institutions in the South with predominately or exclusively Black student enrollments. The establishment of separate but equal institutions due to racial stratification was legitimized by the landmark 
case Plessy v. Ferguson (1896). According to Roebuch and Murty (1993), the court's ruling in Plessy v. Ferguson (1896) would ultimately lead to the enactment of state laws prohibiting Black and White students' attendance at the same institutions.

While not a higher education case, or for that matter even a school case, Plessy preceded three important Supreme Court decisions that supported de jure school segregation: Cumming v. Board of Education (1899), Berea College v. Commonwealth (1908), and Gong Lum v. Board of Education (1972). (Stefkovich \& Leas, 1994, p. 408)

Twenty-five years after Berea College filed suit against the state of Kentucky, the National Association for the Advancement of Colored People (NAACP) launched an aggressive legal campaign to unseat the prevailing jurisprudential doctrine regarding separate treatment of Blacks and Whites spawned by the Plessy $v$. Ferguson decision. (Preer, 1982, as cited in Brown \& Patterson, 2004, p. 343) At the height of support for AA support in the mid-1960s, 1970s, and early 1980s, lawmakers and education policy makers were successful in implementing programs to foster minorities' inclusion in U.S. institutions with the weight of law. Maccabe (2004) asserted, "Although there was no clear rule of law for universities to follow as they tried to establish race-conscious admissions policies that were constitutional, most observers looked at Justice Powell's opinion for guidance" (p. 421). In the famous Regents of the University of California v. Bakke (1978), diversity was identified as a compelling state interest; therefore, educators have focused on diversity, rather than merit, in the hopes that their arguments will pass Constitutional muster. Moses and Chang (2006) stated, "By employing the diversity rationale, Powell shifted the justification of AA in higher 
education from a remedial justification to an educational one" (p. 9). As a result, U.S. businesses and universities have become committed to "diversity" as a concept, which has redefined their basic rules of employment, training, promotion, and admission.

Those who object to AA in education generally argue two points. First, they see the policy as unfair to majority group members; they ask the question, Is AA in education unfair to White or male students? Second, they claim that the policy is unfair to the underrepresented group members themselves. (Downing et al., 2002, p. 15)

Those who defend AA view it as a mechanism to promote equal opportunity and social mobility for underrepresented racial minorities, many of whom have been denied consideration for employment and education opportunities in the past (Fish, 1997; Johnson, 1965; Sher, 1997; West, 1997). Although vocal critics of AA have made the foregoing arguments (Herrnstein \& Murray, 1994; Sowell, 2004; Thernstrom \& Thernstrom, 1999a, 1999b), few empirical studies have sought to evaluate their claims. "Because AA plans presented by colleges and universities were neither defined systematically nor evaluated prior to Bowen and Bok's (1998) landmark study, baseline information for assessing college admissions criteria is weak to nonexistent" (Tienda, Leicht, et al., 2003, p. 1).

In the ongoing national debate regarding ways to enhance access for underserved students and promote the educational, economic, civic, and security benefits associated with a diverse student body, few topics have generated as much heat and as little light as "race-neutral alternatives." (Coleman, Palmer, \& Winnick, 2008, p. 3) 
Colleges and universities recognize the value of diverse student bodies and have worked vigorously to provide inclusive learning environments for students. Proponents have argued that maintaining AA policies in higher education increases the impact on diversity, especially at elite and selective institutions (Bowen \& Bok, 1998).

In view of the importance of improving access to quality education by minorities and in view of the number of states grappling with the same issues and policy choices as Texas, it is vital to understand the consequences of the Hopwood decision and the Top Ten Percent Plan. (Kain et al., 2005, p. ii)

Texas, California, and Florida are implementing different versions of percentage plans. These three states also share the distinction of being the nation's largest and most ethnically diverse states.

Since the use of percentage plans is a relatively new approach for ensuring student diversification in higher education, little is known about the outcomes of such efforts. Although it is difficult to predict how "percentage plans" in Florida and California will impact enrollment patterns in these states, critics contend that class-rank admissions policies will include many underprepared students, while excluding many academically capable students. Only the Texas plan has been in existence for a time period sufficient to analyze the potential impact of using "percentage" for admitting undergraduates. (Shushok, 2001, p. 4)

Texas moved to center stage in higher education during the late 1990s by shifting the terms of the AA debate. Following the 5th Circuit Court's decision outlawing the use of race-sensitive criteria in college admissions decisions, in 1997 the 
Texas legislature approved a bold experiment by changing the acceptable criteria to achieve diversity in higher education. (Tienda, 2006, p. 10)

"In contrast to the widespread dismay that followed the Hopwood decision, response to the Top 10\% Law has been generally favorable (Kain et al., 2005, p. 5). Despite growing opposition from legislators representing affluent school districts and University of Texas (UT) administrators, the Top $10 \%$ Law will remain in force at least through the 2010 admission season (Long, M. C., \& Tienda, 2009). "Like AA in the context of a tightening college squeeze, the Top 10\% Law has resurrected vitriolic debate about what constitutes academic merit" (Tienda, 2006, p. 11).

\section{Purpose of the Study}

The purpose of the current study was to examine Texas HB 588, also referred to as the "Top 10\% Law." The current study examined how the Texas Top 10\% Law influenced underrepresented students' perceptions of, application to, and feelings of acceptance at a Texas flagship institution.

Due to national attention on the constitutionality of race-conscious admission practices generated by the Hopwood, Gratz, and Grutter decisions, a growing body of empirical research regarding the "diversity rationale" has emerged. This research is focused on racial and ethnic enrollment trends at select flagship institutions, with limited insight regarding the impact on actual beneficiaries of AA policies in higher education.

"Although progress has been made, disturbing trends in minority enrollment persist. Students of color remain underrepresented at the most selective undergraduate institutions, in those that offer 4-year programs, and in graduate and professional schools" (U.S. Commission on Civil Rights, 2002, p. ix). The growing controversy about 
the educational benefits of diversity is far from settled. "As AA comes increasingly under fire, and if percentage plans grow in popularity, it is inevitable that the numbers, and subsequently proportions, of minority students pursuing higher education will decrease" (U.S. Commission on Civil Rights, 2002, p. x). There continues to be a pressing need to understand empirically how students, particularly underrepresented students, actually benefit, if at all, from race-neutral policies intended to provide equal access and opportunity since the Hopwood, Gratz, and Grutter rulings. The state of Texas and HB 588 provide a compelling case study because of the following factors: (a) Texas was declared a "majority-minority state" in 2005; non-Hispanic Whites constituted less than half of the state's total population (U.S. Census Bureau, 2005), and (b) the Texas percentage plan "differs from those used in Florida and California in that rank-eligible students are able to choose which public institution to attend, and high schools, rather than a centralized educational body, decide how to compute their class rank distributions" (Tienda, 2006, p. 11).

\section{Significance of the Study}

Political, legislative, and societal justification for using AA in higher education, specifically race-based preferences in admissions, has wavered, causing an unprecedented backlash in recruitment and admissions practices at American colleges and universities that has not been witnessed since the 1978 Bakke decision. Cole and Barber (2003) noted that there is indeed a delicate balance, pointing out that there is no agreement on how to achieve diverse student bodies and faculty. Moses and Chang submitted, 
The end goal of an AA program based on the diversity rationale is not to benefit the particular candidate admitted under the program" but that the "candidate's presence within the school or, subsequently, within the broader professional community is intended to benefit others. (as cited in Brest \& Oshige, 1995, p. 9) "Over the last quarter-century, research on higher education policymaking has been dominated by an open-systems, organization-environment perspective [in which] toplevel administrators within the university mediate and negotiate demands into policy, which is voted on by a board of trustees" (Pusser, 2001, p. 123). Such policies are the percentage plans adopted by Texas, California, and Florida. According to the American Council on Higher Education (2001), the use of percentage plans is a relatively new approach for ensuring student diversification in higher education, and little is known about the outcomes of such efforts. Only the Texas plan has been in existence for a time period sufficient to analyze the potential impact of using "percentage" for admitting undergraduates.

Texas is an appealing case study because it has witnessed quite intense population diversification in recent years; because its college-eligible population will continue to grow well into the future, even as that of others shrinks; because the state fares poorly on various educational indicators compared with other states of comparable wealth; and because the state legislature passed H.B. 588, known as the Top 10\% Law, which was designed to increase college attendance of minority populations after affirmative action was judicially banned. (Tienda, 2006, p. 3) Opponents contend that the law has had unintended consequences of crowding out other qualified students from academically competitive high schools who do not rank in the top 
$10 \%$ of their class. "In effect, the terms of exclusion changed from members of minority groups (Blacks and Hispanics, specifically) to underperforming schools" (Tienda \& Niu, 2006b, p. 713). Arguably, the two groups-minority groups and underperforming schools—are synonymous populations. Again, underrepresented students from less competitive high schools are beneficiaries and victims of the $10 \%$ law. The Top $10 \%$ Law has been criticized for giving students from underperforming schools an unfair advantage. Ironically, HB 588 has become the center of controversy, much like the AA policies that it replaced.

This study can provide legislators, educators, and university administrators data that will generate insight into the thoughts and opinions of African American and Hispanic students regarding HB 588. This study will make a contribution to policy discussions at the state level regarding amending the Top $10 \%$ Law or eliminating the law completely. Given this background, gaining a better understanding of the history and rationale for the Top 10\% Law and underrepresented students' beliefs regarding the law will enable policymakers, Texas legislators, higher education administrators, and university presidents to make informed decisions regarding the future of HB 588 and race-neutral policies in Texas.

\section{Researcher's Positionality}

As the researcher in this qualitative study, I was the primary instrument for gathering and analyzing data. To conduct the study ethically, I needed to be aware of my own research biases as an underrepresented African American student and administrator before attempting to proceed with the study. 
I am an African American male, second-generation college graduate from Mound Bayou, Mississippi. Having grown up in a family of educators (mother a high school guidance counselor and father a mathematics teacher), I personally understood the value of education and the role of AA policies in my degree attainment. My mother made sure that my siblings and I were in college track courses that would allow us to compete for scholarships upon graduation from high school. Although my parents prepared us adequately for our educational pursuits, financial barriers challenged my parents as my brother and I were in college at the same time. Because I had graduated in the top percentile of my senior high school class, I was eligible for certain scholarships that were not available to my peers. I remember vividly on Senior Night feeling somewhat ashamed of all of the accolades and scholarship offers that I had received as a result of my academic success. Although my parents and family were proud of my accomplishments that night, there was unrest among my peers as they considered those of us who were receiving large scholarships to attend college. Due to scholarships and financial aid, I was able to venture from home and attend a 4-year institution in another region of the state. While attending the University of Southern Mississippi, a predominantly White institution (PWI), I was often questioned about why I had chosen to attend that school far from former high school classmates and relatives. The norm for my high school and community (and the experience of my parents) had been to attend the local community college or one of the historically Black colleges or universities (HBCUs) in Mississippi, such as Mississippi Valley State, Jackson State, Alcorn State, or Tougaloo College. One other student from my high school graduating class also chose to attend the University of Southern Mississippi because the opportunity was not always available for African 
American students from my high school to attend a PWI. The majority of our classmates attended a community college or one of the HBCUs close to home. Being an African American student at the University of Southern Mississippi presented academic and social challenges. However, I enjoyed the opportunity and the experience to learn at a progressive 4-year institution and in a progressive community. Although I am proud of my accomplishments at that university, I never really felt the "joy" of being fully accepted because of the perceptions of African American students who were scholarship recipients or beneficiaries of AA policies.

I understand and recognize that race in college admissions is still a contested issue in higher education as institutions strive to increase racial and ethnic diversity on their campuses. My own experiences with AA in higher education caused me at times to question its utility. While conducting this research, I was challenged to be cognizant of my personal biases as a result of my experiences as a college student and an administrator at a flagship institution. I made strong efforts to ask questions that would allow participants to reflect on their own experiences at Texas A\&M University. As a university administrator, I was careful not to impose my presence on participant students. It was important that participants view me as a graduate student doing research, rather than an administrator. I was keenly aware of my role and clearly defined my intent so students would feel comfortable in sharing their real life experiences as Top 10\% recipients.

\section{Assumptions}

Due to extensive media coverage of the Top $10 \%$ Law, it was assumed that students would have a general understanding and opinion of the law. Furthermore, since 
the students interviewed were primary beneficiaries of the law, it was also assumed that the law was a principal reason for their selection of an in-state flagship institution.

\section{Limitations}

A limitation of the study is media attention on the Top $10 \%$ Law. The law has been the topic of constant debate in the Texas Legislature. Texas legislators seeking to change the law are lobbying for a lower percentage of automatic admissions to Texas public institutions. The media coverage of the law may have impacted students' attitudes and knowledge of the law.

Only a small sample of Hispanic and African American students from one Texas flagship institution were interviewed; their responses do not represent the experiences of all underrepresented minority Top $10 \%$ recipients in Texas. Although percentage plans exist in other states, the criteria, demographics, and political climate surrounding the adoption of percentage plans vary from state to state. Therefore, generalizing the findings of this study beyond Texas flagship institutions was not the intent of this study. Qualitative studies are transferable, meaning that it is up to the reader to make inferences concerning the nature and relevance of data (Lincoln \& Guba, 1985). Instead, this study was intended as a data source to contribute to current literature on the Top $10 \%$ Law.

\section{Definition of Terms}

Affirmative action. Voluntary and mandatory efforts undertaken by federal, state, and local governments, private employers, and schools to combat discrimination and to promote equal opportunity in education and employment for all (American Psychological Association, 1996). 
Civil Rights Act of 1964. Signed into law by President Lyndon Johnson on July 2, 1964, the act outlawed segregation in businesses such as theaters, restaurants, and hotels. It banned discriminatory practices in employment and ended segregation in public places such as swimming pools, libraries, and public schools (LegalView, n.d.).

Diversity. Although defined broadly in terms of providing multiple opinions and frames of reference, for most educational institutions the word refers to ethnic and socioeconomic diversity in students' backgrounds (Judkins \& LaHurd, 1999).

Ethnic group. Group of people who share a common heritage and reflect identification with some collective or reference group, often in a common homeland (Cushner, McClelland, \& Safford, 2006).

Executive Order 10925. An executive order mandating government contractors to take AA to ensure that applicants are employed and treated during employment without regard to race, creed, color, or national origin (LegalView, n.d.).

Executive Order 11246. An executive order issued by President Lyndon Johnson in 1965 which required the federal government and each organization that has a contract with the federal government to have an AA plan (Crosby \& Clayton, 2001).

House Bill 588. Bill enacted into law by the 75 th Texas legislature to guarantee college seniors who graduate in the Top $10 \%$ of their class admission to any Texas public college or university (Tienda, Alon, \& Nui, 2008).

Interest convergence. Thesis first proposed by Derrick Bell that the majority group tolerates advances for racial justice only when it suits its interest to do so (Delgado \& Stefancic, 2001). 
Percentage plan. Alternative to race-conscious admissions that calls for colleges and universities to admit the top students of each high school by taking a fixed percentage of the highest achievers and guaranteeing them admission to public universities (Gnagey, 2003).

Predominantly White institution. An institution whose student population is majority White, non-Latino.

Race-neutral policies. Policies that do not consider race in making admissions decisions but are designed to assemble a student body reflecting the diverse composition of the college-age population (Equal Justice Society, 2009).

Rural. Territory, population, and housing units located outside urbanized areas and urban clusters (U.S. Census Bureau, 2002).

Social construction. Process of endowing a group of concepts with a delineation, name, or reality (Delgado \& Stefancic, 2001).

Top 10\% Law. Popular reference to House Bill 588. (Tienda et al., 2008).

Underrepresented student groups. Those racial and ethnic populations that are underrepresented in higher education relative to their numbers in the general population (Association of American Medical Colleges, n.d.).

Urban. All territory, population, and housing units located within an urban area (UA) or an urban cluster (UC). UA and UC boundaries are delineated to encompass densely settled territory, which consists of core census block groups or blocks that have a population density of at least 1,000 people per square mile and surrounding census blocks that have an overall density of at least 500 people per square mile (U.S. Census Bureau, 2002). 


\section{Chapter Summary}

This chapter describes the overall problem, the research questions to be answered, the methodology, theoretical framework, significance of the study, and limitations of the study. The next chapter provides a comprehensive view of the literature surrounding AA and higher education admissions. 


\section{CHAPTER II}

\section{REVIEW OF LITERATURE}

This chapter presents a review of the literature on the history, court actions, and legislative mandates of AA in higher education. Using a funneling approach to research, AA policy is explored broadly and narrowed to the higher education arena. The first section explores the origins of AA and its integration into higher education policy as it relates to the historical and legislative foundations of higher education. The second section focuses on race-based admissions policies and court cases that have supported arguments for and against $\mathrm{AA}$ in higher education admissions. The third section reviews the most recent literature on alternative strategies to AA, specifically the Texas Top $10 \%$ Law.

\section{Civil Rights and Affirmative Action}

"The genesis of the term $A A$ is Executive Order (EO) 10925, issued by President Kennedy in 1961. When Kennedy used the term in 1961, he did so in reference to increasing the racial integration of workforces employed in federally financed projects" (Office for Civil Rights Evaluation, 2002, p. 2). EO 10925 required federal contractors to take AA to ensure that applicants were treated equally without regard to race, color, religion, sex, or national origin. EO 10925 was superseded by EO 11246.

In 1965 a bipartisan movement was launched at the highest levels of government to redress widespread discrimination against women and minorities in the work place. The result of this effort, which ultimately was signed into law by President 
Richard Nixon, was EO 11246, better known as the Equal Employment Opportunity Act, or colloquially, AA. (Reyna, Tucker, Korfmacher, \& Henry, 2005, p. 668)

The order required federal agencies and all private organizations that conduct business with the federal government to identify and eliminate discriminatory barriers. The primary objective of EO 11246 was to protect members of groups that were vulnerable to exclusion.

Government has taken the lead in pushing affirmative action. The employers and schools with affirmative action plans are either part of government, or are government-sponsored, or are private, but have been mandated or encouraged by government regulations to achieve diversity. (Bergmann, 1999, p. 758)

Flores and Rodriguez (2006) concluded, "Fundamentally, AA policies aim to identify individuals from a group that has experienced past discrimination in an attempt to balance access and opportunities for all, although the particular target groups, mechanism, and practice of various programs vary" (p. 303).

\section{Integration in Higher Education}

"It was not until the 1970 s that AA found its place in college admissions policies and substantively redressed the entrenched discrimination against racial and ethnic minorities and women in the admissions process" (Office for Civil Rights Evaluation, 2002 , p. 2). The societal unrest brought on by the civil rights movement of the 1950 s and 1960s prompted many colleges and universities to implement admissions policies aimed at systematically opening the doors of higher education to those to whom they had long and persistently been denied (Thelin, 2004). These practices became commonly referred 
to as AA, and supporters viewed them as a necessary and appropriate spur to ending discrimination of any sort and increasing the racial and ethnic diversity of student bodies and among the employment ranks of institutions of higher education (Clarke, 1996).

AA's dichotomous framing of "the included" and "the excluded" in higher education has been constitutionally challenged on the basis of reverse discrimination and a violation of equal rights under the Fourteenth Amendment of the U. S. Constitution. The affirmation action argument in higher education triggered a series of legal challenges that weakened the "diversity argument" that was eloquently stated by Justice Powell in 1978. Powell framed the Supreme Court decision in Bakke by stating that the educational benefits that flow from a racially and ethnically diverse student body in higher education is a "compelling interest" that can constitutionally support race-sensitive actions.

According to Downing et al. (2002),

In the past decade AA in education has provoked more strong sentiment in the nation than has AA in employment. Even though the number of Americans who are directly touched by AA programs in education is only about one quarter the number of those directly touched by AA in employment, issues of equity and merit in higher education can ignite intense feelings. (as cited in Crosby et al., 2006, p. 256)

While doors to public U.S. educational institutions are technically open to all, the great disparities in the educational system between Whites and ethnic/racial minorities have been diminished only modestly since President Lyndon Johnson signed EO 11246 in 1965, implementing AA policy. (Niemann \& Maruyama, 2005, p. 416) 


\section{Court Cases}

Extensive case law exists on AA and racial preferences in the United States. However, the following seven cases have had the greatest impact on issues pertaining to education: Plessy v. Ferguson (1896), Sweatt v. Painter (1950), Brown v. Board of Education of Topeka (1954), Regents of the University of California v. Bakke (1978), Hopwood v. Texas (1996), Grutter v. Bollinger (2003), and Gratz v. Bollinger (2003).

Although significant, EO 10925 and EO 11246 were politically and socially provoked by events predating the Civil Rights movement. Most notable was the "separate but equal" doctrine that involved two landmark court decisions that changed the political and social landscape of America: Plessey in 1896 and Brown in 1954.

In 1892 the Citizens' Committee to Test the Constitutionality of the Separate Car Law staged a challenge of the 1890 Louisiana Separate Car Act. Homer Plessey, one eighth Black and able to pass as White, agreed to serve as the test case by refusing to leave the White section of the rail car. Under Louisiana law Plessey was required to sit in the "colored" section of the rail car. Plessey was jailed for violating the law. The state courts ruled that he was in violation of the Louisiana law and that his Thirteenth and Fourteenth Amendment rights had not been violated. The case was heard by the U.S. Supreme Court, which upheld the state court ruling that separate but equal accommodations for Blacks and Whites on intrastate railroads was constitutional. The Supreme Court's decision upheld segregation and augmented "separate but equal" accommodations in the United States.

The Supreme Court's ruling had far-reaching social implications. The ruling implied that separate but equal accommodations in public facilities, business 
establishments, and education were acceptable. The Plessy ruling enforced social norms of second-class citizenship and denied equal access to Blacks. This began the social, education, and political divide that has conflicted race relations in America and stifled American colleges and universities.

Sweatt v. Painter (1950)

A forerunner to the Brown decision and just as significant to AA policy was Sweatt $v$. Painter (1950). Instead of using race as a plus factor, as in Hopwood, the University of Texas Law School (UTLS) considered race to exclude African Americans from being considered for admission. The University of Texas had established a separate law school for Blacks and other students of color.

Herman Marion Sweatt, a postal worker, sought admission to the UTLS rather than attend a separate and inferior law school designated for African Americans (Sweatt v. Painter, 1950). In 1950, the legal defense team of the NAACP represented Sweatt and five other African Americans before the U.S. Supreme Court. The Court unanimously agreed that Sweatt had the right to enroll at UTLS under the Equal Protection Clause. Speaking for a unanimous Court, Chief Justice Vinson wrote, "with such a substantial and significant segment of society excluded, we cannot conclude that the education offered [Mr. Sweatt] is substantially equal to that which he would receive if he were admitted to the University of Texas Law school" (Fine, 1973, p. 212). The Court cited that "the law school, the proving ground for legal learning and practice, cannot be effective in isolation from the individuals and institutions with which the law interacts" (Kidder, W. C., 2003, p. 4). The Court also found that the "law school for Negroes," 
which was to have opened in 1947, would have been grossly unequal to UTLS (Forsythe, 2003).

\section{Brown v. Board of Education of Topeka (1954)}

On December 9, 1952, Thurgood Marshall, head of the NAACP legal defense fund, challenged the "separate but equal" doctrine by arguing a Kansas lawsuit. Brown addressed the constitutionality of racial segregation and sought to reverse Plessy by consolidating five cases from the U.S. Court of Appeals from Delaware, the District of Columbia, Virginia, South Carolina, and Kansas (Brown v. Board of Education of Topeka, 1954). The plaintiffs in each case were parents, children, or community leaders challenging the "separate but equal" doctrine. The NAACP brought the suit on behalf of Oliver Brown. Oliver Brown's daughter, Linda, was forced by the local schools in Topeka, Kansas, to walk across railroad tracks miles from her home to attend a segregated school instead of attending a White school located in her neighborhood. The NAACP argued that segregated schools sent the message to Black children that they were inferior to Whites and that the schools attended by Black children were inherently unequal. The Topeka Board of Education's defense was that, because segregation in Topeka and elsewhere pervaded many other aspects of life, segregated schools simply prepared Black children for the segregation that they would face during adulthood (Bowen \& Bok, 1998).

On May 17, 1954, the U.S. Supreme Court ruled in favor of the NAACP's argument and affirmed that segregation of public schools as a form of racial isolation had a damaging effect on Black children. According to Moore (2005), the Court required all school systems to take affirmative steps to remove discriminatory practices. 
The essence of the Supreme Court's opinion in Brown (the consolidated cases) pronounced that the segregation of children in public schools solely because of their race generate in those children a feeling of inferiority as to their status in the community that may affect their hearts and minds in a way that is very unlikely ever to be undone. (Williams, 1987, as cited in Bickel, 2008, p. 5)

The Brown decision did not abolish segregation in other public areas, such as restaurants and restrooms, nor did it require desegregation of public schools by a specific time. However, the Brown decision brought a legal end to the practice of segregated education in the United States and was a bold statement at the federal level to end the stratification of the U.S. citizenry.

\section{Regents of the University of California v. Bakke (1978)}

One of the earliest and most extensive examinations of diversity justification in higher education appeared in Bakke. According to Chang (2005), no court decision has had more widespread influence on higher education admissions policies than Bakke, widely regarded as the cornerstone of the AA debate.

Allan Bakke, a 35-year-old White man, applied for admission to the University of California Medical School at Davis on two separate occasions. He was rejected both times. At the time of Bakke's application the school reserved 16 seats in each entering class of 100 students for "qualified" minorities (Regents of the University of California $v$. Bakke, 1978). To address a history of exclusion and unfair admission requirements for minority medical school candidates, the University of California (UC) reserved seats for minority candidates as their AA remedy. Bakke contended in the California Supreme 
Court and the U.S. Supreme Court that he had been denied admission to the school based solely on his race.

Justice Lewis Powell, Jr. issued the controlling opinion and upheld race-conscious admissions policies as "viable criteria in the admissions process on the groups that they support the important goal of producing a diverse student body representing many experiences and points of view to enrich the discussions and learning experiences on campus" (as cited in Orfield \& Whitla, 2001, p. 143). According to Powell, the selection of diverse students who contribute to an intellectually vibrant academic community was constitutionally permissible. Justice Powell explained that the medical school's desire to create a diverse student body to provide more minority physicians did not constitute a compelling state interest.

Justice Powell noted that there was insufficient evidence in the record that the medical school's special admissions program was needed or that it was likely to promote the stated goal of the program (Regents of the University of California v. Bakke, 1978). Powell also argued that the rigid numerical racial quotas employed at the school during the time that Bakke applied for admission violated the Equal Protection Clause of the Fourteenth Amendment and ordered the University to admit Bakke to the medical school (Orfield \& Whitla, 2001).

Since the Bakke ruling, diversity justification in higher education has been under scrutiny, with notable cases including Board of Education of Piscataway v. Taxman (1996) and Hopwood v. Texas (1996). Moore (2005) asserted that the Bakke case is what White applicants use as their foundation to attack AA based on race. The Bakke case has been characterized as the sample case of how AA negatively affects White applicants. 


\section{Hopwood v. Texas (1996)}

The Fifth Circuit Court of Appeals in Hopwood addressed whether race could be used as a factor in an educational institution's admissions program. The UTLS operated a dual-track admissions program that granted preferential treatment to African American and Mexican American applicants. The Supreme Court, in Podberesky v. Kirwan (1995), had found that race-conscious programs were inherently suspect in light of the Equal Protection Clause and must be subjected to the strictest scrutiny. In order to satisfy strict scrutiny, schools using race-conscious programs must demonstrate that their admission program serves two compelling governmental interests by remedying the present effects of past discrimination and promoting diversity within their student body (Regents of the University of California v. Bakke, 1978).

In 1992, Cheryl Hopwood, Douglass Carvell, Kenneth Elliot, and David Rogers were among the White applicants who applied for law school admission. Based on their Texas Admissions Test scores, the school placed them in the "discretionary zone." If any of the four students had been African American or Mexican American, their respective scores would have placed each of them in a "presumptive admit" category. However, all four applicants were denied. Moore (2005) noted that the university contended that part of its admissions process was established by the Office of Civil Rights through the Texas desegregation plan. The plan required the state to admit 10\% Mexican American and 5\% Black students in its entering class. The four applicants brought suit in federal district court, primarily under the Equal Protection Clause of the Fourteenth Amendment. The plaintiffs contended that they were discriminated against on the basis of race by the law school's process of evaluating their admissions (Hopwood v. Texas, 1996). 
Despite finding constitutionally valid reasons for using race in the admissions process, the district court determined that the admissions process violated the Equal Protection Clause (Hopwood v. Texas, 1996). The Fifth Circuit Court of Appeals went further than other courts in indicating that societal discrimination may not be the basis for remedial action. The court also indicated that diversity does not constitute a "compelling state interest" sufficient to justify remedies that are racially based. The Hopwood decision became the final ruling on race-based admissions policies in the Fifth Circuit (Louisiana, Mississippi, and Texas). The Hopwood court concluded that Texas had fulfilled its obligations to remedy a history of overt discrimination and that it was neither necessary nor permissible to continue racially targeted efforts to raise minority enrollment in the state's public universities (Orfield, 1998).

In 1997, Texas Attorney General Dan Morales issued a formal opinion to clarify the Hopwood decision for the Chancellor of the University of Houston system, William P. Hobby, Jr. Morales cited that Hopwood's race restrictions would apply to all institutional policies, including admissions, financial aid, scholarships, fellowships, and recruitment and retention. Based on this interpretation, the restrictions of Hopwood, in Texas, were extended in educational policies beyond admissions.

\section{Grutter v. Bollinger (2003)}

In 1997, the Center for Individual Rights filed two lawsuits against the University of Michigan, challenging its use of racial preferences in admissions. The first lawsuit, Gratz v. Bollinger (2003), was aimed at the University of Michigan's undergraduate admissions program and the second lawsuit, Grutter v. Bollinger (2003) challenged the University of Michigan's law school admissions system. 
The Grutter case originated in 1996 when Barbara Grutter, a White resident of Michigan, applied to the University of Michigan Law School. Grutter applied with a 3.8 undergraduate GPA and a Law School Admission Test (LSAT) score of 161 (Randall, 2006). Grutter was denied admission and filed suit in December 1997, alleging that she was denied admission because the law school used race as a predominant factor in their decision-making process, giving underrepresented minority applicants an advantage over White applicants. The named defendant in the case was Lee Bollinger, president of the University of Michigan.

The U.S. District Court ruled in 2001 that the admissions policies were unconstitutional because they clearly considered race and were indistinguishable from a quota system. In 2001, the Sixth Circuit Court of Appeals reversed the decision, citing Bakke and allowing the use of a compelling state interest to promote diversity in the law school. The case was appealed to the U.S. Supreme Court in 2003. The Court's ruling was that the Constitution did not prohibit the law school's narrowly tailored use of race in admissions decisions to enhance the diversity of the student body as an educational benefit and a compelling state interest. In Grutter, the Court ruled that, since the law school had taken great lengths to ensure that their admission office had taken a "narrowly tailored" approach in evaluating each of the applicants on an individual basis and to merely "subjectively consider race along with other factors," they had acted in a constitutional manner to achieve a compelling governmental interest (Brooks, 2003, p. 79). The Grutter decision upheld the Bakke decision, which allowed race to be a consideration in admissions policies but held racial quotas to be illegal. 


\section{Gratz v. Bollinger (2003)}

The U.S. Supreme Court heard Grutter v. Bollinger (2003) in conjunction with Gratz v. Bollinger (2003) but rendered separate and distinct rulings. In Gratz, Jennifer Gratz had been denied admission to the University of Michigan law school. Gratz alleged that the undergraduate admissions policies at the University of Michigan discriminated against White students via a point-based system that gave minorities and advantage.

The university used a point scale to rate prospective students on a number of factors, including high school grades, standardized test scores, high school quality, and difficulty of high school curriculum. In addition, a maximum of 40 points could be gained from among the following criteria: geography, alumni relationships, personal achievement and leadership, and a miscellaneous category (up to 20 points). From the miscellaneous category, one of the following point values could be assigned: men in nursing, scholarship athlete, socioeconomic disadvantaged, underrepresented racial or ethnic minority status, or provost's discretion. (Maccabe, 2004, p. 422)

Thus, in Gratz the Court struck down the University of Michigan's point-based undergraduate AA policy by disallowing the use of any quantification in admissions based on race.

The court affirmed that race-conscious admission does meet the strict scrutiny test and that it is constitutional for a university to use race as a criteria. As the court articulated, colleges and universities do have a compelling interest in obtaining a diverse student body. The court upheld the law school admissions policy and 
struck down the university's undergraduate policy for not being narrowly tailored. (Moore, 2005, p. 147)

The Court's decisions to support the University of Michigan's Law School in Grutter and to overturn the University's admissions policy in Gratz only raised more confusion and failed to resolve the ongoing debates over equality, AA, and raceconscious admissions in higher education (Moore, 2005). History was made once again when the Court made it clear that colleges and universities have Constitutional boundaries within which they can implement race-conscious admission policies.

Grutter and Gratz are the cornerstones of a societal and political paradigm shift in relation to AA policies in higher education. The debate is far from over; as Justice Scalia noted, while AA has been given approval for "at least 25 years," intense wrangling will surely continue (Sterrett, 2005, p. 24).

\section{Societal Attitudes on Affirmative Action in Hiring}

Davis (2002) attempted to study the differences in implementation of AA at postsecondary schools. She wished to compare "successful" programs (those with high percentages of minority faculty and students) and "unsuccessful" programs (those with lower percentages). From a list of 60 schools, 30 of which had the highest percentages of minority faculty and students and 30 of which had the lowest, she selected 16 schools that best matched each other regarding the following characteristics: size, cost, state versus private, rigor of administration standards, percentage of in-state students, percentage of older students, percentage of residential students, location (urban, suburban, rural), and state and local percentages of African American and Latino American residents. 
Davis interviewed 4 persons from each of the schools $(N=64)$ : the faculty AA administrator, the student $\mathrm{AA}$ administrator, a faculty member who was an anti-racism campus activist, and a student who was an anti-racism campus activist. The results showed that the successful schools differed from the unsuccessful schools in four main categories: (a) structures: successful schools had formal AA structure (i.e., positions, groups, offices, etc.) and informal structures (activities provoked by those who have no responsibility to do so; (b) practices: unsuccessful schools had fewer and less effective AA efforts than successful schools; (c) competence: employees and activists at the successful schools were more competent, especially among minority recruiters and multicultural affairs employees; and (d) climate: the unsuccessful schools were more likely to mention racism or discrimination as a problem on their campus but the successful schools had more campus-wide support for diversity. Davis's main conclusion was that there are many factors of racial composition on a college campus. She suggested (a) that a larger quantitative research project be attempted to test the validity of her findings, (b) that officials on campuses should provide those in charge of AA such as recruitment a mandate and solid guidelines to help them to become more competent, and (c) that officials consider a curriculum that "reflects racial diversity ... and employee training on affirmative action" (p. 151).

Button and Rienzo (2003) examined data regarding AA and Black employment in six Florida cities representative of the entire southern region of the United States. The researchers gathered data on 167 randomly selected businesses: 39 restaurants, 23 industrial or manufacturing firms, 20 financial businesses, 30 motels and apartment complexes, 43 retail stores, and 12 recreational establishments. They interviewed each 
establishment's hiring or promotional decision maker. The overall response rate $(88 \%)$ was very high, with only 3 businesses per city refusing to participate. The results showed that the mean for Black employment in every city was $26 \%$, whereas the Black population of these cities was $39 \%$. The researchers used an ordinary least squares (OLS) regression to explore the relationship between the independent variables. The regression analysis showed that the higher the percentage of Black applicants, the higher the percentage of Black employees. However, this was not true in professional or managerial positions due to these businesses being prone to promote from within the company. The predictor for this category was the number of Blacks already employed in the firms.

The main conclusion from this study was that a majority of Black employees in these businesses were in the skilled/semiskilled or menial categories in service-based businesses. Employer support of AA policies had a positive effect on the hiring of Blacks. It was also found that, even though enforcement of AA may have lagged, some employers still valued a diverse worker population, even without government influence, thus making AA still an important issue.

Schumaker and Kelly (1999) analyzed interviews with officials from several American cities. The cities were chosen due to their appropriate size and ethnic diversity; both were considered representative of the American population, ensuring that the AA issue would be relevant to them.

The researchers interviewed 112 urban officials in 1993. The interviews collected both qualitative and quantitative data. The researchers found information regarding the participants through stories that they volunteered and responses to open-ended responses. The participants' feelings about AA were rated on a scale ranging from 1 (strong 
opposition) to 7 (strong support). The interviewers questioned the interviewees about their feelings about equal opportunity using justice principles and followed up with a discussion. The participants seemed to have different interpretations of equal opportunity; some stated that it was necessary to create "a level playing field," while others described it as a "tilted playing field" that was necessary to rectify historical and social injustices.

The researchers concluded that, for an AA program to be successful, equal opportunity employment is crucial, while retaining market allocations can hinder progress in such a program. The experimenters suggested that moral principles, as well as the context in which a situation occurs, are required to construct a successful urban paradigm.

Hyer (1985) investigated the implementation of AA at doctorate-granting universities. The study participants were public and private universities that the Carnegie Council denominated as granting doctorates $(N=183)$. Hyer framed this study as a case study, observing the positive changes that had been made at the universities with regard to women faculty. The five criteria were changes that took place in the university faculty: proportion of women on the faculty, ratio of male to female faculty, number of women on the faculty, number of female full professors, and number of tenured women. The study examined base-year data collected in 1971 or 1972 to data collected in 1980-1981 (tenure data were collected in 1974). Of all universities polled, 159 yielded sufficient information. Of those, the three universities with the highest change index were chosen for the study.

The three universities (CKSU, Denby College, and Newton Universityapparently pseudonyms assigned by Hyer) proved to be diverse institutions. Denby 
College and Newton University are both private schools with very high standards and reputations, while CKSU is a public institution with a growing student body and an increased sophistication (typical to the trend that other southern universities have been experiencing). Even among the private schools there was diversity: Denby stressed the strength of its undergraduate populous in liberal arts and Newton was regarded for its graduate education in science and technology. These differences allowed the researchers to understand trends of AA implementation. CKSU approached the mandate of AA later and with much more resistance. However, it was found that on all three campuses there were three diverse but effective AA programs (Hyer, 1985)

The results of this study supported Newcombe's (1980) conclusions that a federal mandate can be more easily enforced with strong leadership from central administration faculty. However, although Newcombe was accurate in her hypothesis that leadership variables are most important in the adoption stage of a mandate, Hyer (1985) found that this study raised question regarding whether there is any stage during which strong leadership is not as important as other factors. The study found that environmental and structural changes played a role as well, although more so at CKSU than at Denby College or Newton University.

Hanna (1988) examined the opinions and reality of the AA movement in two U.S. universities: Stanford University and University of California at Berkeley. Hanna framed this study in the organizational context of the university hiring process. The study examined the (a) ratio of men and women faculty before and after the AA was passed in 1971-1973, (b) the process by which new appointments are made and new faculty are hired, (c) the ratio of men and women faculty in 1988, and (d) the hierarchy of power and 
administration at the two universities and the faculty's opinions about that distribution of power.

Faculty who oversaw most hiring and appointing decisions were interviewed $(N=$ $50+)$ and, with those interviews, evidence of their statements was provided. The interviews were checked for accuracy and validity and the researcher ensured agreement among the faculty. Also, 10 specific administration decisions were studied, ranging from the social sciences, the physical sciences, humanities, and professional schools. The studies spanned through 1970s and 1980s (Hanna, 1988).

The results of Hanna's (1988) study showed that, if AA is to be adopted totally, the administration must be open to stressing the concept. The interviews showed that many faculty members agreed with what the administration proposed (if context and/or culture do not contradict the view); one faculty member said, "If the people who run the place are genuinely concerned about affirmative action, I think that means more to me than anything else" (p. 299). Citing Pfeffer's study conducted in 1981, Hanna indicated that, when the opinions of a faculty are shaped by the administration, that is a demonstration and affirmation of their leadership.

However, in many universities the administration does not oversee appointments in departments; that task is left to the faculty. This lack of involvement by administration leads to AA not being implemented, even with the leadership of the dean, president, provost, or other supervisor. This problem can be resolved by assigning a withindepartment faculty member the task to maintain AA and ensure its enforcement.

Iyer, Leach, and Crosby (2003) investigated the influence of "White guilt" on supporting AA programs. They defined the term as "the dysphoria felt by European 
Americans who see their group as responsible for illegitimate advantage held over other racial groups, such as African Americans" (p. 118). The researchers conducted two separate studies.

The first study used a questionnaire given to undergraduates who self-identified as European American/White $(N=202)$. The results were based on the participants' responses to questions using a 7-point Likert-type scale developed by Swim and Miller (1999) regarding: belief in racial discrimination, belief in illegitimate White privilege, White guilt, and support for AA. The results of this study supported the researchers' hypotheses that beliefs regarding racial discrimination were not predictors of White guilt but that belief in illegitimate White privilege independently predicted White guilt, which was then an independent predictor of support for compensatory AA.

The second study by Iyer et al. (2003) examined the self-focused nature of White guilt, both in its status of a self-focused emotion and whether this status affected support of noncompensatory programs. The focus was on the participants' $(N=250)$ beliefs regarding inequality. Again using a Likert-type scale, the researchers measured the participants' self-focused belief in discrimination, other-focused belief in discrimination, support for compensatory policy, and support for equal opportunity policy.

Noting that the groups showed equal validity and accuracy, the Iyer et al. (2003) combined the two studies for analysis. The main predictor of guilt was self-focus, while an other-focus led to more sympathetic emotions. Guilt predicted support for compensatory policy but not for equal opportunity policy. Both of these results supported the experimenters' hypotheses. Overall, the results seemed to show that the focus of guilt 
(self or other) affected both the feelings of guilt or sympathy (self and other, respectively) and support for compensatory policy or equal opportunity policy.

Swim and Miller (1999) examined the feelings of White guilt and the implications of White guilt regarding opinions about AA. They distributed a questionnaire regarding these issues to 102 White undergraduates from Pennsylvania State University at University Park. The first section of the questionnaire regarded demographic information (race, age, gender, political affiliation, etc.). The next section of the questionnaire measured the following using five scales: (a) collective self-esteem; (b) White guilt; (c) White privilege, levels of prejudice, and attitudes toward AA; (d) prevalence of discrimination against Blacks, and (e) two feeling thermometer ratings, one for Blacks and one for Whites. Overall, scores were low on feelings of White guilt. However, the range and variability of the scores confirmed that there did exist White guilt emotions for some. Also, White guilt had effects on feelings about AA. Both White guilt and prejudice were independent predictors of attitudes regarding AA even after consideration of gender and political association.

In a second study, conducted by Swim and Miller (1999) to test the previous findings in a non-student population, adults waiting in a large airport terminal were asked to complete a survey $(N=51)$. The questionnaire consisted of several filler questions to make the questionnaire appear authentic and several relevant questions that the researchers actually used. Again, the feelings of White guilt were low overall; however, the responses ran the range of possible responses. This indicates some participants' high feelings of guilt. The remaining results were also similar, with White guilt and prejudice being independent predictors of AA program opinions. 
A third study was conducted by Swim and Miller (1999) to ensure validity of the previous two studies. Participants were 364 White men and women in an introductory psychology course. The participants responded to questions regarding White guilt, White privilege, attitudes toward AA, and prejudice. The results were similar to those from the previous two studies and supported the idea of White guilt in predicting attitudes regarding AA.

A fourth study by Swim and Miller (1999) was conducted to reaffirm the construct validity of the previous three studies. Participants $(N=124)$ were students in various psychology courses and a junior/senior level marketing course; they were given a packet questionnaire including demographic information and thermometer ratings on White guilt and the Modern Racism Scale. The results showed a low mean score for White guilt and White guilt was again correlated with prejudice and AA.

All the results of the four studies by Swim and Miller (1999) showed that White guilt was an effect of belief in privilege for Whites, beliefs in the prevalence of Black discrimination, and a low rating of prejudice. Obviously, the studies also confirmed that guilt and prejudice were independent predictors of attitudes on AA. The results disputed the idea that White guilt or AA opinions are affected or caused by political orientation. The researchers concluded that feelings about AA are caused by an amalgam of reasons to support or reject the policy.

\section{Attitudes on Affirmative Action, Admissions, and Higher Education}

There is a body of research that supports the prevailing perceptions and attitudes about AA and diversity in higher education. This section examines the attitudes and perceptions of students regarding issues of race, diversity, and AA in admissions. 
Aberson and Haag (2003) looked at how beliefs related to a person's support for AA policies. A positive correlation was found between support for AA and perceptions that AA is fair and that diversity is valuable. A negative correlation was found between support for AA and a belief in merit. A negative correlation was found between past experience of discrimination and support for AA. Overall, those who perceived AA as fair supported the general and tie-break policies, but fairness was not shown to predict support for using the aptitude testing policy. An opposition to AA in general was predicted by those who had belief in merit. As expected, persons who valued diversity showed more support for all AA policies.

Peterson et al. (2004) considered the impact of the Supreme Court decisions on admissions procedures at selected academic dental institutions (ADI) and their parent institutions. The ADIs consisted of five state-supported dental schools, one private dental school, and one hospital with postdoctoral dental residency programs with training sites in several states. This qualitative study interviewed 58 comparable stakeholders at the ADI, parent institution, state-organized dentistry program, and legislative levels, using a common set of questions during the fall of 2003. The questions were designed to introduce elements of the diversity issue within the context of the Supreme Court decisions, and interviewees were encouraged to introduce related topics as a reflection of their beliefs on the subject. Those interviewed included dental school deans, the officials to whom the deans reported, university provosts (or those in equivalent positions at the institutions of the authors), university presidents, university counsels, state dental society executive directors, and state legislators who were representatives of the dental school districts and chairs of state health-related committees. Findings of the study indicated that 
universities had generally adopted a broader definition of diversity that included not only race/ethnicity but also economic status, gender, and sexual orientation. Educators from ADI and their parent institutions were consistent in their responses that the ruling upheld AA as necessary to achieve diversity. State-organized dentistry officials did not appear to be as aware as others of the rulings, whereas legislators were mixed in their responses.

Fu (2006) proposed a stylized theoretical framework for examining the incentive effects of AA in college admissions that models the process of college admissions as an all-pay auction, to investigate two major questions: (a) Is there any theoretical rationale for an AA admissions rule? and (b) How do such rules affect college candidates' incentives to invest in academic effort? In the auction two candidates—one from a minority group and the other from a nonminority group, simultaneously choose their academic efforts (human capital investments) to compete for a seat in a college. At the beginning of the game the college announces its admissions rule. The screening is primarily based on candidates' scores on a standardized college entrance test. Upon observing the admissions rule, college candidates determine how much academic effort to spend in preparing for the test. The academic efforts are converted to their scores, $Q_{M}$ and $\mathrm{Q}_{\mathrm{N}}$, in the test. The college observes their test scores and admits one of them into the incoming class according to the previously announced rule. Results of the study showed that the equilibrium (AA) admissions rule created a positive "cross-group interaction" between college candidates' incentives to make educational effort. As a consequence, the pro-minority rule leveled the playing field and led both candidates to exert higher academic effort. The results of the study reconciled the commonly assumed conflicts between academic quality and ethnic diversity. Paradoxically, the study showed that the 
nonminority candidate responded to the pro-minority admissions rule more aggressively than did the minority candidate.

Zamani-Gallaher (2007) examined the relationship between levels of support or resistance to AA in college admissions among 2-year collegians in association with student demographics, educational plans, self-interest, and racial ideologies. Using data from the University of California, Los Angeles Cooperative Institutional Research Program (CIRP) Annual Freshman Year Survey, the study assessed determinants of approval or disapproval of AA in 20,339 community college students. Using social mobility theory as a framework, the study used three variables-educational plans, selfinterest, and racial ideology — as a means to operationalize the educational and psychosocial characteristics of interest. Cross-tabulations and chi square were utilized for descriptive analysis. Logistic regression methods were used to examine the relationship between the dichotomous dependent variable and the independent variables. Findings illustrated that, relative to student demographics, race/ethnicity was a significant predictor of attitudes toward AA in college admissions for both male and female community college students in each logistic regression. Overall, White males largely accounted for those most opposed to AA in college admissions. Annual family income and political views were the only additional background characteristic to show statistically significance in predicting AA attitudes regarding college admissions for male students in each model with the addition of other independent variable. Understanding both 2- and 4-year student views of AA in college admissions may assist educational leaders to establish or revise policies and programming efforts as tools for enhancing campus diversity. 
Grodsky and Kalogrides (2008) studied the extent to which institutional characteristics and contextual factors influenced the propensity of colleges to indicate that they engaged in AA in their admissions decisions. The study used survey data collected by the College Board in the Annual Survey of Colleges (ASC) between 1986 and 2003 from a total of 1,392 U.S. colleges and universities over an 18-year period. To test their hypotheses, a three-level binary logistic regression model was used. The authors conceived time (level 1) as nested within institutions (level 2) and institutions nested within states (level 3). Findings indicated that AA in admissions appeared to be a widely institutionalized practice in higher education that was tempered by changes in the policy environment over time. Over half of the comprehensive colleges and universities in the United States claimed to have race-conscious admissions policies in the 1990 s, and they did so in patterned ways. Many states have mitigated the effect of changes in law and policy by creating forms of sponsorship that skirt the issue of race. For example, Texas, California, and Florida have policies that guarantee college admission to students who exceed some percentage threshold in class rank at their high school. Some states have increased the amount of money spent on outreach activities designed to increase the number of minority students in the applicant pool. Thus, AA is not confined to admissions, where it is increasingly regulated; it can take many forms over the course of the college/student matching process.

Andrews, Ranchhod, and Sathy (2009) investigated the impact of Texas's Top $10 \%$ Law to evaluate the effects of the transition from an admissions regime in which class rank was only one factor in the admissions to a regime in which class rank was the primary factor in admissions for a subset of Texas high school graduates. Using cohort 
data from 1996-2004 from two sources (the Academic Excellence Indicator System [AEIS] from the Texas Educational Agency and student-level data [SAT verbal and math scores of every high school senior in the state of Texas] from the College Board) resulted in a pool of data on 916,348 students across all years. The authors used empirical analysis to conduct pre/post comparison of recruitment programs at both of Texas's flagship institutions, UT Austin and Texas A\&M. Findings illustrated that the targeted recruitment programs were successful in attracting potential applications from students at disadvantaged schools. Test takers who reported being ranked in the top decile responded most strongly to the targeted recruitment programs. The study further demonstrated that postsecondary institutions in Texas were able to respond effectively to legal constraints to craft enrollment as they saw fit.

Fischer and Massey (2006) conducted a study to analyze the effects of AA on college outcomes among the 1999 cohort of freshman in 28 selective colleges and universities. The probability sample used data from the National Longitudinal Survey of Freshmen (NLSF). NLSF investigators approached 4,573 randomly selected students and completed 3,924 fact-to-face interviews. The baseline sample included 998 Whites, 959 Asians, 916 Latinos, and 1051 African Americans. The authors developed indices of AA at the individual and institutional levels to test the validity of two charges leveled by critics of AA: that it undermines minority performance by placing academically unprepared students into competitive schools without the required skills and abilities (mismatch hypothesis) and that it stigmatizes all minorities as academically challenged and intellectually weak to produce added psychological pressure that undermines academic performance (stereotype threat hypothesis). The authors found no evidence to 
support the mismatch hypothesis. Findings indicated that, if anything, minority students who benefited form AA earned higher grades and left school at lower rates than others, and they expressed neither greater nor less satisfaction with college life in general. There was evidence to support stereotype threat. Findings indicated that the greater extent to which the institution used AA, the lower the grades, the greater the odds of leaving school, and the less satisfaction with college life expressed by individual minority students, holding constant socioeconomic background, academic preparation, and aptitude. The authors concluded that, despite both positive and negative implications for minority students, AA policies operate, on balance, to enhance the academic achievement of minority students and, as currently practiced, carry a clear benefit for minority students.

Dickson (2006) studied how ending AA in public colleges in Texas affected the percentage of minority high school graduates applying to college. The study analysis was based on data from the Texas Education Agency (TEA) during the period 1994-2001. The empirical strategy of the study was to estimate how the changes in admissions criteria had affected the percentage of students taking a college admissions test (either the SAT or the ACT) at each public high school in Texas. The data included percentage of graduates by race taking a college admissions test, percentage of students on free/reduced-price lunch, attendance rates, dropout rates, and racial composition of the high school. Using these data, the researcher estimated the effects of ending AA and instituting a percentage plan on the percentage of high school graduates taking a college admissions test. Results revealed that ending AA in Texas would reduce the percentage of Hispanic graduates applying to college by $1.6 \%$ (approximately 866 students) and 
reduce the percentage of Black graduates applying to college by $2.1 \%$ (approximately 480 students). It was concluded that the end of AA would not significantly affect the percentage of White students applying to college. The positive effects of the percentage plan were small because the students who benefited from the policy were unlikely to apply to college. The results of the study demonstrated that the percentage plan would increase the percentage of minority student applying to college when the offer of admission was followed by an offer of financial aid. The percentage of public high school graduates choosing to apply to college was predicted to fall after the end of AA and after the institution of a percentage plan.

Brezina and Winder (2003) examined negative racial stereotyping by White Americans' association with race and economic disadvantage. The researchers framed the study on the sociopsychological meanings of group status and stereotyping. Results indicated that beliefs about innate inferiority of Blacks had weakened over time but that many White Americans still assumed that Blacks were inferior in at least one respect: that in general they tended to lack effort or initiative. Research findings further suggested that Whites reasoned that, if Blacks continued to fall behind economically, they "must not be trying hard enough." The larger the perceived economic gap between Whites and Blacks (with Blacks seen as relatively disadvantaged), the greater the Whites' tendency to stereotype Blacks as lazy as opposed to hard working. These findings help to explain the persistence of Whites' opposition to policies designed to alleviate racial inequality and that failure to succeed is still attributed to a lack of effort by the poor and disadvantaged.

D. L. Kidder, Lankau, Chrobot-Mason, Mollica, and Friedman (2004) examined backlash or resistance against AA policies and other diversity initiatives and whether 
there were different reactions among Whites using different justifications for diversity programs within an organization. They compared the results of implementation of a competitive advantage justification (diversity management) and a reactive justification (AA), proposing that there would be greater backlash in the reactive justification. Results revealed significantly less favorable attitudes toward the program in AA scenarios with individual promotion but loss of ethnic group potential compared to individual promotion and loss of ethnic group potential in diversity management justification. The results indicated that respondents were not simply reacting to their personal outcome but were also affected by the justification presented as AA or the alternative diversity management justification.

Klineberg and Kravitz (2003) explored attitudes toward municipal AA by testing predictors of support among Anglos, African Americans, and Hispanics. Results indicated that support for municipal AA contracting was significantly stronger in each minority group than among Anglos. In the Anglo group, support was lower among Republicans than among Independents or Democrats. There was a negative effect of age, with support displayed by younger respondents. The support by women was slightly higher than by men. African American support for set-asides was positively correlated with education and income. Attitudes were positively related to ratings of job opportunities. Fewer women than men approved of the set-asides, and attitudes were positively associated with age. U.S.-born Hispanics who were Democrats expressed more approval than did Republicans. The effect of ethnicity was fully supported as the results revealed that African Americans and Hispanic immigrants had the greatest levels of 
support, followed by U.S.-born Hispanics; the data showed clear opposition by some Anglos.

Malos (2000) examined perceptions of fairness and effectiveness of using socioeconomic need as a criterion for college admission. Malos sought to determine whether socioeconomic need as an admission criterion would improve diversity on campuses better than using race and gender as admission criteria. Results suggested that the admission plans that used economic need as a criterion were achieving their goal without causing resentment from those not selected. The study showed support for the idea that using socioeconomic need would seem fairer than using gender or race in decisions.

Knight and Hebl (2005) studied how to make negative attitudes toward AA and its beneficiaries more positive. They framed the study on the premise that a diverse student body prepares students for an increasingly global and heterogeneous society. The results confirmed that reactions to AA plans were influenced by the type of plan, the type of justification given for it, and gender. Females had more positive attitudes toward AA plans than did males. Findings suggested that the most effective rationale for an AA plan was the utilitarianism justification that emphasized benefits to both minority and majority groups.

Aberson and Haag (2003) looked at how a person's beliefs related to support for AA policies. Specifically, the study focused on reactions to three distinct AA policies: a general AA policy, a tie-break policy that favored African Americans over Whites if they were equally qualified, and a policy using a general aptitude test that considered those who reached a certain cutoff score to be equal. A theory model of support proposed by 
Kravitz and Klineberg (2000) was used as a basis for the research. Confirmatory factor analysis was used for initial analysis. A two-step hierarchical regression was used to determine overall support levels for AA. Path analysis determined mediation effects of variables. A 2 × 2 multiple analysis of variance (MANOVA) was used to determine whether the order of presentation had an effect on support in the tie-break situation. The 273 participants were White undergraduate students, predominately female $(71.1 \%)$, at either a state university or a private college. The independent variables were the three AA policies. Other independent variables were belief in fairness, belief in merit, and belief in value of diversity. Later in the study, other independent variables were added: experience of discrimination, seeing future benefit, political orientation, and gender. The dependent variable was support for AA and its policies. Results showed (a) a positive correlation between support for AA and perceptions that AA is fair and that diversity is valuable, (b) a positive correlation between liberalism and support for AA, (c) a negative correlation between support for AA and a belief in merit, and (d) a negative correlation between past experience of discrimination and support for AA. Overall, those who perceived AA as fair supported the general and tie-break policies, but fairness was not shown to predict support for using the aptitude testing policy. General opposition to AA by those who had belief in merit was predicted. As expected, those who valued diversity showed more support for all three AA policies.

Springer, Palmer, Terenzini, Pascarella, and Nora (1996) assessed the effects of awareness programs on the attitudes of White students toward diversity on campus. The authors framed the sociopsychological research on intergroup relations to determine the extent to which collegiate environments, such as the socializing influences of major fields 
and of racial or cultural awareness programs, affected students' attitudes toward diversity. A quasi-experimental design utilized a three-wave panel design to assess attitudes. A sample was collected from 17 colleges and universities across the United States, varying in characteristics such as geographic location, size, governance, degreegranting status, racial composition, and ethnic composition. Results indicated that gender-related and major field-related differences in attitudes toward diversity were separate. The more favorable attitudes among women in general could not be attributed entirely to the greater number of women concentrated in such liberal majors as education and the social sciences than in such traditionally conservative majors as engineering and the physical sciences. The results suggested that participating in a racial or cultural awareness workshop promoted development of more favorable attitudes toward diversity on campus among White students. The findings are significant because students in conservative majors (especially male students) start college with significantly less favorable attitudes toward diversity on campus (Springer et al., 1996).

Milem and Umbach (2003) explored the relationship between Holland types and students' diversity-related plans. The study used the categories of academic disciplines related to Holland's theory of careers. Theoretically grounded on Holland's interaction theory, the study drew from research on the effect of school desegregation, the outcomes of diversity, peer group effects, and the social psychology of race and race relations. Data used were results of a survey of first-year students at a public research university in the eastern United States. Independent variables were gender, race, age, family income, firstgeneration college status, private or public school, high school grade point average (GPA), Holland major category (realistic, artistic, investigative, enterprising, or 
undecided), and diversity construct (diversity of neighborhoods, schools, and friends). Dependent variables were students' plans to engage in diversity-related activities, measured by a 4-item standardized factor score. Means and standard deviations were calculated on independent variables, and a three-race (White, African American, and Asian Pacific American) regression model was constructed to analyze the data set.

Results suggested that White students were least likely to be prepared to engage in diversity while in college. Among students of color in the study, there was evidence of greater variation in the racial diversity of their precollege environments. Students in social and artistic majors were more likely than students in other majors to report that they planned to engage in activities that break the cycle of segregation in society. Likewise, students in realistic, investigative, and enterprising majors were more likely to perpetuate segregation. The findings reflect those of previous research indicating that, despite the country's increasing racial and ethnic diversity, society remains highly segregated, particularly in neighborhoods and in schools (Milem \& Umbach, 2003). Hurtado (2002) studied the effects of diversity on students' self-perceived improvement in the ability to contribute positively to a pluralistic democracy. The author framed the study in cooperative learning to enhance the academic achievement of students from all racial ethnic groups. Theoretically grounded in cognitive and social development theory, the study examined the extent to which (a) the racial/ethnic background of a faculty member made a difference in the classroom, (b) opportunities to interact with someone from a different racial/ethnic background in a learning situation enhanced a student's assessments of his/her own learning, and (c) the diversity that faculty introduced into the curriculum made a difference in terms of students' 
assessments of their own learning. Hurtado analyzed data from the 1989-1990 Faculty Survey administered by Higher Educational Research Institute at UCLA, consisting of responses from over 16,000 faculty at 159 medium and highly selective predominantly White institutions across the country. These faculty data were used to examine racial and gender differences in the instructional techniques most commonly used in undergraduate courses. In addition, longitudinal student data were examined to understand the link between activities associated with a diverse student body and student self-reported growth on 20 general educational outcomes. These responses came from the 1987-1991 CIRP student survey, also administered by UCLA's Higher Educational Research Institute. Chi-square tests were performed on the faculty data to determine significant gender and race differences in instructional techniques. Partial correlations were conducted on the student data. The analyses showed that diversity of the faculty and student body was linked with the fundamental work of teaching and learning in higher education. These findings cast substantial doubt on the veracity of the Fifth Circuit Court of Appeals' Hopwood decision, which asserted that the ethnic and racial diversity of a student body or faculty was of no relative consequential value to the education offered by a college or university. Hurtado's study strongly suggests that such diversity may contribute significantly to students' improvement on key learning outcomes that are associated with both academic development and the critical abilities needed to work in diverse settings.

Gurin, Nagda, and Lopez (2004) studied the benefits of diversity based on interaction between diverse students, not just their co-existence. The researchers suggested that just being around students of different backgrounds and cultures does not 
have the same educational benefits as interacting with them in significant ways. The researchers sought to identify benefits from this interaction and proposed that students' involvement in a multicultural program would help the students in many ways. A quasiexperimental study and a longitudinal study were conducted. The quasi-experimental study used undergraduate students who were involved in an intergroup relations (IGR) program and a control group who were not involved in the IGR program ( $n=87$ for each group). The longitudinal study focused on 1,670 University of Michigan students who were surveyed at the beginning of college, at the end of their IGR course, and in their senior year. It was hypothesized that participating in the IGR program would increase skills needed for plural democracy. The independent variable in both studies was involvement in the IGR program. The dependent variables in both studies were nine measures of democratic sentiments and civic activities: perspective taking, nondivisiveness of deference, perception of commonalities in values across groups, mutuality in learning about own and other groups, acceptance of conflict as a normal part of social life, interest in politics, participation in campus politics, participation in community service, and commitment to post-college civic participation. The longitudinal study also included a measure of experience with diversity. A MANOVA of the results of the quasi-experimental study showed that the IGR students were significantly more inclined to be interested in politics, participate in more campus activities, and display higher levels of motivation to take the perspective of others into account. Results from the longitudinal study showed similar results. White students who were involved with an IGR program gained educational benefit, although the benefit did not seem to be as strong for non-White students. The authors suggested that the IGR might be a more novel 
experience for White students interacting with those outside their race than the other way around. The overall suggestion from this research was that higher educational institutions should make use of multicultural programs that bring students together to learn from one another.

Antonio (2004) studied ways in which race and ethnicity were implicated in the formation and meaning of friendship groups on a multicultural campus. The author framed the study in the interpersonal world of college friendships groups to understand how students of different racial backgrounds experienced racial diversity within racially diverse or homogeneous circles. Theoretically grounded in contact theory, the study examined (a) how racial or ethnicity mattered in friendship group formation, and (b) whether students intentionally focused on the creation of racially diverse or homogeneous friendship groups. A sample of 18 male informants was selected according to a form of maximum variance sampling designed to maximize the variation among selected cases along the chosen criteria of interest: racial identity and the degree of racial diversity within the friendship groups. Racial makeup of friendship groups was determined from survey data, and two students from each ethnic group were interviewed to identify the experiences, meanings, and values involved in male students' interactions with their friendship groups and interactions outside of those groups. A semistructured interview protocol that covered background information, friendship group descriptions, racial or cultural interactions with the friendship group, racial or cultural interactions outside the friendship group, and experiences and perceptions of racial diversity on campus was followed. Data were analyzed using a method similar to both a grounded theory approach and Patton's (1990) utilization-focused approach. Findings illustrated that the role of race 
in students' friendships was dependent not only on attitudes and values toward cultural diversity and friendships but also on students' social patterns on campus, their precollege social patterns, and their perceptions of diversity on campus. The meaning attached to race and its importance in friendship selection depended on previous socialization and on current social context and varied as a social construct linked to culture, social position, or intergroup relations. The results suggested that a relatively diverse campus does not guarantee that the experience of diversity will be one of mutual enhancement or even of segregation.

Based on this review of the literature, there appear to be mixed opinions and inconsistent support for AA initiatives that are race based and an even greater divide about the value of diversity in the work place and on college and university campuses. Color-blind and merit-based practices are not as stigmatized as racial practices but have not gained widespread support from proponents of AA as equitable options to improve access and diversity on college campuses. This impasse is worthy of further exploration, since Texas flagship institutions and state demographics have experienced significant population diversification in recent years.

Higher education has always had preference for a variety of students: gender, arts, and most certainly, legacy students.

Despite their legitimacy (as established by the Supreme Court in Bakke in 1978) and utility in improving diversity on college campuses, race-conscious higher education admissions policies in Texas, California, and Florida have been fiercely challenged and, ultimately, abandoned in the past decade. (Horn et al., 2003, p. 11) 
"The aftermath of AA has pushed colleges into a zone that requires the reconsideration of all activities that may suggest preference, especially regarding race and ethnic issues" (Slaughter, 2007, p. 4). Peterson et al. (2004) asserted, Although the rulings have provided guidelines for achieving diversity using race/ethnicity as one of several factors, the rulings may be challenged, thus requiring vigilance on the part of parent institutions and their ADI to ensure compliance with the spirit of the ruling and to avoid attack from opponents of AA. (p. 932)

\section{Race-Based Admissions}

Affirmative Action measures in tenure selection and hiring have been heavily debated in higher education, but admissions policies have been the most widely litigated, with broad implications for American colleges and universities. "Since the mid-1960s U.S. colleges and universities with selective admissions policies have used race and ethnic preferences ('AA') to diversify their student bodies, specifically targeting historically underrepresented groups" (Tienda et al., 2008, p. 2). The end of the 20th century marked the elimination of race-conscious admissions in California, Georgia, Texas, and Washington.

State lawmakers have been reactionary to many of the court rulings by reshaping and eliminating programs and practices to enhance the diversity of the student body. The result has been a sharp decrease in the number of the minority applications to top-tier institutions and programs (Horn et al., 2003). The national attack on AA can be attributed mainly to efforts by lawmakers and lobbyists in three states: California, Florida, and Texas. 
The majority of the rulings out of the Fifth District (Texas, Louisiana, Mississippi) and Sixth District (Kentucky, Michigan, Ohio, Tennessee) circuit courts have redefined the national support and debate on AA. States may use AA in admissions but it must be narrowly tailored with considerations given to race-neutral alternatives to diversify the student body. Horn et al. (2003) asserted,

Decisions by a court in Texas (Hopwood), by the Board of Regents referendum in California (SP-1 confirmed by Proposition 209), and by executive order of the governor in Florida (the One Florida Initiative) have ended the ability of universities in these three states to use race/ethnicity as a consideration in the admission process. (p. 11)

While some states are considering abandoning race-conscious AA policies, others have adopted percentage plans to meet AA and diversity goals.

The best known of the race-neutral policies are percentage plans, used in some form in California, Florida, and Texas and recently proposed for Colorado. Percentage plans guarantee admission to public universities for some proportion of a high school's graduating class. (Lloyd, Leicht, \& Sullivan, 2008, p. 1106) Paradoxically, three of the four states (California, Florida, and Texas) are among the most populated and diverse states in the nation. The following section summarizes court cases and state strategies on race-based admissions.

\section{Alternative Strategies (State Policies)}

Niu, Sullivan, and Tienda (2008) acknowledged that, "in a climate of continued opposition to the use of race preferences, in college admissions, administrators have sought alternatives to diversity their campuses while complying with the protections of 
the Fourteenth Amendment" (p. 831). As an alternative to race based admissions, California, Florida, and Texas implemented percentage plans (Coleman et al., 2008). Horn et al. (2003) noted that, although, at first glance, the Texas, California, and Florida plans appear to be very similar, in fact they vary widely, and key differences must be noted when considering their implementation and effectiveness. "Proponents praise the plans as a race-neutral alternative, whereas critics hail them as an inadequate approach to equal educational opportunity and not a replacement for AA" (Moore, 2005, p. 176).

B. T. Long (2003) asserted that the logic behind the percentage plans as an alternative to AA rests on assumptions about the distribution of high school students by race. This section explores the percentage plans of California, Florida, and Texas.

\section{California Higher Education Affirmative Action Policy}

"Around the same time as the Hopwood ruling, California began efforts to eliminate the consideration of race/ethnicity in hiring, contracting, and admissions decisions" (Horn et al., 2003, p. 172). According to Chavez (1998), in 1996 the California Civil Rights Initiative (Proposition 209) amended the California Constitution to create an AA ban beyond higher education admissions, including public employment and contracting (as cited in Horn et al., 2003, p. 17).

Governor Gray Davis proposed a 4\% plan, also referred to as Eligibility in Local Context (ELC), as an alternative to race-based admissions. Prior to the $4 \%$ plan, the UC system's Board of Regents had voted to ban the use of race/ethnicity in its admissions process (SP-1). The ELC guaranteed admission to the UC system to each public and private high school graduate in the top $4 \%$ of the class. 
The ELC or $4 \%$ plan did not bring about a major change in UC admissions. The California Master Plan for Education already guaranteed admission to California residents graduating from high school in the top 12.5 percent of students statewide, and an estimated 60 to 65 percent of students in the top 4 percent of their local high schools were already eligible for UC admission under the statewide 12.5 percent plan. Thus, the 4 percent plan merely broadened the UC eligible pool to include an estimated additional 3,500 to 4,000 students who ranked near the top of their schools but were not among the top 12.5 percent of students statewide. The addition of the 4 percent plan was expected to increase underrepresented minorities, yielding an additional 300 to 700 Chicano/Latino and African American students within UC's eligibility pool. (U.S. Commission on Civil Rights, 2002, p. 15)

Unlike the Texas and Florida plans, the $12.5 \%$ plan applies only to UC system research institutions. Horn et al. (2003) noted that an ELC student is not guaranteed a seat in a particular institution; all the traditional admission considerations of the individual institutions remain in place for the ELC applicant. Texas and Florida imposed the percentage plan more broadly; their plans apply to the students' high schools, not statewide; California students must be in the top $12 \%$ of students statewide to gain admission to the UC system (U.S. Commission on Civil Rights, 2002).

\section{Florida Higher Education Affirmative Action Policy}

In November 1999, Florida Governor Jeb Bush implemented "One Florida" (EO 99-281; Florida, 1999), which eliminated the use of race- or gender-conscious decisions in government employment, state contracting, and higher education (Horn et al., 2003). 
Concurrent with the implementation of "One Florida," Governor Bush implemented the Talented 20 policy as an alternative to race-conscious decisions in higher education banned by EO 99-281. The Talented 20 policy guarantees admissions to the Florida State University System (SUS) to public school graduates who graduate in the top $20 \%$ of their class.

The One Florida Equity in Education Initiative has two components. The First component consists of the three pathways to enrollment in SUS. The first pathway is the Talented 20 Program (T20 Program). The T20 program guarantees admission to one of Florida's 11 public institutions for any Florida resident who graduated in the top 20 percent of his or her public high school class and completed a prescribed 10-unit academic high school curriculum. The second pathway to enrollment in SUS is through the use of traditional admissions criteria such as high school grade point average and SAT. This pathway is available to all high school graduates. The third pathway is profile assessment, where a college admissions decision is arrived at through a weighing of weak high school academic performance, first-generation college participation, socioeconomic status, inner-city or rural residence, and special talents, such as athletic ability. (U.S. Commission on Civil Rights, 2002, p. 53)

"While Bush's plan eliminated the use of race and gender in college and university admissions decisions, race consciousness was still permissible in awarding scholarships, conducting outreach, or developing precollege summer programs" (Horn et al., 2003, p. 19). 


\section{Texas Higher Education Affirmative Action Policy}

"The Hopwood decision has had a lasting impact on participation by minority group members in Texas' institutions of higher learning, especially at its flagship institutions" (U.S. Commission on Civil Rights, 2002, p. 31). "As the two selective public institutions that practiced AA prior to Hopwood, UT Austin and Texas A\&M University witnessed significant declines in minority student enrollment" (Long, M. C., \& Tienda, 2009, p. 48). Chapa (2005) noted, Texas's top 10\% plan began with the passage of House Bill (HB) 588 in 1997. This legislative response to the Hopwood decision requires all Texas public universities to automatically admit students who graduate in the top $10 \%$ of their high school class. (p. 188)

HB 588 guarantees high school graduates in the top 10 percent of their class admission to Texas' public institutions of higher learning. The Texas plan also provides public universities with admissions guidelines for students not ranked in the top 10 percent of their class. In addition to considering a student's academic performance, universities are instructed to "consider all of, any of, or a combination of" 17 other factors when determining whether to admit a first-time freshman applicant. (U. S. Commission on Civil Rights, 2002, pp. 33-34)

"Assessments of HB 588 based on institutional enrollment data suggest that its primary impact has been in achieving greater geographic diversity, although modest improvements in ethno-racial diversity also followed" (Monteja, 2001, as cited in Tienda, Cortes, \& Niu, 2003, p. 3). The intended effect of the automatic admissions policy is to eliminate the use of standardized test scores as a barrier to admissions (Chapa, 2005, p. 
188). The Texas percentage plan differs from those used in Florida and California in that (a) rank-eligible students are able to choose which public institution to attend, and (b) high schools, rather than a centralized educational body, decide how to compute class rank distributions (Tienda, 2006).

Since the use of percentage plans is a relatively new approach for ensuring student diversification in higher education, little is known about the outcomes of such efforts. Only the Texas plan has been in existence for a time period sufficient to analyze the potential impact of using "percentages" for admitting undergraduates (American Council on Higher Education, 2001). As the state with the oldest of these programs, Texas has been the focus of much of the research in this area (Long, B. T., 2003). To date most of the policy and research attention has focused on the direct effects of the policy changes on admissions and changes in the composition of freshman enrollment, to the almost complete neglect of possible changes in application behavior. (Long, M. C., \& Tienda, 2009, p. 49)

Tienda, Cortes, et al. (2003) contended that "institutional data cannot address whether and how the college decision-making behavior of high-achieving minority and lowincome students was affected by the automatic admission provision because these data do not reveal the alternatives that have been considered" (p. 3). Figure 1 provides a summary of the three percentage plans.

This literature review indicates that considerations of AA and race in admissions have been studied extensively. What is further indicated is that quantitative studies focusing on attitudes and perceptions are far more prevalent than qualitative studies. Although statistical data are significant in illustrating the support, discontent, and 
- Guarantees admission to any student ranked in top 10 percent of his or her high school class. Qualified students are guaranteed admission to any public institution in the state.

\section{California}

- Guarantees admission to any student ranked in the top 4 percent of his or her high school class. Unlike Texas, this plan only guarantees admission to one of the University of California campuses. It does not guarantee students admission to the institution of their choice.

\section{Florida}

- Guarantees admission to any student who completed a prescribed 19 unit academic high school curriculum and is ranked in the top 20 percent of his or her high school class. Like California, this plan only guarantees admission to one of Florida's state colleges or universities.

Figure 1. Summary of the percentage admissions plans in Texas, California, and Florida. Adapted from Percentage Plans for College Admissions, by F. Shushok, 2001, Washington, DC: American Council on Education, Center for Policy Analysis.

misconceptions regarding race in admissions, the voices of those who are impacted have not been fully explored. This study seeks to raise the voices of students who are impacted by AA policies. By adding to the already robust quantitative research agenda on AA, this qualitative study offers a lens into the reality of students who are recipients of a policy that creates opportunity and contention. By hearing and adding the voices of these students, the literature on AA and race neutral admissions becomes more rich and enlightening.

Chapter III focuses on the research methodology, research design, data collection procedures, data analysis, role of the research, and trustworthiness of the study. 


\section{CHAPTER III}

\section{METHODOLOGY}

The purpose of this qualitative case study was to explore the experiences of Top 10\% African American and Hispanic students at Texas A\&M University. This chapter describes the study's methodological approach and procedures. The chapter begins with a discussion of the research design and rationale, research context, description of the case, selection of participants, and role of the researcher. The chapter concludes with a discussion of sources of data collection, methods of interviewing, data analysis, validation, and ethical considerations.

This study utilized a qualitative research approach to investigate how the Top 10\% Law influenced African American and Hispanic students' perceptions of, application to, and feelings of acceptance at a Texas flagship institution. Qualitative research, broadly defined, is "any kind of research that produces findings not arrived at by means of statistical procedures or other means of quantification" (Strauss \& Corbin, 1990, p. 17). Because the main research interest in the current study was to understand students' perceptions of and experiences as Top 10\% African American and Hispanic students, a qualitative approach was appropriate for this study. Merriam (1998) described qualitative research as having the following characteristics: (a) interested in understanding the meaning people give to their experiences; (b) the primary tool for collecting data is the researcher; (c) involves fieldwork; (d) builds on hypotheses, concepts, and theories; and (e) data collection involves rich descriptions of the 
phenomenon being studied. Glesne (2006) described the purposes of qualitative research as to conceptualize, interpret, and understand phenomenon. Attempting to understand African American and Hispanic students' experiences as Top 10\% recipients at a university of their choice lent itself to a qualitative approach.

Qualitative research was most pertinent in the current study to understand what has influenced students' perceptions of and application to, as well as their feelings of acceptance as Top 10\% students at Texas A\&M University. Qualitative research allowed examination of the inner experiences of participants to determine how meanings were formed through and in culture (Corbin \& Strauss, 2008). The study was designed to understand the experiences of Top 10\% African American and Hispanic students and engender an awareness of the impact of AA and race-neutral policies on this group of students.

\section{Statement of the Research Questions}

Using a case study design, the current study used qualitative methods to investigate Top 10\% African American and Hispanic students' experiences at Texas A\&M University. The goal of this case study method was to describe as accurately as possible the case being studied by answering the following research questions:

1. How do African American and Hispanic students who are admitted to Texas A\&M University under the Top $10 \%$ Law view their higher education experience?

2. In what ways did the Top 10\% Law influence students' selection of a flagship institution as a higher education option?

3. Having been admitted under the Top 10\% Law, how has this influenced their perceptions of others' acceptance of their presence on campus? 
4. What is the opinion of African American and Hispanic students admitted under the Top $10 \%$ Law concerning its effectiveness in creating race-neutral admissions in Texas?

To uncover responses to these questions, a research protocol was developed. Examples of questions from the protocol are: What influence did the Top 10\% Law have on your application and selection to attend Texas A\&M University? Was money a factor? Do you feel the Top 10\% Law is a fair admissions policy and adequately provides equal access and opportunity to all students? If the Top $10 \%$ Law was abolished or reduced to $5 \%$, how do think that would have affected you and your admissions to Texas A\&M?

In a case study methodology, the researcher intuitively retains the holistic and meaningful characteristics of real-life events (Yin, 2009). Creswell (2007) defined qualitative research as "beginning with assumptions, a worldview, the possible use of a theoretical lens, and the study of research problems inquiring into the meaning individuals or groups ascribe to a social or human problem" (p. 37). For example, the question, "do you consider your high school to be academically elite, competitive, satisfactory or marginal and what evidence supports your answers?" illustrates the case study approach to inquiring into the meaning of participant's perspectives and experiences.

Figure 2 is a conceptual illustration of the research questions and the case.

\section{Theoretical Tradition}

According to Creswell (2009), philosophical ideas held by researchers influence research practices and should be identified early in a study. Creswell (2009) termed the 


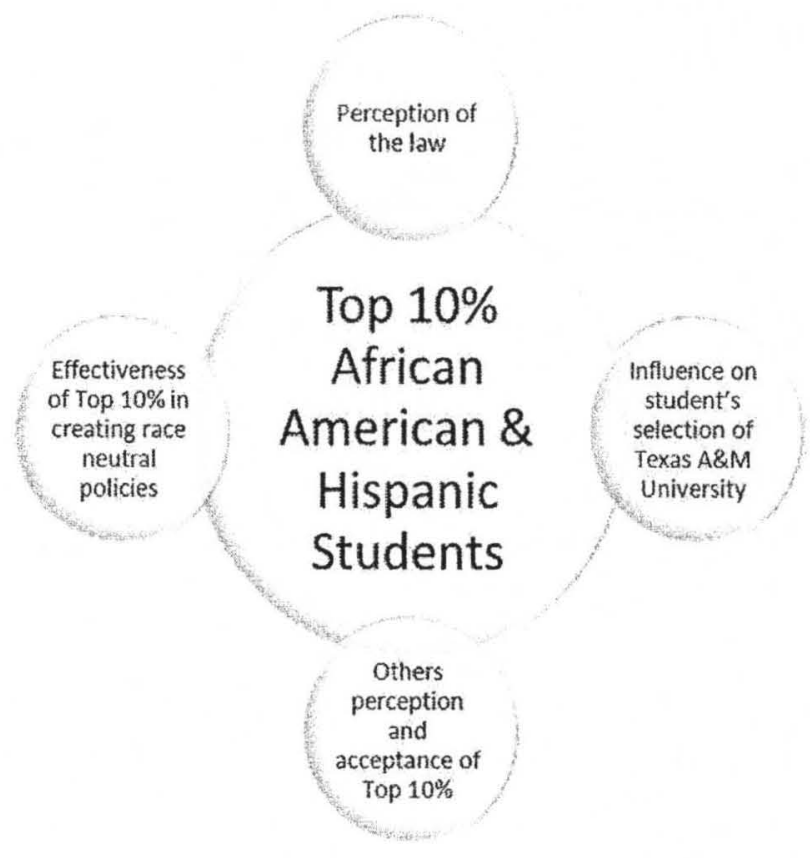

Figure 2. Conceptual illustration of the current study research questions and case.

researcher's philosophical ideas a worldview. These worldviews are categorized as postpositivism (challenging the traditional notion of the absolute truth of knowledge), constructivism (seeking understanding of the world in which they live and work), advocacy/participatory (holding that research inquiry should be intertwined with politics and a political agenda), and pragmatism (the worldview that arises out of actions, situations, and consequences rather than antecedent conditions; Creswell, 2009, p. 8).

Creswell noted that a researcher's beliefs often influence the qualitative, quantitative, or mixed-methods approach to doing research. This study applied the advocacy/participatory worldview and a critical analysis perspective as a theoretical framework to understand the lived experiences of African American and Hispanic students as Top 10\% recipients at Texas A\&M University. Creswell (2007) posited that 
the advocacy/participatory worldview seeks reform and an action agenda that may impact the lives of study participants and the environments in which they live.

Critical race theory (CRT) served as the theoretical framework for the current study. An example of a CRT case study is Solorzano, Ceja, and Yosso's (2000a) article which focused on African American college students' experiences with racial microaggressions and campus climate. In the study, Solorzano et al. (2000a) used focusgroups to illustrate how African American students experience the racial climate of their college campus. Solorzano et al. (2000a) contended that the CRT framework for education is different from other CRT frameworks because it attempts to place race and racism in the research in the foreground and simultaneously challenges the traditional paradigms, methods, texts, and separate discourse on race, gender, and class by showing how these social constructs intersect to impact communities of color.

Today, the term "critical race theory" generally signifies attempts to (a) name and discuss the pervasive, daily reality of racism in U.S. society that serves to privilege whites but to disadvantage people of color; (b) expose and deconstruct seemingly "colorblind" or "race-neutral" policies and practices that entrench the disparate treatment of non-white persons; (c) legitimize and promote the voices and narratives of people of color as sources of critique of the dominant social order that purposefully devalues them; and (d) revisit civil rights law and liberalism to address their inability to dismantle and expunge discriminatory sociopolitical relationships. (Nebeker, 1998, p. 26)

Similarly, Parker (1998) suggested that CRT is important to education because of its ability to dismantle prevailing notions of educational fairness and neutrality in educational policy. Delgado and Stefancic (2001) agreed that critical writers use counter stories to question, challenge, and supplant pernicious beliefs regarding race. Counter stories and narratives give marginalized groups opportunities to reflect critically on their role in society and to challenge the privileged discourse of the majority. Parker (1998) supported this approach to research by stating that a central tenant of CRT methodology 
is to provide countertruths of racism and discrimination faced by African Americans, Latinos, and others through racial storytelling and narratives (p. 33). Delgado and Stefancic (2001) explained that CRT contains an activist dimension that not only seeks to understand racial lines and hierarchies but seeks to transform them for the betterment of society.

Several CRT tenets and themes were explored through the use of interview questions and a review of written documents. Social construction is the process of endowing a group or concept with a delineation, name, or reality (Delgado \& Stefancic, 2001, p. 155), based on the position that race and races are products of social thought and relations. According to Delgado and Stefancic (2001), "Society constructs the social world through a series of tacit agreements mediated by images, pictures, tales, and scripts" (p. 43). The concept of intersectionality in CRT is the belief that groups and classes have shared interest and traits. Differential racialization in CRT explores the treatment of racial and ethnic groups by society. The primary research question that propelled this study was how the Top 10\% Law influenced African American and Hispanic students' perceptions of, application to, and feelings of acceptance at a Texas flagship institution.

Social construction, intersectionality, and differential racialization aligned with the current research agenda and supported the decision to use counter narratives of racial groups, in this case African American and Hispanic students, to construct and name their reality. Through their individual experiences and stories, the study drew on knowledge of African American and Hispanic students to gain an understanding of their experiences as Top 10\% students at Texas A\&M University. 
Figure 3 illustrates the linkage of research questions to theory and current

literature.

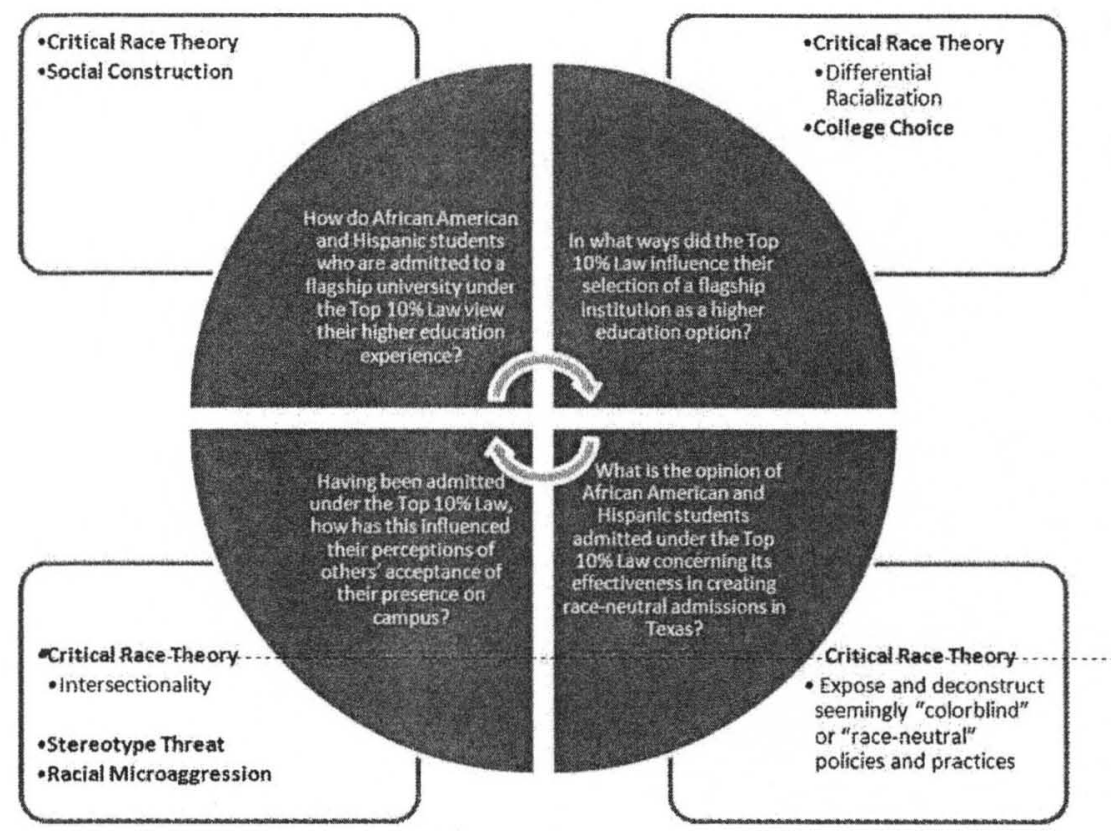

Figure 3. Linkage of the current study research questions to theory and current literature.

\section{Research Design}

This study followed a qualitative, single case study design. Yin (2003) defined case study research as "an empirical inquiry that investigates a contemporary phenomenon within its real-life context, especially when the boundaries between phenomenon and context are not clearly evident" (p. 13). Merriam (1998) viewed case study as "a thing, a single entity, or a unit around which there are boundaries" (p. 27). Merriam contended that case study design lends itself to discoveries and interpretations and is not designed to test hypotheses. Yin (2009) discussed a five-aspect rationale for employing single case study design: critical case, extreme or unique case, representative or typical case, revelatory case, and a longitudinal case. 
Case study research can be designed for single or multiple case units. A single case study design was determined to be most appropriate for learning about African American and Hispanic students' experiences as Top 10\% scholarship recipients at a single site. According to Yin (2009) and Merriam (1998), a case can be a single unit of analysis within a group of individuals, small groups, organizations, or partnerships. In this study the unit of analysis was viewed as a single case, consisting of a group of student scholarship recipients at Texas A\&M University.

\section{Site and Sample Selection}

Purposeful and criterion sampling were used to select the institution and participants for this study. According to Creswell (2009), the significance of purposeful sampling is to select participants or sites that will help the researcher to understand the problem and the research question. An example of purposeful and criterion sampling is Duncan's 2010 dissertation, which focused on three students at Inland High School who stated that hip hop was at the core of their identity. Merriam (1998) stated that a case study might be selected for its very uniqueness, for what it can reveal about a phenomenon, for knowledge that would not otherwise be accessible. The lived experiences of Top 10\% African American and Hispanic students at Texas A\&M University was the phenomenon of focus in the current study. The Top $10 \%$ law, in Texas is a unique policy because it is the only race-neutral admissions policy in higher education that guarantees automatic admission to any state public school based on class rank. This study meets Yin's (2009) rationale for using a single case study design.

The institution and participants for this study were purposefully chosen based on predetermined criteria. In this case, the researcher targeted undergraduate, upper-class, 
Top 10\% African American and Hispanic students at Texas A\&M University during the fall 2010 semester.

\section{Institution}

Texas A\&M University, a Texas flagship institution, was an obvious choice as a site for this study. The university is a predominantly White, research-based land grant, sea grant, and space grant institution founded in 1876. Its 10 academic colleges offer more than 120 undergraduate degree programs and more than 240 graduate programs. According to its website, the university enrolls one of the 10 largest student bodies in the nation and the largest outside a major metropolitan area. Fall 2009 enrollment was a record 48,885, with a record 9,104 entering freshmen. Gender distribution was approximately equal, and $25 \%$ of the freshman class were the first in their family to attend college. There were 8,500 graduate students. The Texas A\&M 2010 statistics booklet lists the number of first-time-in-college students among the Top 10\% in fall 2009 was as 3,932 (2,1718 White, 158 Black, 842 Hispanic, 180 Asian, 22 American Indian, 8 international, and 4 other).

Texas was one of the first states to eliminate race in admissions as a result of the Hopwood v. Texas (1996) ruling. Reaction from state lawmakers and educators focused on the impact of this ruling on African American and Hispanic access and enrollment at the state flagship institutions. Both the University of Texas and Texas A\&M University had a history of struggling to reach federally mandated desegregation goals promulgated by the Office of Civil Rights.

As a result of the Hopwood ruling, Texas public institutions adopted the Top Ten $10 \%$ Law as an alternative to AA measures. Texas House Bill (HB) 588 received national 
attention for its elimination of race-sensitive admission practices at the state's public institutions and a guarantee of admission to all seniors who graduated in the Top $10 \%$ of their high school class (thus, the name "Top 10\% Law"). The Top 10\% Law changed the admissions landscape at Texas public institutions not only by eliminating race in admissions but also by eliminating legacy and other forms of preferential treatment in the Texas admissions process. Students who were in AA classifications were lumped into the Top $10 \%$ pool for guaranteed admission to any Texas public institution. A result of the Top 10\% Law was geographic diversity in the number of high schools eligible to send students to Texas flagship institutions. "After affirmative action was taken away as an option, some of its leading critics began attacking universities that focus on recruitment in concentrated poverty schools, where most students are likely to be African American or Hispanic" (Horn et al., 2003, p. 9). Eleven years after enactment, the legislation is no longer viewed as an alternative to race-sensitive policies, but rather a "soft" AA initiative that has not truly benefited either proponents or opponents of AA in higher education.

\section{Study Participants}

This study focused on the lived experiences of Top 10\% African American and Hispanic students at Texas A\&M University. Patton (1990) contended that sample size depends on certain factors: what one wants to know, the purpose of the research, the reasons for inquiry, what is at stake, what data are useful, and availability of time and resources. Qualitative research is not intended to generalize information but to elucidate the participant's experiences of interest to the study (Creswell, 2007). For case study research, Creswell recommended inclusion of no more than four or five cases in a single study. 
Purposeful and criterion sampling were used to select the participants for this study. Purposeful sampling was intentional to identify informed participants who could provide rich answers to the research questions. Purposeful sampling allows the researcher to inform an understanding of the research problem and central phenomenon in the study. Criterion sampling is recommended when all selected participants have experienced the phenomenon being studied (Creswell, 2007).

This study targeted undergraduate, upper-class, Top 10\% African American and Hispanic students at Texas A\&M University. To obtain richness of data, a diverse mix of male and female participants and urban and rural students was sought. Considerations were given to recruiting an equal number of Hispanic and African American students. The first 10 students (across categories) who agreed to participate in the study received $\$ 10$ cash compensation at the end of the interview in appreciation of their time.

\section{Researcher's Role Management}

In this study, the researcher was considered to be the key instrument for data gathering, reviewing the pertinent literature, designing the study, and conducting the face-to-face face interviews with participants to elicit their views and perspectives on the topic. According to Creswell (2009), an interview protocol is recommended for asking questions and recording answers during a qualitative interview. The interviews in this study followed a semistructured format. The interview questions were designed to invite participants to share their lived experiences through dialogue. An interview protocol was used to present the same questions to all study participants. The interview protocol contained 13 semistructured questions or issues for exploration during the interview. Questions were developed from a review of the literature and CRT tenets and themes. 
Use of qualitative interview techniques elicited accounts of the lived experiences of study participants as Top 10\% African American and Hispanic students. A structured format would have limited the ability to obtain information about findings that emerged during the interviews; thus, the semistructured format was appropriate. All interviews were audio recorded and transcribed verbatim by a professional transcription service. Data were presented in rich, descriptive, and expressive language, as prescribed by qualitative research methods.

\section{Entry}

After approval of the study design by the Institutional Review Board of the University of Louisville, assistance from the staff of the Department of Multicultural Services (DMS) and Greek Life at Texas A\&M University was procured to gain entry to participants. Key contacts in each department assisted with the search for students who met the criteria of Top $10 \%$ scholarship recipients. Since DMS staff members serve as advisors and sponsors for the Black Student Alliance Council and the Hispanic President's Council, their assistance was sought to identify and engage underrepresented minority students for the study. Greek Life also had a strong link to the Hispanic and African American communities through the Greek system. A Greek Life staff member, assisted in identifying potential study participants. Both contacts were colleagues and employees of Texas A\&M University. Both contacts taught classes (leadership and Freshman seminar) that gave them access to students. Both contacts announced the study to their student groups and shared the criterion for the study and information about how to contact the researcher to indicate interest in the study. Several students made contact via email, telephone, or text messages to agree to participate in the study. This process 
resulted in selection of 13 students for participation. A consent statement was sent to all participants via email prior to scheduling the focus groups and individual interviews. The statement explained the purpose of the study, length of the interview, and how the results of the study would be used.

\section{Reciprocity}

According to Creswell (2009), both the researcher and the study participants should benefit from the research. Cresswell noted that ethical issues of reciprocity arise when this relationship is not balanced. An example of reciprocity is to provide participants a copy of the completed report of the study, which was accomplished in this study. In the course of the study, participants received copies of interview transcripts so they could review and affirm their statements and provide feedback and corrections. Such member checks allow interview participants to review interpretations, findings, and conclusions (Lincoln \& Guba, 1985) from the transcribed data. Member checking is crucial to establishing the credibility of a study. This method also guards against misrepresentation or misinterpretation of transcribed data and allows editing to be a collaborative endeavor between the researcher and study participants (Etter-Lewis, 1993). Member checking in the current study consisted of taking the transcribed data back to study participants for review, correction, and confirmation of narrative accounts. After audio recordings were transcribed, study participants were contacted via email and asked to verify and edit comments and statements from the transcription. Comments from the participants were noted and corrections were made to transcripts based on the feedback. Participants were also informed that they would receive a link to an electronic copy of the study once it was completed. 


\section{Ethics}

Another concern in conducting qualitative research relates to ethical issues. Lipson (1994, as cited in Creswell, 2007) grouped ethical issues into informed consent procedures; deception or covert activities; confidentiality toward participants, sponsors, and colleagues; benefits of research to participants over risks; and participant requests that go beyond social norms. To address these ethical issues, a consent statement was sent to all participants via email prior to scheduling the focus groups and individual interviews, explaining the purpose of the study, length of the interview, and how the results of the study would be used. Once responses were received from the first email participation request, a follow-up confirmation email was sent to all participants, reaffirming the time and location of the interview and including an informed consent statement and a statement of confidentiality for participant review. Prior to the interviews, participants were asked to sign the consent statement, acknowledging that their participation was voluntary and that they could withdraw from the study at any time, and acknowledging assurances that their identities would remain confidential. During data collection, information from the interviews was not shared with anyone other than the actual participants, the dissertation committee chair, the methodologist, and the data transcriptionist.

\section{Data Collection}

The researcher served as the primary tool for data collection. The participating students were studied in a natural setting. According to Berg (2007), focus group interviews are a useful data-gathering strategy or a line of action in a triangulated project. Merriam (1998) identified interviewing as "the best technique to use when conducing 
intense case studies of a few selected individuals" (p. 72). Ely, Anzul, Friedman, Garner, and Steinmetz (1991) defined logs as "chronological records of what we learn and our insights about how we learn it" (p. 69). Data were gathered in this study via semistructured individual interviews, a focus group, a researcher's log and a review of written documents.

Individual interviews were conducted with four students to understand their experiences as Top 10\% African American and Hispanic students and to engender an awareness of the impact of AA and race-neutral policies on this group of students. According to Yin (2009), case study protocol questions should distinguish among five types or levels of questions: (a) Level 1, questions asked of specific interviewees; (b) Level 2, questions asked of the individual case; (c) Level 3, questions asked of the pattern of findings across multiple cases; (d) Level 4, questions asked of an entire study; and (e) Level 5 , normative questions about policy recommendations and conclusions, going beyond the narrow scope of the study.

For case study protocols, Yin (2009) recommended concentrating heavily on Level 2 questions: questions in the case study protocol to be answered by the researcher during a single case. For example, asking participants about their thoughts and experiences related to the Top 10\% Law addresses the greater case question of feelings and reactions to AA policy. Following the research protocol, 13 semistructured questions were asked of individual participants and follow-up questions were documented to ensure conformity with the focus group questions. Individual interviews were designed to provide a complementing or different perspective from that offered by the focus group to 
understand students' knowledge, acuity, and experiences with the Top 10\% label at Texas A\&M University.

\section{Individual Interviews}

Individual interview participants consisted of two African Americans (one male, one female) and two Hispanics (one male, one female) enrolled at Texas A\&M University and coming from urban or rural settings. Individual interview participants met the following criteria: (a) upper-class student (junior or senior), (b) current recipient of a Top 10\% scholarship, and (c) enrollment as a full-time student. Biographical and demographic information was collected at the beginning of each interview. The interviews (scheduled for 30-45 minutes each) were conducted face to face in the privacy of an administrative office or conference room in the Student Services building on the campus of Texas A\&M University. Prior to audio recording of the interviews, each participant was assigned an alias. All participants were referenced in the study report by alias to ensure anonymity. All recorded and transcribed interview data were kept confidential and locked in a file cabinet in an administrative office. At the conclusion of the interviews, all participants signed a human subjects receipt for compensation and received $\$ 10$ for participation in the study.

\section{Focus Group}

One focus group session was scheduled for 1.5 hours. Participant criteria were the same as for individual interviewees: (a) upper-class student (junior or senior), (b) current recipient of a Top $10 \%$ scholarship, and (c) enrollment as a full-time student. The six focus group participants were three African Americans (one male, two females) and three Hispanics (three males). 
The focus group was conducted face to face in the privacy of a conference room in the Student Services building on the campus of Texas A\&M University. Following the research protocol, 13 semistructured questions were asked of focus group participants, as well as follow-up questions. Prior to audio recording the focus group session, each participant was assigned an alias. All participants were referenced in the study report by an alias name to ensure anonymity. At the conclusion of the focus group session, all participants signed a human subjects receipt for compensation and received $\$ 10$ for participation in the study.

\section{Study Questions}

The questions for the study were developed through consultation with the dissertation committee chair, focusing on sensitivity. According to Corbin and Strauss (2008), research sensitivity is derived through immersion in the data during data collection and analysis. Based on the review of the literature, examination of documents, and the researcher's personal experience, the generated questions ensured trustworthiness. Patton (1990) identified six types of questions that affect the quality of interview responses: experience/behavior questions, opinion/values questions, feeling questions, knowledge questions, sensory questions, and background/demographic questions.

First, experience/behavior questions concern what a person does or has done (Patton, 1990). The question of this type for the current study was, "What has been your with class mates who have not been accepted into Texas A\&M because they were not Top 10\%." Second, opinion/values questions are aimed at understanding participants' cognitive and interpretive processes and lead to understanding of participants' goals, 
desires, and values (Patton, 1990). The question of this type for the current study was, "Do you think Top 10\% underrepresented minority students are viewed different than majority students?" Third, feeling questions are aimed at understanding the emotional responses of people to their experiences and thoughts. The question of this type for the current study was, "Tell me about your overall feelings of race neutral admissions and its utility to ensure fairness, equity, and access to top tier colleges and institutions." Fourth, knowledge questions are asked to learn what factual information the respondent has (Patton, 1990). The question of this type for the current study was, "What is your understanding and perception of race neutral policies in higher education admissions." Fifth, sensory questions ask about what is seen, hear, touched, tasted, and smelled (Patton, 1990). Sensory questions were not used in the interview protocol in the current study. Sixth, background/demographic questions collect information about the identifying characteristics of the person being interviewed (Patton, 1990). The question of this type for the current study was, "What high school did you attend and where is your hometown?" These questions were posed at the beginning of the interview process and followed up at the end for clarity and correction.

Questions from the interview protocol were asked during the focus group session and in individual interviews. The first set of questions in the interview were introductory in nature and allowed participants to become comfortable with the environment and interviewer. Creswell (2007) stated, “Asking appropriate questions and relying on participants to discuss the meaning of their experiences require patience and skill on the part of the researcher" (p. 140). The second set of questions probed the experiences and the meaning of those experiences of being a Top 10\% student. Creswell (2007) referred 
to this process as a narrowing of the central question and subquestions in the research study. Demographic questions and clarifying questions were asked at the end of the interview and focus group session to allow participants to clarify previous responses and/or information shared during the interview.

\section{Managing and Recording Data}

All of the interview data were transcribed by a professional transcription service. Information was stored on a flash drive and locked in a secured file cabinet in the researcher's office. A researcher's log with notes from the focus group session and each individual interview was maintained to document learned experiences or reflections from the interview process. The researcher's log was an unobtrusive way to document observational field notes of focus group and interview participants. The log assisted in organizing thoughts and documenting genuine reactions and observations to questions from study participants. Data were analyzed and assessed using the NVivo $8.0^{\circledR}$ research software.

\section{Trustworthiness of the Study}

Questions of trustworthiness refer to the validity and credibility of a study. Creswell (2009) stressed the importance of employing various research procedures to reduce threats to qualitative validity. Trustworthiness was assured in this study through various measures. Yin (2009) recommend that case study research follow formal procedures to ensure quality control during the data collection process: (a) use multiple sources of evidence, (b) create a case study database, and (c) maintain a chain of evidence. These three methods were used in the current study to establish construct validity and reliability of the case study evidence. 
Multiple sources of evidence were used for triangulation of qualitative data. Individual interviews, a focus group session, review of documents (Appendix A), and a researcher's log comprised the multiple data sources. Creswell (2009) suggested corroborating multiple data sources to minimize problems of construct validity. Patton (1990) suggested cross-checking data for consistency by (a) comparing observational data with interview data, (b) comparing what people say in public with what they say in private, (d) checking for consistency of what people say about the same thing over time; and (d) comparing the perspectives of people from different points for view. Patton's suggested method was applied in the current study, as described below.

To address Patton's first suggestion, "comparing observation data with interview data," notes from the researcher's log were compared with notes from the individual interviews and the focus group session. The $\log$ contained observational data noted during interactions with the study participants, including observed behaviors or comments, as well as the researcher's personal positionality. Creswell (2009) contended that triangulating several sources of data or perspectives from participants adds to the validity of the study. The process of triangulation was used to increase accuracy of findings by converging multiple sources of inquiry and constantly reviewing data for accuracy.

To address Patton's second suggestion, "comparing what people say in public with what they in private," the transcriptions from the individual interviews were compared with the transcriptions from the focus group session. Using the software, NVivo8 assisted in noting similarities, patterns, and differences between groups. 
Patton's third suggestion was not applicable in this study, which was not longitudinal in design and thus did not lend itself to comparing responses over time.

Patton's fourth suggestion, "comparing the perspective of people from different points of view," was followed by ensuring diversity study participants for the case, within the limits of the purpose of the study. Targeted participants were undergraduate, upperclass, Top 10\% African American and Hispanic students at Texas A\&M University. Diversity within those criteria was ensured by recruiting both male and female participants from both urban and rural home origins.

Yin (2009) noted that a case study database increases the reliability of an entire case study. To address this issue, the data analysis software NVivo8 was used to manage data storage, organization, and analysis. Data material included documents, pictures, audio recordings, video recordings, spreadsheets, and database tables. This software was used to organize, synthesis, and classify data (notes, logs, and transcripts) quickly and interchange data in word processing and spreadsheet software to create charts for data illustration.

Yin (2009) also suggested that maintaining a chain of evidence increases reliability of a study by allowing an external observer to follow the evidence from the initial research question to the case study conclusions. Multiple sources of data and a case study database provided a chronicle and methodological approach to the study that increased the quality and reliability of the case data. Figure 4 illustrates Yin's (2009) chain of evidence model in ascending order.

To further strengthen the trustworthiness of case study research, Creswell (1998) suggested utilizing two or more of eight verification procedures (prolonged engagement, 


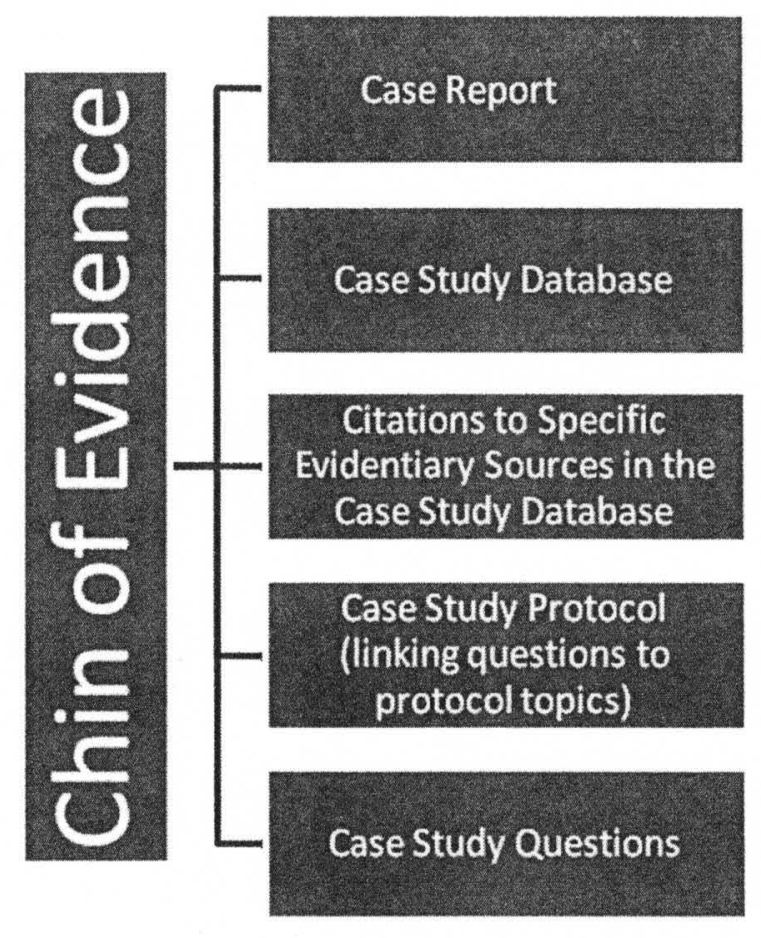

Figure 4. Yin's chain of evidence model, with elements in ascending order.

triangulation, peer review, negative case analysis, clarifying researcher bias, member checks, thick descriptions, and external audits) to ensure credibility. In the current study, methods used to establish trustworthiness of the study included member checks, triangulation, peer review, and clarification of researcher bias.

Peer review calls on the expertise of colleagues who have conducted similar research. Since the participating methodologist has conducted similar research on underrepresented students in STEM majors (science, technology, engineer, and mathematics), he offered insight and a different lens for data interpretation. The dissertation committee chair and methodologist provided constant feedback to ensure accuracy of data and agreement. Email updates and reviews generated valuable feedback 
and critiques of the work in progress from the dissertation committee chair and the methodologist.

Clarifying research bias required identification of preconceptions, assumptions, or biases that might influence the study. Upon review by the dissertation committee chair, biased or opinioned statements that were not researched or peer reviewed were removed from the text. Researcher bias was acknowledged by disclosing the researcher's personal experiences (see the researcher's positionality statement in Chapter I). The researcher acknowledges status as an underrepresented minority student at a PWI with experience as the former DMS director, either of which might be considered as possible influences on the conduct of the study.

Engaging in multiple verification procedures increased the trustworthiness of the this study. These strategies did not eliminate all threats but aided in ensuring that all data and thoughts were accurately represented according to commonly accepted standards of qualitative research.

\section{Data Analysis}

All interviews and the focus group session were semistructured, audio recorded, and transcribed by a professional transcriptionist. Qualitative data can be analyzed using various techniques, including Holsti's (1969) content analysis method, Riessman's (1999) narrative analysis, and Glaser and Strauss's (1967) and Corbin and Strauss's (1990) constant comparative method. The constant comparative method and Creswell's (2009) model for analyzing and organizing qualitative data were chosen for the current study. According to Glaser and Strauss (1967), the constant comparative method is a process of analyzing and comparing newly collected data with previous data that had 
been collected in one or more earlier studies. Figure 5 is a representation of the Glaser and Strauss (1967) constant comparative method.

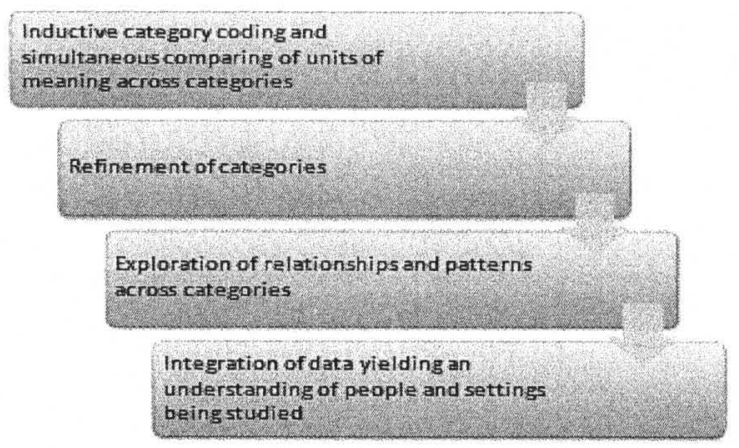

Figure 5. Summary of the Glaser and Strauss constant comparative method.

Creswell's (2009) model for analyzing and organizing qualitative data was appropriate for the current study due to the extensive review of literature and documents addressing issues related to AA and college admissions. A large body of data and literature already existed with which to compare the research findings in the current study.

Coding was one method of examining data in the current study. The constant comparative method employs open, axial, and selective coding to identify and draw connections to data. Open coding is the process of breaking down, examining, comparing, conceptualizing, and categorizing data (Strauss \& Corbin, 1990). Labeling data was drawn from the open coding process. Words such as minority and Top $10 \%$ are examples of open codes. Such words were searched for in the transcriptions of the 
interviews and reviewed documents to identify clusters and patterns of words during the open coding phase.

Axial coding reassembles the data identified in open coding in new ways by making connections between a category and its subcategories (Strauss \& Corbin, 1990). Application of Strauss and Corbin's axial coding model made it possible to (a) identify what caused the phenomenon to occur, (b) what strategies or actions the actors employed in response to the phenomenon, (c) what context and intervening conditions influenced those strategies, and (d) what consequences resulted from those strategies (Cresswell, 2007). This process enables systematic analysis of data. For example, causal conditions in the current study were the reasons underrepresented minority students had selected Texas A\&M University as their institution of choice.

The third coding phase was selective coding. Selective coding is the process of selecting the core category, systematically relating it to other categories, validating those relationships, and filling in categories that need further refinement and development (Strauss \& Corbin, 1990). The selective coding phase involves validating relationships and creating the storyline to explain what happened in the phenomenon being studied. An example of selective coding in the current study was the use of underrepresented minority students and institutional environment as categories of meaning related to the participants' perceptions of being Top 10\% students.

Utilizing NVivo $8.0^{\circledR}$, in vivo codes were used to title categories that emerged from the data. NVivo 8.0 is a software package that assists researchers to organize unstructured information such as documents, surveys, audio and video materials, and pictures. In vivo codes are words drawn from the data and used by study participants. 
Key phrases and words using in the focus group session and interviews were placed in nodes. A query search of these nodes revealed recurring words and phrases from across focus group and interviews. Categories that emerged from the focus groups were crosscompared to categories that emerged from the interviews and the researcher's log. The computer software facilitated the processes of data organization, coding, and analysis of emerging categories.

A holistic analysis of the case was presented in thick description. Holistic analysis occurs when the researcher examines the entire case (Yin, 2003) and presents descriptions, categories, and interpretations or assertions related to the whole case (Creswell, 2007). According to Creswell (2009), "thick description" provide detailed descriptions of the setting and added to the validity of the findings. In thick description, the voices, feelings, actions, and meanings of interacting individuals are heard (Denzin, 1989).

Data analysis involves making sense of collected data. Using the constant comparative model and Creswell's (2009) six steps for analyzing and organizing qualitative data, the data were analyzed and categorized as follows: (a) Transcribed interview data, field notes, and log notes were collected and organized; (b) all data were read to gain a general sense of the information and record emerging ideas; (c) open coding involved organizing segments of data and text into categories; (d) axial coding involved reviewing the coded data, making connections, and generating categories; and (e) selective coding involved identifying categories that emerged from the previous coding processes to generate narrative, rich descriptions. The categories captured recurring patterns across the data, informing the narratives utilized in telling students' 
stories. The final step was to interpret the findings and frame recommendations for practice and further research. These qualitative data analysis methods revealed connections across data collected from the focus group session, individual interviews, and the researcher's log, all of which led to understanding the Top $10 \%$ students' experiences at Texas A\&M University.

\section{Chapter Summary}

Qualitative research methods were employed throughout this study. Case study methodology and CRT were used to understand the "meaning" of being a Top $10 \%$ African American and Hispanic student at Texas A\&M University. Interviews followed a semistructured interview format. Triangulation of data, coding, member checks, and peer review were qualitative techniques used to ensure trustworthiness.

Chapter IV presents the stories of a select of group of Top $10 \%$ underrepresented minority students at Texas A\&M University. Narrative and descriptive analysis was used to analyze and interpret the data from interviews. Chapter V presents an analysis of the findings, conclusions, and recommendations for future research. 


\section{CHAPTER IV}

\section{DATA PRESENTATION AND ANALYSIS}

The purpose of this study was to examine how the Texas Top 10\% Law influenced underrepresented students' perceptions of the law, application to universities under the law's provisions, and feelings of acceptance at a Texas flagship institution. Critical Race Theory (CRT) tenets and themes were used to examine the Top 10\% Law and its impact on African American and Hispanic students in the context of race. Using this approach to data analysis, a focus group, personal interviews, researcher's log, a review of documents were the primary methods of data collection.

This chapter presents the results of the research regarding the perceptions of African American and Hispanic students on the Top 10\% Law and its impact on their matriculation at Texas A\&M University using case study analysis. The chapter is divided into two sections. The first section addresses the demographic data with descriptive details of the focus group participants and the individual interviews. The last section presents the comments of individual interviewees and focus group participants. Data from individual interviews, focus groups, researcher's log, and reviewed documents are presented on a conceptually clustered matrix and subsequently discussed and summarized.

\section{Overview of the Study}

Texas A\&M University was the case study site selected for examination of the experiences of African American and Hispanic students at a Texas flagship institution. 
Texas A\&M University is a public, 4-year, coed, Research I institution founded in 1876. Many of the university's degree programs are ranked in the top 10 nationally. With more than 120 undergraduate degree programs and more than 240 master's and doctoral programs, the university enrolls one of the 10 largest student bodies in the nation, and the largest outside a major metropolitan area. Fall 2009 enrollment was a record 47,802, with a record 9,104 entering freshmen. While it has been more than four decades since Texas A\&M was an all-male military college, its Corps of Cadets remains the largest uniformed body of university students in the nation outside the U.S. service academies, with approximately 2,000 men and women in Reserve Officer Training Corps (ROTC) programs in all four military branches.

The average SAT score for freshmen is 1210 , well above the national average. Texas A\&M consistently ranks among the country's top universities in attracting National Merit Scholars. The university is home to one of the largest chapters of Phi Beta Kappa, the nation's oldest and largest academic honor society. Texas A\&M ranks at the top statewide in student retention and graduation, making it the university of choice for students from all walks of life. About $80 \%$ of the student body receives about $\$ 420$ million in financial aid annually. Twenty-five percent of the freshman class are the first in their family to attend college. The majority of students attending the university are Texas residents.

\section{Site and Procedures}

The focus group session lasted approximately 1 hour 15 minutes in the Koldus Student Services building at Texas A\&M University. The site was chosen due to its central location and familiar buildings located across the street: the Memorial Student 
Center and the Rudder Tower administration building. Both of the aforementioned buildings are heavily accessed by students and are in well-known and publicized locations. Focus group participants met the researcher in the conference room of the office of the Vice President of Student Affairs, where the researcher introduced himself and directed the students to the conference room. Window blinds were closed to assure privacy. The participants sat at a long square conference table that seated 12 ; the researcher sat at the head of the table to be visible and accessible to all participants. The room was furnished with water, an audio recorder, index cards with alias name plates, informed consent forms, and the interview protocol (Appendix B). The researcher began the session by providing background information about himself and the study. Measures to ensure confidentiality were described, as well as plans for follow-up email containing a transcription of the session to solicit participant feedback. At the end of the session, each participant signed a Human Subject Receipt for Compensation form verifying receipt of $\$ 10$ for participation in the study.

Individual interviews were conducted following essentially the same process, including introduction, explanation of the purpose of the study, provision of convenient materials, and signing of consent forms and receipt for compensation forms.

\section{Study Participants' Characteristics}

Personal demographic information was collected at the beginning of the focus group session and each individual interview. There were 10 participants in this qualitative case study. Participants were African American and Hispanic Top 10\% students at Texas A\&M University. Participants were either full-time Juniors or Seniors. Study participants were from urban and rural areas. Four of the six participants were also in the Corps of 
Cadets at Texas A\&M University. Fifty percent of study participants were Hispanic and $50 \%$ were African American. Females represented $40 \%$ of study participants and males represented $60 \%$.

\section{Focus Group Participants}

The focus group consisted of four males and two females, graduates of both urban and rural high schools in Texas. Two participants (Participant 4 and Participant 8) were members of the Corps of Cadets. This is significant to note due to the historical presence of the Corps of Cadets on the Texas A\&M campus and the role of women and ethnic minorities in the integration of the state of Texas and the Corps of Cadets.

Urban cities represented by focus group participants were Houston, Texas; Katy, Texas; and Monterrey, Mexico. Rural settings were Wilmer, Texas; Ennis, Texas; and Valdosta, Georgia. Majors represented by focus group participants were Communications, Biomedical Engineering, Industrial Engineering, Biological and Agricultural Engineering, Agricultural Economics, International Studies, and Computer Engineering. Focus group participants are identified as Participants 1 through 6 . Table 1 summarizes the demographic characteristics of the focus group participants.

\section{Interview Participants}

Two male students and two female students were interviewed individually. The male students had graduated from high schools in rural areas and the female students had graduated from high schools in urban areas. Urban areas represented by interviewees were Galveston and Dallas, Texas; rural settings were Brownsville and Farmersville, Texas. Majors represented by interviewees were Interdisciplinary Studies, Information and Operations Management, Psychology, and Communications. The interviewees were 
Table 1

Demographic Characteristics of Focus Group Participants

\begin{tabular}{llllll}
\hline Participant & Race & Home town & High school & Gender & Classification \\
\hline Participant 1 & AA & Urban & Marginal & Female & Junior \\
Participant 2 & H & Rural & Satisfactory & Male & Junior \\
Participant 3 & AA & Urban & Competitive & Female & Senior \\
Participant 4 & H & Urban & Elite & Male & Junior \\
Participant 5 & AA & Rural & Satisfactory & Male & Senior \\
Participant 6 & H & Urban & Elite & Male & Junior \\
\hline
\end{tabular}

Note. $\mathrm{AA}=$ African American, $\mathrm{H}=$ Hispanic.

evenly divided in ethnicity, two Hispanic and two African American. Individual interview participants were identified as Aggie 1, Aggie 2, Aggie 3, and Aggie 4. Table 2 summarizes the demographic characteristics of the four interviewees.

Table 2

Demographic Characteristics of the Interview Participants

\begin{tabular}{llllll}
\hline Participant & Race & Home town & High school & Gender & Classification \\
\hline Aggie 1 & H & Rural & Elite & Male & Senior \\
Aggie 2 & AA & Rural & Satisfactory & Male & Senior \\
Aggie 3 & AA & Urban & Competitive & Female & Junior \\
Aggie 4 & H & Urban & Marginal & Female & Junior \\
& & & & & \\
\hline
\end{tabular}

Note. $\mathrm{AA}=$ African American, $\mathrm{H}=$ Hispanic. 


\section{Summary of Reviewed Documents}

According to Yin (1994), documents play an explicit role in any data collection in case studies. Documents that were reviewed in the current study to inform the research on the Top 10\% Law included legislative documents, the Texas A\&M Enrollment Fact Book, the Texas A\&M 2010 Statistics Booklet, the Texas A\&M Admissions Booklet, newspaper articles on House Bill 588, and judicial documents related to Hopwood v. Texas (1996). These documents were helpful in understanding the past and present status of Affirmative Action measures in Texas and their impact on college admissions at Texas public institutions. According to Yin (1994), the are four major strengths in using written documentation as a source of evidence: (a) stable - can be reviewed, (b) unobtrusivenot created as a result of the case study, (c) exact—contain exact names, references, and details of an event, and (d) broad coverage_-long span of time, many events, and many settings. All of the written documents that were reviewed supported this research on the Top $10 \%$ Law.

\section{Plan for Reporting Results}

Results of data collection are reported according to the focus group session, individual interviews, the researcher's log, and document review. These methods of data collection were utilized to strengthen the overall design of the study. Each data source provided valuable information that would not have been as clear if these methods had not been employed in combination.

Information from each of the data sources was transcribed and coded using the constant comparative method. Open coding involved organizing segments of data and text into categories; axial coding involved reviewing the coded data, making connections, 
and generating categories; and selective coding involved identifying categories that emerged from the previous coding processes to generate narrative, rich descriptions (Creswell, 2009). The selective codes, herein referred to as categories, started to emerge following the axial coding process. The emerging categories guided the grouping of data with similar units of meaning and extrapolation of relationships from the data.

\section{Emergence of Four Categories}

Using the NVivo $8.0^{\circledR}$ software, data sets were coded and categories emerging from the focus group session and the interviews were identified. The following categories emerged from the data collection process: (a) importance of diversity and race, (b)

personal success and rewards, (c) family expectations and support, and (d) knowledge of the law. Figure 6 illustrates the emerging categories.

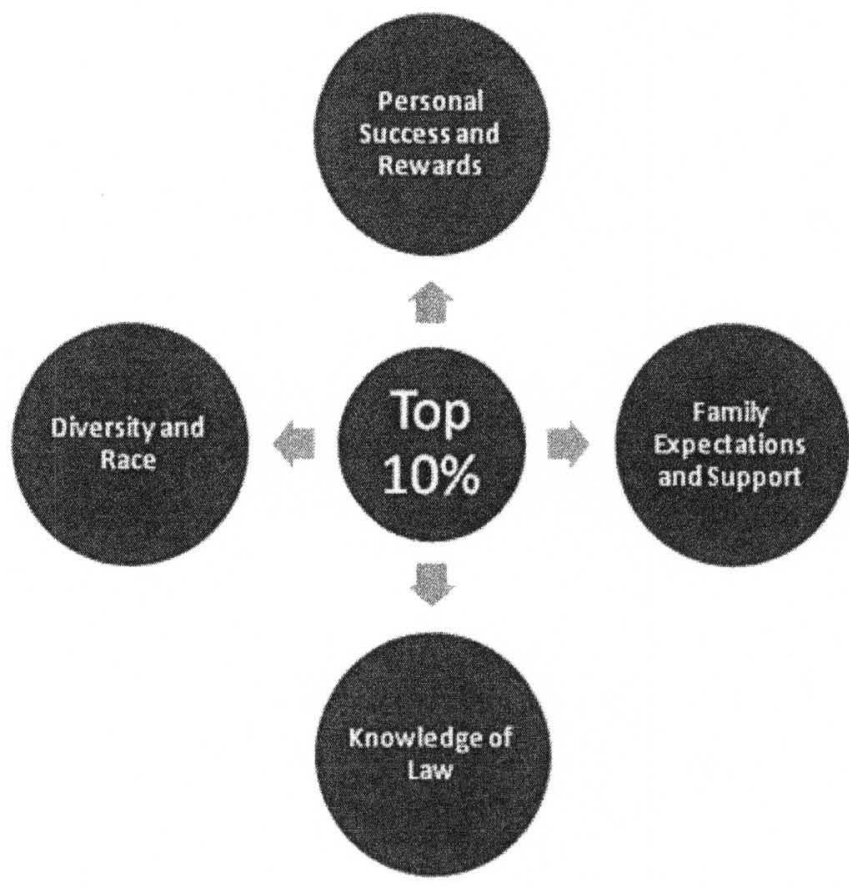

Figure 6. Categories that emerged from the data. 
A conceptually clustered matrix is used to display the four categories and information provided by each participant in the case study. According to Miles and Huberman (1994), a display is a visual format that presents information systematically so the user can draw valid conclusions and take needed action. A conceptually clustered matrix enables the researcher to cluster several research questions so the meaning can be visualized more readily. According to Miles and Huberman (1994), reading across rows and down columns provides a thumbnail profile of each informant and allows comparisons among responses to different questions. Table 3 depicts the conceptually clustered matrix for the focus group. The matrix displays the four categories previously identified along the first row of the grid and the names of the participants along the first column.

The purpose of this study was to examine how the Texas Top $10 \%$ Law influenced underrepresented students' perceptions of the law, application to universities under the law's provisions, and feelings of acceptance at a Texas flagship institution. This study specifically focused on the lived experiences of African American and Hispanic students at Texas A\&M University. The statements reported in the matrix led to several observations. This section presents a discussion of each category and summarizes the responses provided by the focus group and interview participants as they related to the research questions. Quotations from the interviews are used to provide depth to the description of the respondents' expressed feelings. 
Table 3

Conceptually Clustered Matrix for Individual Interviews

\begin{tabular}{|c|c|c|c|c|}
\hline Participant & $\begin{array}{l}\text { Diversity and Race is } \\
\text { Important }\end{array}$ & $\begin{array}{l}\text { Personal Success } \\
\text { and Rewards }\end{array}$ & $\begin{array}{c}\text { Family Expectations and } \\
\text { Support }\end{array}$ & Knowledge of Law \\
\hline Aggie 1 & $\begin{array}{l}\text { It was definitely an advantage; } \\
\text { I saw a lot easier access to } \\
\text { scholarships, financial aid, } \\
\text { internships and opportunities } \\
\text { of that sort, whether it be } \\
\text { college-bound programs or } \\
\text { orientations to meetings and } \\
\text { things that we were invited to } \\
\text { that were for the minorities or } \\
\text { for the Hispanics. }\end{array}$ & $\begin{array}{l}\text { That was my motivation to be } \\
\text { in that group. (To) the kids } \\
\text { that didn't get admitted } \\
\text { because they weren't in that } \\
\text { group, "Well, I tried harder } \\
\text { than you!" That's the way I } \\
\text { see it. I'm a very competitive } \\
\text { person }\end{array}$ & $\begin{array}{l}\text { It was definitely an advantage, } \\
\text { easier access to scholarships, } \\
\text { financial aid, internships } \\
\text { opportunities of that sort, } \\
\text { whether college-bound } \\
\text { programs or orientations to } \\
\text { meetings for the minorities or } \\
\text { for Hispanics. }\end{array}$ & $\begin{array}{l}\text { It was actually explained to } \\
\text { me my freshman year coming } \\
\text { in, by a Counselor. }\end{array}$ \\
\hline Aggie 2 & $\begin{array}{l}\text { The only difference that I } \\
\text { would see would be the } \\
\text { scholarships based on race, } \\
\text { being a minority, but as far as } \\
\text { just being admitted on the top } \\
10 \text { percentile, I don't think } \\
\text { there is a big difference there } \\
\text { between minority and } \\
\text { majority students. I haven't } \\
\text { encountered any problems. }\end{array}$ & $\begin{array}{l}\text { I decided to work harder just } \\
\text { to be one of the upper } \\
\text { numbers of the top } 10 \\
\text { percentile of my class. It was } \\
\text { definitely motivation. }\end{array}$ & $\begin{array}{l}\text { Some scholarships take time. } \\
\text { They have several essays and } \\
\text { things that you have to write, } \\
\text { or do to get the scholarship. } \\
\text { Being in the Top } 10 \% \text {, [I'm } \\
\text { not worried] about what goes } \\
\text { along with the admission } \\
\text { process. }\end{array}$ & $\begin{array}{l}\text { The only thing I knew about } \\
\text { the law was that I would get } \\
\text { automatic admission to any } \\
\text { public school in Texas. }\end{array}$ \\
\hline
\end{tabular}


Table 3 (Continued)

\begin{tabular}{|c|c|c|c|c|}
\hline Participant & $\begin{array}{l}\text { Diversity and Race is } \\
\text { Important }\end{array}$ & $\begin{array}{l}\text { Personal Success } \\
\text { and Rewards }\end{array}$ & $\begin{array}{c}\text { Family Expectations and } \\
\text { Support }\end{array}$ & Knowledge of Law \\
\hline Aggie 3 & $\begin{array}{l}\text { Standards for top } 10 \% \text { are } \\
\text { flexible; you are guaranteed } \\
\text { that you will be accepted. } \\
\text { [There are] advantages } \\
\text { because of race; the SAT } \\
\text { scores and national-level } \\
\text { exams tend to be a lot lower } \\
\text { than other ethnicities. Race } \\
\text { plays a major factor in } \\
\text { applying to a college; if I } \\
\text { would choose to go to the } \\
\text { University of Texas at Austin, } \\
\text { I wouldn't have that many } \\
\text { opportunities because it's a } \\
\text { more diverse campus. }\end{array}$ & $\begin{array}{l}\text { I think I was prepared more so } \\
\text { because I challenged myself } \\
\text { and I didn't take just the } \\
\text { regular classes. Most of my } \\
\text { classes were AP classes. That } \\
\text { challenged me. }\end{array}$ & $\begin{array}{l}\text { I took the application process } \\
\text { seriously because I know they } \\
\text { give you different essays and } \\
\text { some are optional, but they } \\
\text { might be used to determine } \\
\text { scholarships and stuff like } \\
\text { that. So I think that's why I } \\
\text { actually took the } 10 \% \text { as } \\
\text { seriously as I did. }\end{array}$ & $\begin{array}{l}\text { I don't even think the } \\
\text { Counselor told me. I think } \\
\text { there was some type of word } \\
\text { of mouth thing. I never } \\
\text { remember being formally told } \\
\text { that. }\end{array}$ \\
\hline Aggie 4 & & $\begin{array}{l}\text { I'm a strong believer that it all } \\
\text { comes down to personal } \\
\text { determination and how much } \\
\text { you want it. It's not about your } \\
\text { brain, how intelligent you are, } \\
\text { but how much you want it. }\end{array}$ & $\begin{array}{l}\text { There was never an expecta- } \\
\text { tion for me to go to college. I } \\
\text { told my mom I was coming to } \\
\text { college, and for her it was } \\
\text { shocking. She never thought I } \\
\text { would say that. Financially, } \\
\text { my parents could not afford to } \\
\text { give me money to come to } \\
\text { college. So it was never } \\
\text { expected, nor demanded. }\end{array}$ & $\begin{array}{l}\text { [In] my senior year in high } \\
\text { school, second semester, when } \\
\text { we were getting ready to apply } \\
\text { to universities in Texas, it was } \\
\text { explained to me that the Top } \\
10 \% \text { rule was for being } \\
\text { admitted automatically, } \\
\text { acceptance to a public Texas } \\
\text { university. }\end{array}$ \\
\hline
\end{tabular}




\section{Results Produced by the Focus Group}

\section{Category 1: Importance of Diversity and Race}

Study participants discussed the value of diversity but were skeptical about its utility to enhance diversity as a function of the Top 10\% Law. They were not sure of the benefits of simply relying on GPA as a sole indicator of a student's achievement and of success in college. They reiterated that personal motivation and involvement were just as important as a high GPA. The purpose of the Top 10\% Law is to maintain diversity and increased enrollment by underrepresented minority students (in this case, African Americans and Hispanics) without focusing on race. The study participants agreed that geographic diversity was achieved in equalizing higher education opportunity by permitting students from a greater number of Texas high schools to enroll in the most selective public universities (Tienda, Cortes, et al., 2003).

Participant 4 stated that he knew that ethnic diversity was important to colleges and universities. He commented on his understanding of his advantages, "A lot of universities want to really focus on diversity, so if you have two participants that are really, really close and one of them will help that diversity factor, I think they would definitely go for that one."

Participant 5 also viewed his race as an advantage but did not agreed that it was as significant as it was rated by other study participants:

I do think that race and ethnicity gave me a possible advantage because there are regular scholarships and then there were scholarships based toward my race or ethnicity that I can also apply for, so it kind of gave me a broader range of financial compensation for me to actually attend school. 
Niu and Tienda (2010) pointed out that this law disguises the use of race in admissions because of pervasive school segregation in the state of Texas. Focus group participants noted several instances in which their race was viewed positively and sometimes treated differently by college recruiters.

Participant 1 described how high school equity is viewed:

I have heard some White students say that they've taken all these different classes, AP classes and all this different stuff, but they went to Bellaire High School or The Woodlands High School and these students from I don't know what other high schools are in Houston that are lower income, but that those high schools are not as qualified or they wouldn't be as qualified to come here. Participant 4 commented, Personally, I don't think that they're viewed differently. Being in the Top $10 \%$ is more based on your academic achievements, so everyone has the same opportunity to get to that level as anybody else. So personally, I don't see that as anything ... I've never actually perceived the minority students as being viewed differently. I mean partly because I guess my high school was very diverse when it came to race.

CRT proponents Delgado and Stefancic (2001) referred to this as differential racialization. Differential racialization is reflected in differential treatment of racial or ethnic groups by mainstream society due to their perceived advantage or disadvantage.

Participant 1 elaborated on Top 10\% not being a factor:

I don't believe that minority students in the Top $10 \%$ are viewed differently because they're in Top 10\% and minority. I believe that if they're viewed 
differently, it's because they're a minority. People [don't] look at you and say, “Oh, she's Top 10\%" or "He's Top 10 percent." No, they say, "Oh, she's Black, she's Hispanic."

Participant 3 explained the contradictions that he experienced with race and the Top 10\% Law:

We don't walk around with signs on us saying that we were accepted because we're Top 10\%. A lot of times, it reverts back to like, question number one as far as you being a minority. I know a lot of people I'm surrounded by in the Corps automatically think I got in because of Affirmative Action. Nobody even stops to ask, "Hey, were you Top 10\%?" They openly will just say, "Oh, you must have been accepted because you're-because of Affirmative Action." So that's why I was surprised when you said number one as far as the race neutral. I had never even heard of that, so really, Top $10 \%$, being a minority, don't even coincide really on a daily basis for me.

Participant 6 expressed frustration with these contradictions and concluded: From what I know, they made the Top $10 \%$ rule to eliminate using race as like an acceptance and like what we were just talking about like we both, all of us or most of us said that we would use race as like a possible advantage, that kind of, that's not, it's kind of a Catch 22.

CRT uses intersectionality (Delgado \& Stefancic, 2001) to examine race, sex, class, national origin, and sexual orientation and how their combination play out in various settings. Study participants indicated that their Top $10 \%$ status was not an issue on campus, but their race was an issue. Since study participants were African American 
and Hispanic women and men and represented diverse national origins, the concept of intersectionality was explored. Participants indicated that race was more of an issue for them than was their Top 10\% status. One participant stated, "You can't see Top 10\% but you can see my race."

Participant 3 stated that diversity was important but noted that the Top 10\% Law worked to achieve diversity only in high schools that were predominately minority.

You would think that it would help diversity because you have people from different backgrounds, not just Anglos or Asians that are doing really well in their classes, because if I'm going to a predominately minority school, that means predominately, the people graduating Top $10 \%$ are gonna be minority, so I would think that would actually help in the sense of diversity.

Participant 4 realized the benefits of diversity but held that institutions used diversity inappropriately to achieve diversity outcomes: "A lot of universities want to really focus on diversity, so if you have two participants that are really, really close and one of them will help that diversity factor, I think they would definitely go for that one." Koffman and Tienda (2008) posited that the Top 10\% Law expanded college access to top decile students from poor schools by eliminating the SAT filter. Long and Tienda (2009) found that the law benefited seniors in the Top $10 \%$ of their class who had low ACT/SAT scores.

Equality of schools based on racial composition was also identified by focus group participants as impacting diversity. Participant 1 commented on her observation of other minority students in her high school cohort: 
I don't think they had the motivation to do as well because of the environment they grew up in. A lot of their parents hadn't gone to college, so that's not really something that some of them aspired to do.

Participant 3 elaborated on the sacrifices that she and others in her high school had made:

And so amongst the Top $10 \%$, we were the ones that really did care about our grades. I mean, everybody [else] kind of had that mentality of, "I'll just graduate high school and see what I'm gonna do after that." But those of us in the Top $10 \%$ cared about what schools [we would] go to; our GPR scores were more important to us. ... We didn't have all the other opportunities other people had. A lot of the students I am surrounded by at Texas A\&M had Advanced Placement (AP) classes for pretty much anything they wanted to go do. Dual credit classes? None of us had ever even heard of dual credit classes at my high school. I don't know if that was because we were military or because our school didn't have as much money as other schools did.

Participant 6 agreed: "It was like you were playing catch up the last 2 years of high school, trying to take as many AP classes as you could just to get into the Top $10 \%$. You're like, 'Oh crap, I'm behind!'”

A review of related legislative documents confirmed that Texas high schools were given autonomy to determine class rank distributions and that there was no uniform curriculum for qualifying for the Top $10 \%$. In 2001, recognizing deficiencies in the law, the Texas legislature amended the law to require an academic curriculum. Although geographic diversity among high schools was supported by study participants, they were 
not supportive of class rank serving as the sole indicator of merit. They agreed that other factors, such as test scores, leadership, and involvement in extracurricular activities are equally important to creating a well-rounded student and should be part of the determination of eligible students.

In summary, focus group participants were conflicted about the utility and fairness of the Top 10\% Law, although they were beneficiaries of the law. The majority of the focus group participants agreed that the Top 10\% Law was not the major issue, but cited race as the major issue instead. They noted the absence of a statewide "standard" for being a Top $10 \%$ student, which negatively influences the overall effectiveness of the law.

The results for the focus group related to this category are aligned with findings reported by Tienda, Alon, et al. (2008). Focus group participants were heavily engaged in discussion when the questions about their perceptions of race and diversity arose. Tuckman (1965) referred to this occurrence as the performing stage, when the group works in the most productive and interactive ways to form the debate and redefine the issue. Focus group participants whose parents had served in the military had responses opposing those of the other group members. Both Participant 8 and Participant 4 seemed to minimize the issue of race. This observation is not surprising, since the military stresses color-blindness and loyalty to country and minimizes race and gender differences.

\section{Category 2: Personal Success and Rewards}

When asked how they viewed their educational experience, the focus group participants clearly agreed that they were very fortunate to be in their positions. Focus 
group participants had come from an array of high schools, from marginal to elite, but all considered that they had achieved something special because they were attending an elite postsecondary institution. When discussing motivation, Participant 1 stated, "So Top 10 $\%$ gave those students a motivation, like teachers who really want these students to succeed, like, 'Why don't you go to college? You're in the Top 10\%, there's no reason that you can't succeed."'

Participant 3 elaborated on the sacrifices that she and others in her high school had made:

So those of us that tried to do well, we were able to get into the schools that we wanted to go to. You have to have the desire to do well and you have to desire to stay in school, not just get in and drop out.

Participant 5 also commented on his view of being in the Top 10\%: "It was a comforting feeling, knowing that your hard work and you gaining Top $10 \%$ status would pay off by being accepted into the school that you really wanted to go to in the end."

Participant 4 saw his Top 10\% as a kind of insurance: "I saw it as a reward for I guess different accomplishments and in a sense, a safety net."

Woven into personal success and rewards was a sense of service from study group participants. Participants 4,5 , and 2 spoke of how their service to their community and in extracurricular activities was an important influence in helping them to achieve Top 10\% status. Participant 2 stated,

I was also in the top 5\% and I think I could have gotten in if I wasn't in the Top $10 \%$, I did a lot of extracurricular activities and I was doing some other things that can weigh more on a competitive level with other students. 
Participant 4 agreed:

I was actually in top 5, but if I hadn't been in top 5\%, I still feel that my application would have been strong enough to have gotten into A\&M. I guess there's the other factors, as mentioned before, the community service, extracurricular activities as well as the SAT score.

Again, Participant 5 added that because he had worked hard and was involved; he felt that he would have been admitted to the school of his choice.

I feel like what I did and how I made myself competitive towards the Top $10 \%$ would have let me in anyway because of all the things I've done outside the classroom, in the classroom, around the community and everything like that. So my application would have outweighed my status of not being Top $10 \%$.

The importance of personal accomplishment, sacrifice, and service resonated strongly with focus group participants. Although their levels of academic accomplishments varied, they all had a sense of personal achievement and that being in the Top $10 \%$ was the ultimate reward. Top $10 \%$ allowed each of them to explore educational opportunities not accessible to students who had not made similar personal sacrifices.

In summary, focus group participants stressed the importance of their personal sacrifices and accomplishments outside of the classroom as indicators of their academic success. They stated that their merit would have propelled them to the institution of their choice, regardless of the Top 10\% Law. They shared experiences with majority students that had called into question their right to attend Texas A\&M University. They expressed frustration about the lack of acknowledgment of their merit, which was sometimes 
overshadowed by the perception that their matriculation at Texas A\&M was due to some form of AA. The episodes reported by African American and Hispanic focus group participants are aligned with the research on stereotype threat and racial microaggression theory. Solorzano, Ceja, and Yosso (2000b) stated that racial microaggressions in both academic and social spaces have real consequences, the most obvious of which are the result of a negative racial climate in which minority students must navigate through myriad pejorative racial stereotypes that fuel creation and perpetuation of racial microaggression. Although subtle, for most participants achieving Top $10 \%$ status was a monumental accomplishment and not being fully acknowledged because of their race rather than merit led to microaggressions in their social and academic environments. The results of Fu's (2006) study reconciled the commonly assumed conflicts between academic quality and ethnic diversity.

\section{Category 3: Family Expectations and Support}

Familial influence and support was a major category that emerged from the focus group session. According to Teranishi and Brisco (2006), the support needed to socialize and develop youth is provided by a close-knit network of cooperative members of a kinship. Kinship agents are also referred to as protective agents. Protective agents are parents, relative, and peers. Focus group participants acknowledged the importance of family in their college selection process and continued matriculation.

Participant 2 reported her parents' reaction to automatic admission to Texas A\&M University because of her status as a Top $10 \%$ student:

When I talked to my parents about going to college, their first reaction was,

"Well, you know, you have to pay for college and college is expensive and we 
can't afford it." I'm the first one in my family to attend a public university, like a 4-year. My sister is doing a 2-year one, but I'm doing a 4-year one. So they were that way and I had to rely on, or actually am relying on, financial aid to pay for my education for the 4 years.

Participant 3 expressed similar feelings about her parents regarding her college intentions:

They had always harped on, "If you want to go to college, you need to make your way." So I never wanted to depend on my parents for anything, but I knew that if it came down to it, my parents would have gone in debt for me to go to school. The current study supported the literature on the impact of family on college choice. However, participants eloquently described family support as metaphorical rather than fiscal. Study participants shared intimate thoughts about their family expectations with regard to college.

Participant 4 described how he felt about not wanting to be a burden on his family: "I really didn't want that burden on them, so that's one of the main reasons why I worked hard to obtain, an academic scholarship and Top $10 \%$ that would relieve them of that."

According to Hossler, Braxton, and Coopersmith (1989), econometric models posit that a person makes a decision about attending college by comparing the benefits and costs for all possible alternatives and then selects the alternative with greatest net benefit. Participant 3 illustrates the econometric model in her comments:

My parents had always raised me to be - to tell me, "You need to find a way to college, so we're not gonna just give you the money, you need to look for 
scholarships." And so I felt that, if I didn't have the money, if I didn't get a scholarship, I wasn't gonna be able to go to college. So once I got my scholarship, I said, "Okay, now let me look at where I can use it." .. . So once I knew exactly how much the Air Force was gonna pay for my school, I was like, "I have this much money already set for me, so what other school can I look at? What's the tuition gonna be once I subtract that amount?"

Although their Top 10\% status guaranteed college admission, many focus groups participants conveyed that their family had viewed their college selection with excitement and hesitation: excitement for being in the Top 10\% and hesitation for selecting Texas A\&M, a large, expensive, predominantly White institution (PWI) not close to home. Both African American and Hispanic students reported that their families had not been prepared financially to assist them with college expenses. Participant 1 concluded:

I made it a point to work hard so they wouldn't have to pay for me to go to college. That was really my main motivation for working so hard, because I don't want my parents to have to pay for me to go to school.

In summary, Hossler and Gallagher (1987) stated that parents play an important role in shaping attitude toward higher education and college choice. The current study supported the literature on the impact of family on college choice. According to Teranishi and Brisco (2006), parents are significant influences on students' college selection, but siblings, extended relatives, and friends are another important set of social networks. These influences were illustrated by the participants. The focus group participants were fully aware of their parents' financial status and how it would factor into their college selection. These students were determined not be dependents to their parents beyond high 
school and saw the academic achievement and scholarship attainment as the solution. As a result of their family socioeconomic status, most participants reported that they felt obligated to "make their own way" and not to rely on their parents or support network for financial assistance. This point is contradictory to the college choice literature that heavily emphasizes the role of family in college selection. Although family had significant influence on focus group participants, the decision and ability to attend college was less formalized than the literature would suggest, because of the automatic admission provided by the Top $10 \%$ Law.

\section{Category 4: Knowledge of the Law}

Across the board, focus group participants did not know how the law had come into existence or how it really worked. Common was the understanding that the Top $10 \%$ Law was a tool to gain access to the best schools in Texas. Learning the details about the law was not something that they had experienced consistently. They indicated that they had not been fully aware of the law until their senior year in high school. Participant 5 explained when he first heard about the law. "My senior year, it was explained, but that's all I understood ... they said, 'Top 10 percent automatically gets accepted into any Texas School.' And that was as far as the explanation went."

McDonough (1997) drew similar conclusions regarding the experience of underrepresented minority students and their knowledge of the college admissions process. McDonough, Antonio, and Trent (1997) reported that schools serving minority or low-income students were organized in a way that provided little time for counselors to share college information or college help with high school students.

Participant 6 spoke candidly about his first knowledge of the Top 10\% Law. 
That's kind of what I heard as well. My dad was in the military as well, so I only spent the last 2 years of high school in Katy. When I came and I learned about the Top $10 \%$ rule, the way it was stated to me was just, "If you're in Top $10 \%$ of your school in Texas, then you can go to any school in Texas."

The National Center for Education Statistics (2004) reported that first-generation college students, particularly Black and Hispanic students, may be disadvantaged by higher education markets if they are unable to obtain relevant information from family, school, or community. For many students, the mention of the Top $10 \%$ has meaning, but the knowledge to prepare adequately and to take advantage of the law is realized by few, especially students in low-income communities and schools.

In summary, an understanding of the college admissions process is essential to successful entrance and matriculation by underrepresented minority students. The students in the focus group had a basic understanding of the Top 10\% Law but were not fully aware of the benefits and advantages of early application. The significance of this finding is helpful in understanding the disparity in the numbers of underrepresented minority students utilizing and qualifying for Top $10 \%$ scholarships in Texas. For example, according to the Texas A\&M 2010 Statistics Booklet, of the 3,932 Top 10\% freshman enrolled at Texas A\&M University in fall 2009, 158 were African American and 842 were Hispanic, as compared to 2,718 White students. Also worth noting from the above numbers, 153 of the 158 Black students, 775 of the 842 Hispanic students, and 1,084 of the 2,718 White students were first-generation college students. These findings support the literature on underrepresented minority students and first-generation students' access and understanding of college admissions. Establishing relationships and/or 
partnerships with middle school and high school counselors is essential for underrepresented minority students and their parents to fully understand the resources that are available to them as they prepare for college. If this understanding and knowledge of the law is absent, opportunities are lost for students as early as the seventh grade.

\section{Results Produced in the Individual Interviews}

The four interviewees were also students at Texas A\&M University under auspices of the Top 10\% Law. Demographic characteristics of the interviewees are presented in Table 2. Each individual interview lasted approximately 30 to 45 minutes. All interviews were conducted in a private conference room in the Student Services Building on the Texas A\&M University campus. All interviews followed an interview protocol (Appendix B). The four interviewees are herein designated as Aggie 1 through Aggie 4. As described in the section on focus group participants, documents were reviewed in preparation for these interviews and it was determined that the documents supported the research on the Top $10 \%$ Law. Results of the four individual interviews are reported in this section by emerging category: (a) importance of diversity and race, (b) personal success and rewards, (c) family expectations and support, and (d) knowledge of the law.

\section{Category 1: Importance of Diversity and Race}

The aim of understanding the role of diversity and race in relation to the Top $10 \%$ Law guided the study. Interviewees revealed that their race was a factor but did not guarantee any benefits beyond heightened awareness and access and educational resources. They reported that their perceived advantages were available to any student 
who excelled academically. According to Brezina and Winder (2003), persistence of Whites' opposition to policies designed to alleviate racial inequality and failure to succeed are still attributed by Whites to a lack of effort by the poor and disadvantaged.

Aggie 2 stated that race was an advantage but only concerning scholarships, not the admissions process.

The only difference that I would see would be the scholarships based on race, being a minority. But as far as just being admitted [based] on the Top 10 percentile, I don't think there is a big difference there between minority and majority students. I haven't encountered any problems.

Aggie 4 contended that race provided advantages but only for those who are academically eligible. She explained that not having to take the SAT was an advantage of being in the Top $10 \%$, which is not just for minority students.

I would say race does play a major factor when you're applying to a certain college simply because, if I would choose to go to the University of Texas at Austin, I wouldn't have that many opportunities because there's more-it's a more diverse campus. The standards for the Top $10 \%$ are really flexible because you are guaranteed that you're gonna be accepted to it. But as far as having some advantages because of the race, I think there is, simply because the SAT scores and all the national level exams tend to be a lot lower for other ethnic groups. Aggie 1, similar to Participant 5 in the focus group, rated diversity as important and cited pressure to achieve diversity through the recruitment process. He recalled his experiences at the prospective student center: 
I've even heard it from admissions and people, who say-and even prospective student center people who are trying to get a lot of minorities up to these large universities. And they themselves place a stigma on the Top 10\% students.

The discussion of diversity and race also called into question the motivation of institutions to recruit underrepresented minority students. According to Knight and Hebl (2005), highlighting the value of a diverse student body might be effective in changing nonbeneficiaries' attitudes because it shows Whites how a racially diverse campus is in their self-interest.

Aggie 4 remarked that the emphasis on race was overshadowed by the benefits of a having a diverse student body. "They want numbers so that they can say, 'We're a diverse campus.' It comes down to numbers pretty much, they want the numbers. I think it's more so at the beginning of everything, they ask your race."

Aggie 2 shared mixed feelings about the value of the Top $10 \%$ Law. She understood the need for diversity but pointed out that it yielded only one African American student from her senior class, and she questioned its utility for enriching educational experiences.

I don't think it diversifies the student population here at all. Me being in the top $10 \%$ of my class, I was the only African American in the top 10 percentile. So A\&M just got one African American student from the whole senior class of Farmersville. I don't think that it diversifies so much.

Aggie 4 further explained how the Top 10\% Law had caused unfavorable feelings and reactions from those who were not Top $10 \%$. She explained how, despite their (White classmates') privilege, they viewed the law as unfair. 
Oh, I would say that has been a really rough, that has been a shaky situation simply because they feel like they have the potential and they have what it takes, and that their score should not be based on admission. And they look at the Top $10 \%$ bad, simply because they say that a lot of them get accepted simply because we're the Top 10. And they have the money to come here and they have like the SAT scores to come here and they feel like it's unfair. I would say it does provide equal opportunities, but coming from a high school that was not great academically, I would say it was fair. But if I would have gone to a higher-level high school or magnet school, things would have been different. So I think that's where the disadvantage comes into play, like what type of high school you're in. Aggie 4's comments are supported by Knight and Hebl's (2005) study in which they concluded that, across all types of AA program and groups, utilitarian justification that emphasized benefits to both minority and majority groups was the most successful approach in gaining positive support for AA initiatives.

In summary, so long as AA programs, such as the Top $10 \%$ Law, are viewed as proportionally disadvantaging another group, scrutiny in higher education as a diversity quota rather than student merit appears to be attached to underrepresented minority students at PWIs. Hurtado, Inkelas, Briggs, and Rhee (1997) stated that preferences for underrepresented minority groups in admissions have not created unfair advantages, particularly when the number of underrepresented minority students who overcome adversity to reach higher education is so small and access remains a significant problem. 


\section{Category 2: Personal Success and Rewards}

The importance of feeling successful and rewarded from accomplishing Top $10 \%$ status is highlighted in this section. Personal success and rewards was a consistent message mentioned by all interview participants. Interviewees took pride in being in an elite group and noted that, due to their personal sacrifices and lifestyle choices, the Top $10 \%$ was one of many rewards.

Aggie 1's comments summed the feelings expressed in most of the individual interviews.

That was my motivation to be in that group [Top 10\%)]. The kids that didn't get admitted because they weren't in that group: "Well, I tried harder than you!" That's the way I see it. It wasn't even so much coming to a large university like A\&M, it was just the thought in my mind, “Okay, I'm gonna get into college if I make this Top $10 \%$, because I'm part of this elite group."

Aggie 1 also commented on how he valued his accomplishment and how he wanted his experience to influence his family.

It was a key to college. It was a key to a university, a degree. So I took it as that. Just seeing me here, the Top $10 \%$ rule allowed me to be here. So it's like me starting my Aggie generation. My little sister really wants to come here. She's a freshman right now. She's really working hard towards that.

Aggie 4 described similar feelings but focused his comments on the motivation that is required to be in the Top 10\%: "So I'm a strong believer that it all comes down to personal determination and how much you want it. It's not about your brain, how intelligent you are, but how much you want it." 
Aggie 3 stress the important of personal motivation by taking challenging classes and not settling for norm. He stated that, by taking advanced placement classes, he had been prepared to compete and qualify for the Top $10 \%$ scholarship. "I think I was prepared and I think it was more so because I challenged myself and I didn't take just the regular classes. Most of my classes were AP classes. That challenged me."

The interviewees were generally congruent with the focus group participants; however, the interviewees appeared to be more vocal about how other factors had influenced the perception of them on campus. Similar to focus group participants, interviewees reported that they did not feel that they were perceived as academically astute based on hard work and merit. Aggie 3 stated, "They don't necessarily think, 'Oh, they got in because they're Top $10 \%$ like me.' It's, 'Oh, yeah, Top $10 \%$, but they got it because they're African American or because they're Hispanic.' That whole quota factor comes into it again."

Nacoste and Lehman (1987) reported that nonbeneficiaries of AA often assumed that minorities were admitted only through AA programs rather than on their own merit, they considered beneficiaries to be less qualifies than their peers.

There are certainly negative thoughts on the Top $10 \%$, especially when I came here to Texas A\&M, I encountered one, racism, two, discrimination, and anything that was negative towards the minorities here at Texas A\&M simply because they said, "You got here because of the Top 10\%; otherwise you should not be in here."

Feelings reported by Aggie 3 and Aggie 4 are comparable to stereotype threat and microaggressions discussed in the results of the focus group session. Although not always 
implied, underrepresented minority students are cognizant and sensitive to the perceptions of their presence on campus. Aggie 3 stated a belief in the value of the Top $10 \%$ Law but was adamant about not being exclusively judged on race.

I think it kind of goes back to what I said earlier, with most majority students thinking there's a quota that schools have to meet and they have to have so many African American students. A ton of majority people think that, like, application process is, and admissions are based off that. . . I I think it's equal when it comes to those competitive or satisfactory schools, but then those other schools that are all about academics, the ones that don't even have sports because they're known just for academics. I don't think it's fair to them because most of them are smart and it's impossible for everyone to be in Top $10 \%$, even though they all deserve to be there. Yeah, I definitely think it's fair. I don't think anyone should be admitted to anything because of your race. Like, at the end of the day you're not gonna get a job because of your race, either. So I don't think it'll prepare you in any way for you to be accepted into something just because of what color your skin is.

In summary, the interviewees expressed pride in what they had accomplished. They stated that they deserved the accolades and benefits because they had gone above and beyond their fellow classmates to achieve Top $10 \%$ status. They reported that, based on interactions with majority students, they realized that their accomplishments were not viewed by all as equitable. They reported a perception held by some that they are at Texas A\&M University as a result of AA and not their own merit. As noted in the focus group session, there continue to be subtle racial microaggressions in academic and social 
spaces for Top 10\% underrepresented students that influence their sense of pride and belonging on campus.

\section{Category 3: Family Expectations and Support}

Interviewees reported myriad reasons to accept the Top $10 \%$ scholarship. Consistent with focus group participants, the interviewees cited financial support and family expectations. Research by Hossler and Gallagher (1987) on college choice indicated that gender, family income, and parents' highest educational attainment were significant influences on a student's choice of a college. This finding was noticeable in many of the comments from these interviewees.

That's the only reason why I think I took the application process seriously; I know they give you different essays and some are optional, but they might be used to determine scholarships. So I think that's why I actually took that part as seriously as I did.

Aggie 4 also stressed the importance of financial considerations and her socioeconomic background:

What made me decide A\&M was, one, the Corps. But mainly it was financially simply because A\&M gave me more scholarships for being a first-generation student and coming from a lower socioeconomic background, and coming from an underdeveloped high school. So finances did come into play.

The above statements support findings by Hurtado et al. (1997) that underrepresented minority students who score similarly on college entrance tests and have comparable socioeconomic backgrounds are more strategic than their White counterparts about the college application process. Many study participants reported that 
they had used their time strategically to apply for more scholarships and research other opportunities to offset the cost of college because they were not required to worry about the extensive admissions process due to their Top $10 \%$ status.

Aggie 4 reported that the Top 10\% stat us had made a major difference in her decision to attend college. Although her family had not discouraged her from attending college, she was clear about their expectations of her:

There was never an expectation for me to go to college. I told my mom I was coming to college my senior year, and for her it was shocking. She never thought I would say that. Financially my parents couldn't, and up until this point, could not afford to give me money to come to college. So it was never expected nor demanded. Well, I'm a first-generation student, and I'm obviously Hispanic, and I come from a first—I'm the first one to graduate high school. So it gives opportunities to people like me to break the chains from my house and be the one that comes to college first and graduates. People like me that want to be someone in life, and these opportunities, these laws are really helping those students. Aggie 4's statements aligned with the research on Latino students and college choice. Hurtado et al. (1997) reported that Latino students had the lowest expectations for degree attainment, were least likely to enroll in college immediately after high school, and tended to apply to fewer colleges than other students.

In summary, both the African American and Hispanic interviewees indicated that their parents had not been financially prepared to send them to college. Knowing that their child had been automatically admitted to a university through provisions of the Top $10 \%$ Law was met with mixed feelings of joy and hesitation by the participants' parents. 
By being in the Top 10\%, these students were also eligible for resources and scholarships because they were exceptional students academically. The interviewees reported that their families had been excited about their achievement of being in the Top 10\% but had not seemed to have a plan to support the students as they continued their education. The Top 10\% Law clearly influenced the interviewee's college selection decisions, with an emphasis on maximizing financial aid, grant, and other scholastic benefits. Parental financial support was nearly nonexistent and was not a major factor in any interviewee's decision to attend or not to attend college.

\section{Category 4: Knowledge of the Law}

Navigating the college admissions process continues to be an issue for underrepresented minority students. Perna (2000) concluded that African Americans in her study had less access to information and knowledge about how to acquire a college education and achieve their educational goals. Similarly, Olivia (2008) reported that students had differential access to college knowledge and information and suggested that institutions should become more culturally responsive and helpful to underrepresented students. The conclusions reached in the cited research were acknowledged by interviewees as they expressed when and how they had become aware of the Top 10\% Law.

Aggie 2 commented, "The only information that I received was that, if you're in the Top $10 \%$ of your class, then you would be admitted in any of the Texas universities."

Aggie 3 reported limited knowledge of the Top $10 \%$ or benefits associated with the scholarship: "I don't even think the Counselor told me. I think there was some type of word of mouth thing. I never remember being formally told that, though." 
Aggie 4 shared that she had been made aware of the Top 10\% Law during his senior year in high school, but only when he had begun the application process to attend a Texas institution.

Yes, it was actually my senior year in high school, second semester, when we were getting ready to apply to universities in Texas, and it was explained to me that the Top $10 \%$ rule is for being automatically admitted, acceptance, to a public Texas university.

The lack of timely and complete information to underrepresented minority groups regarding college admissions and available resources continues to plague higher education. Perna (2006) observed that low enrollment rates for African American and Hispanic students are attributable to students being poorly informed about the cost and economic benefits of higher education.

Aggie 1 was the only interviewee to report a different experience. He explained that the law had been explained to him as a freshman, although without great detail. It was actually explained to me my freshman year coming in, by a Counselor. They basically said, "Your clock starts now, do your best, because if you make the Top $10 \%$, you can get into any public university within the state of Texas." In summary, research by Perna (2006), Olivia (2008), and Perna (2000) indicated that access to information and knowledge of the intricacies of the college admissions process are still barriers for underrepresented minority students. Interviewees expressed appreciation of their counselors sharing information about the Top 10\% Law. All indicated that they were informed about the basics of the law. Specific information about 
the law was not timely and could have had adverse effects on the interviewees' college admission if they had not been strong academically.

\section{Researcher's Log}

Documents that were reviewed in the current study to inform the research on the Top 10\% Law included legislative documents, the Texas A\&M Enrollment Fact Book, the Texas A\&M 2010 Statistics Booklet, the Texas A\&M Admissions Booklet, newspaper articles on House Bill 588, and judicial documents related to Hopwood v. Texas (1996). Also, a researcher's log documented observations gained in interactions with the focus group participants and interviewees. Table 4 summarizes observations from the researcher's log according to the four categories that emerged during the data collection process. This section highlights notes from the researcher's log regarding the focus group session and the individual interviews.

\section{Researcher's Log for the Focus Group Session}

I followed up with each via email, phone, and text messages. Once all students were confirmed, I provided directions to the office of the Vice President for Student Affairs in the Koldus building since not everyone knew of its location. This observation was made during my phone contact with the participants, so I noted to make sure everyone had directions to the interview site.

The focus group started 10 minutes behind schedule at 7:40 p.m. Two participants did not show. I had oversampled the focus group and anticipated that one or two students would not show. Litosseliti (2003) advised having a reserve pool in case some original participants do not attend. Therefore, the focus group consisted of six participants: two females and four males. I asked the participants whether they 
Table 4

Summary of Researcher's Log

\begin{tabular}{|c|c|c|c|c|}
\hline $\begin{array}{l}\text { Participant } \\
\text { group }\end{array}$ & $\begin{array}{l}\text { Diversity/race } \\
\text { is important }\end{array}$ & $\begin{array}{l}\text { Personal success } \\
\text { and rewards }\end{array}$ & $\begin{array}{l}\text { Family } \\
\text { expectations } \\
\text { and support }\end{array}$ & $\begin{array}{l}\text { Knowledge } \\
\text { of the law }\end{array}$ \\
\hline \multirow[t]{2}{*}{ Focus group } & \multirow[t]{2}{*}{$\begin{array}{l}\text { Participant said } \\
\text { that her high } \\
\text { school experi- } \\
\text { ence had not } \\
\text { been positive or } \\
\text { enriching } \\
\text { because she } \\
\text { came from a } \\
\text { low-achieving } \\
\text { high school. }\end{array}$} & $\begin{array}{l}\text { Aside from aca- } \\
\text { demic achieve- } \\
\text { ment, there was } \\
\text { an apparent } \\
\text { strong commit- } \\
\text { ment to personal } \\
\text { causes and } \\
\text { leadership from } \\
\text { participants. }\end{array}$ & $\begin{array}{l}\text { Parents of } \\
\text { participants } 3 \\
\text { and } 6 \text { were in the } \\
\text { military and had } \\
\text { stressed the } \\
\text { importance of } \\
\text { service. }\end{array}$ & $\begin{array}{l}\text { Participant } 3 \text { had } \\
\text { not known that } \\
\text { Texas had race- } \\
\text { neutral policies } \\
\text { nor realized the } \\
\text { intent of the law. }\end{array}$ \\
\hline & & $\begin{array}{l}\text { Participants were } \\
\text { confident that } \\
\text { they would have } \\
\text { gained admission } \\
\text { to Texas A\&M } \\
\text { regardless of Top } \\
10 \% \text { Law. }\end{array}$ & $\begin{array}{l}\text { Most of the } \\
\text { group reported } \\
\text { inadequate } \\
\text { financial support } \\
\text { from parents to } \\
\text { attend college. }\end{array}$ & $\begin{array}{l}\text { Participant } 7 \\
\text { reported continu- } \\
\text { ing to study the } \\
\text { law and looking } \\
\text { deeper into the } \\
\text { quality of high } \\
\text { schools. }\end{array}$ \\
\hline \multirow[t]{2}{*}{ Interviews } & & $\begin{array}{l}\text { Aggie } 4 \text { is a first- } \\
\text { generation } \\
\text { college student } \\
\text { and proud of her } \\
\text { accomplishments } \\
\text { thus far. }\end{array}$ & $\begin{array}{l}\text { Aggie } 2 \text { was } \\
\text { struggling } \\
\text { financially to } \\
\text { stay in school but } \\
\text { had not let that } \\
\text { stop him from } \\
\text { being involved } \\
\text { and succeeding } \\
\text { academically. }\end{array}$ & $\begin{array}{l}\text { Aggie } 2 \text { was not } \\
\text { as familiar with } \\
\text { the law but con- } \\
\text { cluded that the } \\
\text { law's intent was } \\
\text { good. }\end{array}$ \\
\hline & & $\begin{array}{l}\text { Aggie } 1 \text { had been } \\
\text { president of one } \\
\text { of the larger } \\
\text { Hispanic groups } \\
\text { on campus. }\end{array}$ & $\begin{array}{l}\text { Aggie } 4 \text { stated } \\
\text { that the Top } 10 \% \\
\text { had made a } \\
\text { significant } \\
\text { impact on her } \\
\text { because her } \\
\text { parents had not } \\
\text { expected her to } \\
\text { go to college. }\end{array}$ & $\begin{array}{l}\text { Aggie } 2 \text { had } \\
\text { already told his } \\
\text { sister, cousins, } \\
\text { and friends in } \\
\text { high school that } \\
\text { the law "really } \\
\text { works." }\end{array}$ \\
\hline
\end{tabular}


knew each other; only two participants (Participant 7 and Participant 4) responded. Participant 7 stated that he had seen Participant 4 before at ExCEL and other programs sponsored by the Department of Multicultural Services. I asked everyone to introduce himself or herself and explained that aliases would be used to protect confidentiality. Everyone nodded affirmatively and I proceeded to engage the group by reading a brief introduction about the Top 10\% Law. Immediately after I finished the introduction, Participant 4 stated that she had not known that Texas had race-neutral polices nor realize the intent of the law. Other members agreed with her statement. As I proceeded to ask questions of this group, I noticed that they were not completely comfortable in answering the questions in the group setting. I started to make eye contact after I asked questions to elicit responses. Finally, Participant 8 responded to a question and gave a long explanation of his high school experience and how the Top 10\% had impacted him. His statements drew agreement from the others and seemed to put the group at ease. Participant 2 disagreed with Participant 8 , stating that she believed that her high school experience had not been positive or enriching because she came from a low-achieving high school. Because the group was engaged and talking about their high school experiences, I stayed with that line of questioning. Following questions related to high school experiences, I asked the focus group participants about their perceptions of the Top 10\% Law. Everyone appeared to be more comfortable and started to share their experiences. I asked Participant 3 next questions directly to solicit his feedback. Thus far, he had not commented on any of the questions. I reaffirmed that everyone's participation was voluntary and 
welcomed. With the presentation of the next question, he leaned forward and began to engage in the discussion.

During the focus group, two participants (Participant 4 and 8) shared that they were in the Corps of Cadets and that this was a major reason for attending Texas A\&M. Their parents were in the military and had stressed to them the importance of service. Both Participant 4 and Participant 8 seemed to minimize the issue of race because of their military upbringing and linkage with the Corps. Participant 4 stated in the Focus Group, ... "When it came to schools, I wasn't looking at how may minorities are at this school or how many do I think they will accept. I just thought I was well rounded and I just thought because of A\&M's history of having well rounded people and plus I wanted to be in the Corps of Cadets here at A\&M as well." The majority of the Focus Group did agree that the Top 10\% Law was not the bigger issue, but cited race as the major issue instead.

All Focus Group participants resonated with the concept of "service" and shared how they had given to their communities or were doing so while in college. Aside from the academic achievements of Top 10\% students, I began to sense a strong commitment to personal success and leadership in the participants. They were proud of their accomplishments in and out of the classroom and considered the Top $10 \%$ Law to be a reward for their personal achievements and sacrifices in high school. Everyone in the group contributed to the discussion and appeared to have had similar experiences in high school based on the information they shared. They were confident that they would have gained admission to Texas A\&M University 
regardless of the Top 10\% Law because they were heavily involved in student organizations, sports, clubs, and community activities.

The focus group session revealed the values of the participants and what motivated them to achieve Top $10 \%$ status. It was apparent from their comments that most of the group did not have adequate financial support to attend college without the scholarships. Another observation was the desire of the students to not be a burden to their parents after high school. The focus group session ended at 8:55 p.m. Participants expressed appreciation for the opportunity to learn more about the Top $10 \%$ Law and to share their experiences as Top $10 \%$ students. Participant 7 was intrigued by the study and expressed the hope that I would continue to study the law by looking deeper into the quality of the high schools as a part of the considerations for selecting Top $10 \%$ students.

\section{Researcher's Log for the Interviews}

I allotted about 45 minutes for each interview; only one interview lasted longer than that. The interview with Aggie 1 was by far the most engaging. Aggie 1 had been a star athlete in high school but he stated that he had no intention to play sports in college. Aggie 1 had been president of one of the Hispanics groups on campus. He shared his experiences about being a Top $10 \%$ student and especially about being an underrepresented minority student at Texas A\&M University. Aggie 2 was not engaging at first but was very inquisitive about the purpose of the study. I reviewed the informed consent statement. I explained that my intent was to use the data to inform future decisions about the utility of the Top $10 \%$ Law. He openly admitted that he was not as familiar with the law as he should be, 
since he was a recipient, but he concluded that the law's intent was good. He said that he had already told his sister, cousins, and friends in high school that the law "really works." Aggie 2 displayed candor and a light-hearted approach to college. More than the other interviewees, he reported that he was struggling financially to stay in school but had not let that stop him from being involved on campus and succeeding academically.

Aggie 3 presented the shortest of the four interviews. No matter how I phrased or restated a question, she was short and direct with responses. She clearly considered me to be an authority figure and was professional throughout the interview, providing formal responses such as "Yes, sir" and "No, sir." I tried to put her at ease by restating the purpose of the research and the confidentiality of the interview process. She shared that she was in the Corps of Cadets, which changed my approach to the interview process. I used subtle cues to draw more information from her to the best of my ability, rephrasing her responses and asking for clarification. This technique led her to elaborate on her responses somewhat and provided usable interview data.

Aggie 4 arrived 15 minutes early for her interview; she said that she is always early to appointments because she has to walk everywhere. Aggie 4 is from Dallas, a first-generation college student, and proud of her accomplishments thus far. She had a heavy Spanish accent that required me to listen especially attentively to her comments. She was interested in how the study would assist Hispanics. I told her that this study was one of many that was intended to contribute to the literature on the Top 10\% Law and to inform persons who make 
decisions about the law. She shared information about her personal situation with finances and her family. She stated that the Top $10 \%$ had made a significant impact on her because her parents had not expected her to go to college.

\section{Results of the Review of Supporting Documents}

A host of documents supported this study: legislative documents, Texas $A \& M$ Enrollment Fact Book, Texas A\&M 2010 Statistics Booklet, Texas A\&M Admissions Booklet, newspaper articles on H.B. 588, and judicial documents on Hopwood v. Texas (1996). The legislative documents and judicial documents were extremely helpful in understanding the past and present status of AA measures in Texas and their impact on college admissions at Texas public institutions in relation to African American and Hispanic students.

Legislative documents included House and Senate analysis of H.B. that gave a rationale for the creation of law, definition of terms used in the bill, mandates to all Texas public institutions, eligibility requirements, and reporting structures. The judicial documents included Hopwood v. Texas (1996) court briefings, court rulings, majority and dissenting opinions. These documents were useful in explaining the genesis of H.B. 588 due to concerns on the part of Texas legislators that the state might not be in compliance with the Office of Civil Rights. Court documents also provided a clear historical timeline of AA efforts in desegregating higher education institutions in the state of Texas.

\section{Chapter Summary}

This chapter report $\mathrm{s}$ data obtained from the focus group session, individual interviews, the researcher's log, and review of pertinent written documents. These various data collection methods were used to assist with triangulation of data to discover 
Top 10\% African American and Hispanic students' experiences at Texas A\&M University as a result of their Top $10 \%$ status. Information was presented by using thick description in the form of quotes from study participants. Other data collected is presented in table and matrix formats to illustrate connections to categories that emerged to address the research questions. 


\section{CHAPTER V}

\section{CONCLUSIONS AND RECOMMENDATIONS}

The purpose of this study was to examine how the Texas Top 10\% Law influenced underrepresented students' perceptions of the law, application to universities under the law's provisions, and feelings of acceptance at a Texas flagship institution. This study followed a qualitative, single case study design to learn about African American and Hispanic students' experiences as Top 10\% scholarship recipients at a single site, Texas A\&M University. Purposeful and criterion sampling were used to select the institution and participants for the study. The institution and participants were purposefully chosen based on predetermined criteria: undergraduate, upper class, Top 10\% African American and Hispanic students at Texas A\&M University. To obtain richness of data, a diverse mix of male and female participants and urban and rural students was recruited. The researcher served as the primary tool for data collection via semistructured individual interviews, a focus group, a researcher's log, and a review of written documents.

\section{Relation to Theoretical Framework}

Critical race theory (CRT) served as the theoretical framework for the study, applying the advocacy/participatory worldview and a critical analysis perspective to understand the lived experiences of African American and Hispanic students as Top 10\% recipients at Texas A\&M University. The goal of CRT is to (a) present stories about discrimination from the perspective of people of color, (b) argue for eradication of racial 
subjugation while simultaneously recognizing that race is a social construct, and (c) address other areas of difference, such as gender and class, and inequities experienced by individuals (Parker \& Lynn, 2002). CRT tenets and themes of social construction, differential racialization, and intersectionality were explored in analyzing data from study participants.

This study established a linkage with the CRT tenet of social construction. Social construction is the process of endowing a group or concept with a delineation, name, or reality (Delgado \& Stefancic, 2001). Most of the study participants knew and accepted their reality as beneficiaries of the Top $10 \%$ Law, Texas's affirmative action policy that replaced a former policy centered on racial preferences. This holds true for Top 10\% African American and Hispanic students and aligns with social construction and CRT framework. Instead of feeling marginalized, as CRT would suggest, the study participants' reality was one of pride and personal success as members of an elite group. Instead of viewing their Top $10 \%$ status as a product of an Affirmative Action replacement initiative, most study participants viewed it as a reward for years of sacrifice and hard work. Findings do indicate salient issues of social construction are associated with Top $10 \%$ students with regard to academic merit and institutional diversity goals.

The CRT theme differential racialization was also acknowledged by study participants. Differential racialization is reflected in differential treatment of racial or ethnic groups by mainstream society due to their perceived advantage or disadvantage (Delgado \& Stefancic, 2001). Study participants noted that they were cognizant of their race and perceived it as a potential advantage in certain admissions situations. Although the Top 10\% Law was intended to be race neutral, African American and Hispanic study 
participants were conscious of their race and considered how to leverage their perceived advantage in the recruitment process. They noted several instances in which their race was viewed positively and sometimes treated differently by college recruiters.

In relation to the CRT theme of intersectionality, study participants indicated that their Top 10\% status was not an issue on campus, but their race was an issue. Participants indicated that race was more of an issue for them than was their Top 10\% status. One participant stated, "You can't see Top 10\% but you can see my race."

While CRT challenges the traditional paradigms, methods, texts, and discourse on race, gender, and class by showing that these social constructs intersect to affect communities of color (Smith-Maddox \& Solorzano, 2002), it does not take into account the positive constructs that could result from an underrepresented group's reality. There were strong data linkages to CRT tenets of social construction and differential racialization from the stories shared by participants. The CRT theme of intersectionality was less pervasive due to participants' admission that the Top $10 \%$ label was not an issue for them at Texas A\&M University.

\section{Relation to Research Questions}

This study applied qualitative research methods to addressed four research questions. Stories from African American and Hispanic students revealed their lived experiences as Top 10\% students at Texas A\&M University.

\section{Research Question 1}

Research question 1 asked, How do African American and Hispanic students who are admitted to Texas A\&M University under the Top 10\% Law view their higher education experience? 
Focus group participants and interviewees expressed pride in their academic and personal accomplishments. Participants had come from an array of socioeconomic backgrounds and high schools, from marginal to elite. Regardless of their educational and socioeconomic status, they were attending an elite postsecondary institution and considered their achievements to be special. Despite past and current challenges, the participants reported that they had overcome barriers and sacrificed more than their classmates to prepare for the rewards of being a Top $10 \%$ student.

And so amongst the top $10 \%$, we were the ones that really did care about our grades. I mean, everybody [else] kind of had that mentality of, "I'll just graduate high school and see what I'm gonna do after that." But those of us in the top $10 \%$ cared about what schools [we would] go to; our GPR scores were more important to us. (Participant 3)

Members of both groups agreed that their Top $10 \%$ status was based on their ability to focus and achieve academically in high school. Although the majority of the participants had been heavily engaged in extracurricular and leadership activities, they indicated that they would have been able to meet admissions requirements for Texas A\&M without the Top 10\% Law. Aggie 1 was willing to debate anyone about his academic and leadership credentials because he considered that he had earned the right to be in the Top 10, through hard work.

Members of both groups mentioned that personal motivation, involvement, and the desire to attend the college of their choice separated them from classmates who were not in the Top $10 \%$. Data from the participants revealed positive overall educational experiences at Texas A\&M University by these Top 10\% African American and Hispanic 
students. This is indicated by the levels of service and leadership engagement that participants expressed were important while attending Texas A\&M University. Several participants were members of the Corps of Cadets, others held leadership positions in premiere sponsored student organizations (ExCEL, Southwestern Black Student Leadership Conference, Hispanic President's Council, National Society of Black Engineers, Fish Camp) and all were involved in service-oriented projects (Big Event, Alternative Spring Bring, RePlant) on campus. Having matriculated beyond the freshman and sophomores years in their majors and fully engaging in campus life are key indicators of a positive educational experience among study participants.

\section{Research Question 2}

Research question 2 asked, In what ways did the Top 10\% Law influence students' selection of a flagship institution as a higher education option?

This study provided a critical race perspective of how African American and Hispanic students made their college selection while factoring in their automatic admission privilege. Participants indicated that finances and scholarships, race, and family expectations were major factors that influenced their college selection.

These factors are similar, yet different from the rational choice model of college selection that emphasizes tuition cost, financial aid, and distance from home. Since Top $10 \%$ was a factor, the majority of the study participants indicated that Texas A\&M University or the University of Texas was their first choice. The Top 10\% Law ensures automatic admissions to any public institution in the state of Texas; this factor alone weighed heavily on each study participant's decision to stay in Texas and to attend the best public schools the state had to offer. Participant 6 explained that the Top 10\% gave 
students options to attend top-tier public schools without paying tuition to private or semi-private schools.

Study participants explained that being in the Top $10 \%$ removed the stress of college admission and allowed them to focus on scholarships and grants to supplement the cost of attending the school of their choice. Aggie 2 agreed that being in the Top $10 \%$ and gaining automatic admissions allowed him to look for scholarships and other things to help prepare for college because he did not have to worry about the admissions process or the SAT.

The current study supported the literature on the impact of family on college choice. However, participants eloquently described family support as metaphorical rather than fiscal. Study participants shared intimate thoughts about their family expectations with regard to college. Participant 1 stated the sentiments of both groups with regard to family and college support by stating that he was motivated to do well and get scholarships because he did not want to be a burden on his parents.

Data from the participants revealed that, although their Top $10 \%$ status guaranteed college admission, their family had viewed their college selection with excitement and hesitation: excitement for being in the top $10 \%$ and hesitation for selecting Texas A\&M, a large, expensive, predominantly White institution (PWI) not close to home. Both African American and Hispanic students reported that their families had not been prepared financially to assist them with college expenses. Although family encouragement to attend college was present, finances were not readily available. The likelihood of Top 10\% African American and Hispanic students staying in state is an bonus of the Top $10 \%$ Law, as the literature indicated and participants confirmed that 
underrepresented minority students' parents are not financially prepared to assist them, especially if students were to look beyond the state of Texas.

\section{Research Question 3}

Research question 3 asked, Having been admitted under the Top 10\% Law, how has this influenced their perceptions of others' acceptance of their presence on campus?

Based on the dialogue in the focus group session and in individual interviews, being Top $10 \%$ was not perceived as an issue on campus; instead, being a member of an underrepresented minority appeared to be the issue. Both groups conveyed that they were not labeled because of their academic success as reflected in Top $10 \%$ status but were viewed as being at Texas A\&M because of AA or a quota system. Participants shared experiences with majority students that called into question their right to attend Texas A\&M University. Participant 1 elaborated on Top $10 \%$ not being a factor because, while race can be seen, academic status cannot be seen.

Participants also expressed frustration due to the lack of acknowledgment of their merit, which was sometimes overshadowed by the perception that their matriculation at Texas A\&M was due to some form of AA. Several participants mentioned that diversity referred to numbers and that this is how majority students viewed the presence of these Top $10 \%$ students on campus. Aggie 3 confirmed this observation by stating that majority students think that universities apply a quota system in the admissions process.

Overall, there appeared to be diverse perspectives about the influence of race on campus but not about the Top $10 \%$ label. It was easily concluded that, across all participants, race is more noticeable than Top $10 \%$ status. 


\section{Research Question 4}

Research question 4 asked, What is the opinion of African American and Hispanic students admitted under the Top 10\% Law concerning its effectiveness in creating raceneutral admissions in Texas?

One of the goals of the Top $10 \%$ Law is to maintain diversity and increase enrollment by underrepresented minority students (in this case, African Americans and Hispanics) without focusing solely on race. As the study participants indicated, geographic diversity was achieved in equalizing higher education opportunity by permitting students from a greater number of Texas high schools to enroll in the most selective public universities (Tienda, Cortes, et al., 2003), but the actualization of increased diversity in the student body was called into question.

Study participants were conflicted about the fairness of the Top $10 \%$ Law, even though they were beneficiaries of the law. They noted the absence of a statewide "standard" for being a Top 10\% student. Aggie 1 shared his thoughts on the standards issue: "A lot of the times they would say that other high schools are not as competitive as other high schools. So there's no really, there's not a standard of what a true top $10 \%$ student is."

The issue of fairness was expressed with regard to the quality of high schools and no set standard for being a Top $10 \%$ student across high schools. Although study participants were fortunate to be in the Top $10 \%$, they also stated that the equity and quality of high schools should be addressed when making decisions about the Top $10 \%$.

Although geographic diversity among high schools was supported by study participants, they were not supportive of class rank serving as the sole indicator of merit. 
They agreed that other factors, such as test scores, leadership, and involvement in extracurricular activities are equally important in creating a well-rounded student and should be part of the determination of eligible students.

Overall, data from participants supported the creation of the Top 10\% Law as they agreed that the law was effective in creating access to diverse communities across Texas. Data also revealed that participants considered the law fundamentally flawed due to a lack of emphasis on other characteristics and standards of success.

Lack of awareness or late awareness of the Top $10 \%$ Law was the final finding with regard to the effectiveness of the law in creating race-neutral admissions. All but one participant reported learning about the law prior to the senior year in high school, if at all. Aggie 1 was the only participant who had had what he considered to be a timely experience in learning about the Top 10\% Law, during his freshman year in high school. Participant 2 commented that her senior class students might have been much different if they had been made aware of the benefits of the Top $10 \%$ when they entered high school.

\section{Relation to the Literature}

A review of the literature on societal attitudes on Affirmative Action revealed that successfully mandated AA programs have strong leadership, whereas institutions that lack upper administration support of AA have struggled. Hanna (1988) concluded that the lack of involvement by administration leads to failure to implement AA policies, even with the leadership of the dean, president, provost, or other supervisor. These findings correlate with study participants' experiences with the Top 10\% Law. Although the law was mandated by the Texas Legislature, it is clear that this AA initiative is not widely supported or understood within the state of Texas. Study participants consistently 
indicated that the law was not explained or communicated effective from Kindergarten through college. Newcombe (1990) concluded that a federal mandate can be more easily enforced with strong leadership from central administration and faculty.

Brezina and Winder (2003) examined negative racial stereotyping by White Americans' association with race and economic disadvantage. Results suggested that Whites' opposition to policies designed to alleviate racial inequality are based on beliefs that Blacks lack effort or initiative. This finding, although not as salient as other factors in this study, was expressed by study participants as being a common belief about minority students' matriculation at Texas A\&M University. Study participants expressed disappointment in not being recognized for their academic merit, especially since had they worked extremely hard to achieve Top $10 \%$ status. Although study participants were recipients of the benefits of the law, they understood the sentiments of fellow students and agreed that the law is flawed and should take other factors into consideration for Top $10 \%$ scholarships. Malos's (2000) study supported students' reaction to the faimess of the Top 10\% Law. Malos concluded that admission plans that used economic need as a criterion were achieving their goal (diversity) without causing resentment on the part of those who were not selected.

Issues of diversity on college and university campuses were documented in the literature review. Hurtado (2002) studied the effects of diversity on students' selfperceived improvement in the ability to contribute positively to a pluralistic democracy and concluded that diversity contribute to the ability to work in diverse settings. Antonio (2004) studied ways in which race and ethnicity were implicated in the formation and meaning of friendship groups on a multicultural campus. Findings from the Antonio 
study suggested that a diverse campus does not guarantee that the experience of diversity will be one of mutual enhancement or even of segregation. Study participants resonated with the findings of the above studies with regard to diversity on college and university campuses. Collectively, study participants agreed that diversity on a college campus was important, but for different reasons. They stated that universities wanted underrepresented minority students on their campuses simply for their presence and not for the richness of experiences, culture, and ideas that they could bring to the college community. Study participants claimed that college and university administrators viewed diversity numerically or by reaching a certain quota; they did not agree that they genuinely contributed to the richness of the campus based on their race or ethnicity alone. Court cases from the literature review were linked to the findings of this study. Hopwood v. Texas (1996), Grutter v. Bollinger (2003), and Gratz v. Bollinger (2003) had implications for the use on race in admissions. Hopwood eliminated race-based admission in Texas, while Grutter and Gratz affirmed the use of race-conscious admission but only when the universities have a compelling interest in obtaining a diverse study body and when the practice is narrowly tailored to meet such goals. As several study participants noted, the greatest advantage of the Top $10 \%$ Law is that it provides access and choice to students in geographic areas where they might not have access to the top-tier institutions in the state. However, due to the pervasiveness of segregated high schools in Texas, participants also questioned the utility and fairness of law. The variance in the quality of high schools and the segregation of Texas high schools led participants to question whether achieving diversity on college and university campuses is a realistic expectation without taking race into consideration. Niu and Tienda (2010) noted that the Top $10 \%$ 
Law has apparently achieved its goal of broadening access, particularly for Hispanics and graduates of schools where minority students predominate, as well as for average high schools with limited prior representation at the University of Texas or Texas A\&M University.

\section{Recommendations for Practice}

1. Identify alternative marketing strategies to educate parents and low-resource schools about the Top 10\% Law. Ensure that literature is available in Spanish and English and in multiple forms (brochure, Facebook ${ }^{\circledR,}$ Twitter $^{\circledR,}$ postcard, etc.).

It was evident from the data gathered in this study that there is a communication disconnect in the African American and Hispanic communities regarding the Top 10\% Law. To improve college readiness of minority students, institutions and administrators must understand the importance of access and transparency of college admissions information. Access is important because first-generation college students may not come from families that understand the complexity of the admissions process. Therefore, putting information in various locations and in different forms of media, and communicating with African American and Hispanic populations early increase the levels of preparedness, achievement, and college aspirations of minority students.

Transparency refers to the diversity of messages about the Top 10\% Law. The law is currently viewed as an AA initiative and/or replacement that benefits underrepresented students. This is a gross misrepresentation of the law and recipients of the scholarships. Of the 3,932 Top $10 \%$ students admitted in 2009 at Texas A\&M University, 158 were African American and 842 were Hispanic. Clearly, this law is benefitting more than just 
African American and Hispanic students; given their demographic make-up in the state, these numbers are relatively low.

Institutions and college administrators must address the disparity in information and communicate accurate data that reflect the reality of the law and identify those who benefit from it. Opportunities to impact underrepresented minority students' participation in higher education are missed, creating distrust in the face of poor communication and inaccurate information. Information must be presented in various forms that reach technology-aware youth and must be presented in various languages in nontraditional markets to ascertain that target populations are aware of and able to access the information about educational opportunities in Texas.

2. Attach financial aid information packages to Top 10\% offers. For African American and Hispanic students in this study, college choice was primary centered on affordability. Due to the lack of consistent, timely, accessible, and accurate information regarding college access and affordability, underrepresented minority students are often misinformed about the costs associated with college. Research shows that, due to this lack of information, underrepresented minority students overestimate or underestimate the cost of college and the economic benefits of obtaining a degree and opportunities to apply for and maximize financial aid and grants are not realized until late in the admissions process. Top $10 \%$ literature should map out the benefits of the scholarship and offer financial examples and scenarios illustrating how the scholarship provides linkages to financial resources in the state and at state institutions. Financial aid information should be presented in various stages and forms to parents and students, starting in middle school and continuing through high school. These measures will 
increase the awareness of resources available to assist with college costs and lessen the fears and stress associated with not knowing. The "College For All Texans" website is an excellent resource provided by the Texas Higher Education Coordinating Board, with many of the above recommendations. This website should be highly visible, often cited in school literature, and widely publicized in middle schools and high schools.

In addition to state and federal financial aid resources, Top $10 \%$ literature should educate underrepresented parents about state-sponsored college savings plans. These plans allow anyone to save for college through predetermined monthly payments, locking in current tuition rates. This added resource can give underrepresented minority students' parents the opportunity to contribute financially to their education regardless of socioeconomic status.

\section{Require all schools to present evidence that they have provided yearly and} updated information about the Top 10\% Law (requirements, eligibility, and benefits) to students and their parents. The Texas legislature mandated that public institutions provide information regarding the Top $10 \%$ Law. Specifically, the law mandates that information be published in the institution's catalog and made available to the public. Although it might be assumed that schools will interpret the above statement with due diligence, this is not the case. There is a lack of information about the law from middle school through Grade 11. Study participants concurred that they began to hear about the law during their senior year in high school. Texas legislators and the Texas Higher Education Coordinating Board should re-examine or update the mandate to institutions regarding publishing the Top 10\% Law. Catalogs quickly become outdated and electronic media are not always user friendly, translatable, or accessible. Therefore, a uniform 
statewide initiative in the schools is recommended to provide consistent, timely, and age appropriate information about the Top $10 \%$ Law. The Coordinating Board currently requires public higher education institutions to report on their freshman classes. This practice should be modified and extended to middle schools and high schools in Texas. The report should outline what steps were taken to inform students and parents about the law, measures of success in reaching the population, and longitudinal plans for providing college preparedness information to students and parents. Since Texas high schools are highly segregated (Tienda \& Niu, 2006a), emphasis should be placed on schools with high concentrations of underrepresented minority students.

\section{Capitalize on the academic merit of students and stress the no-SAT/ACT} requirement for Top 10\% students, especially in schools with high concentrations of underrepresented minority students. Study participants consistently stressed the importance of not having to take the SAT as an added benefit of the Top 10\% Law. There is a body of literature that argues that standardized tests are counterproductive and pose a barrier to college access for underrepresented students. Study participants, although academically astute, were relieved that they did not have to rely on the SAT as a measure of aptitude and preparedness for college. This factor alone could be a selling point or motivator for students to aspire to be in the top decile of their class. Removing the standardized test and replacing it with performance-based measures could prove to be an incentive for African American and Hispanic students to apply to flagship institutions in Texas.

5. Create an alternative incentive program for students who are not in the Top $10 \%$ but score high on the SAT. This group should be acknowledged and encouraged to 
stay in the Texas higher education system to minimize talent loss due to out-of-state offers. The inequality of high schools in Texas has given the Top $10 \%$ Law a negative perception. Minority and majority students from high-performing and competitive schools do not automatically qualify for the Top $10 \%$ based on the competitive nature of the schools that they attend. These same students score high on standardized test and, although they are not in the Top $10 \%$, are often left out of the eligibility to attend institutions of their choice. Educational access and opportunity should extend to students who are in this category as well. Top $10 \%$ students alone constituted nearly $50 \%(3,932)$ of the freshman class at Texas A\&M University in 2009. Demographic projections for Texas indicate that the Texas high school population will continue to rise, creating a need for more schools. The addition of schools will undoubtedly encroach on available admission slots for non-Top 10\% students. Providing equitable opportunities and incentives for high achieving students who are not in the Top $10 \%$ to stay in the state for educational opportunities should become a priority of the Texas Higher Education Coordinating Board. Reducing the percentage of Top 10\% slots at public institutions has been discussed since the inception of the Top $10 \%$ Law. Claims of "brain drain" persist due to misinformation about the beneficiaries of the law. Unless this issue is seriously addressed, these arguments will continue to impact the perception of the Top 10\% Law in a negative manner.

\section{Implications for Further Research}

Researchers (Koffman \& Tienda, 2008; Long \& Tienda, 2007; Niu et al., 2008; Tienda, Cortes, et al., 2003) have studied percentage plans and know a great deal about the utility of the plans with regard to enrollment trends, college choice, and structural 
socioeconomic factors. This study provided an understanding of the experiences of African American and Hispanic Top 10\% students at one selective flagship institution, Texas A\&M University.

There remains much to be learned about the Top 10\% Law and its impact on educational choices and access for African American and Hispanic students. Further research might include studying CRT and the Top 10\% Law from the perspectives of White students. White students accounted for 2,718 of the Top $10 \%$ students at Texas A\&M in 2009. Their perspectives and experiences with the law could provide comparative data regarding available resources, communication, and basic knowledge of the law. Research could include a comparative study with similar student populations from the University of Texas, the other state flagship institution, to confirm or repudiate African American and Hispanic students' perceptions about merit.

Findings of this study are meaningful to higher education officials, elected leaders, and policy makers in several ways. First, results clearly indicate that the Top $10 \%$ Law is working, as reflected in the demographic composition of racially isolated schools. This fact substantiates the validity and utility of the law as a race-neutral alternative. Second, the emphasis of the Top $10 \%$ law is on undergraduate admissions; the law does not impact enrollments or diversity goals for graduate and professional schools. Higher education officials should be cognizant of the even greater gap that exists between White students and underrepresented minority students in obtaining terminal and professional degrees. The current law, as written, does not address this disparity. Third, communication and dissemination of information between $\mathrm{K}-12$ schools and postsecondary institutions lacks consistency. Partnerships and collaborations between 
Texas state education boards must be strategic, intentional, and systemic to address differential access, achievement, and information gaps that challenge African American and Hispanic students. Fourth, policy makers must hold schools and school administrators accountable for current and future legislation to assist with college preparedness and access. Such legislation includes but is not limited to (a) SB 158, which requires elementary, middle, and high schools counselors to provide college information to students' families, including information about admissions, financial aid, and the Top $10 \%$ Law; (b) HB 400, which mandates that the lowest decile, by percentage, of high schools sending students to college enter into partnerships with local community colleges or universities to improve college-going rates; and (c) SB 573, which established a statewide marketing campaign to encourage young people to attend college. As a result, "Go Centers" were spawned in high schools to encourage college recruitment.

This study applied qualitative methods to address four research questions. A quantitative analysis might reveal similar or different categories that impact African American and Hispanic students' perceptions and experiences with the Top 10\% Law. A larger sample of students and inclusion of White and Asian students in a focus group might provide rich data on attitudes, perceptions, and lived experiences of Top $10 \%$ students in Texas. More qualitative research may be warranted in the area of school quality, merit rankings, and socioeconomic status in relation to Top $10 \%$ attainment.

\section{Conclusion}

The overarching research question for this study was how the Top $10 \%$ Law influenced African American and Hispanic students' perceptions of the law, application to universities under the law's provisions, and feelings of acceptance at a Texas flagship 
institution. The goal of the case study was to describe as accurately as possible the students' comments and stories to address four research questions. Stories and statements from study participants validated much of the research on college choice and access. Using CRT as a framework, this study provided an alternative perspective on how African American and Hispanic students perceived, related to, and applied the Top 10\% Law.

Recent literature and data from this study have revealed that the Top 10\% Law appears to have achieved the goal of broadening educational access to selective public institutions in Texas by underrepresented minority students. Due to segregated schools and state demographics, the Top 10\% Law has positively impacted educational opportunity particularly for African American and Hispanic students.

This study invited African American and Hispanic students to describe their experiences as Top $10 \%$ students at Texas A\&M University. Through the use of counter stories, the students affirmed their merit as Top 10\% students and dispelled misinformation about the role of affirmative action on their college matriculation.

The implementation of the Top $10 \%$ Law was a creative and cutting-edge education policy. To its credit, it has helped to increase the geographic and demographic diversity of selective Texas public institutions. Some the success of the Top $10 \%$ Law is directly attributed to the demographic increases and shifts in minority populations in Texas. However, after nearly 14 years, the Top $10 \%$ Law is still not widely known or utilized by African American and Hispanic students and parents. 


\section{REFERENCES}

Aberson, C. L., \& Haag, S. C. (2003). Beliefs about affirmative action and diversity and their relationship to support hiring policies. Analyses of Social Issues and Public Policy, 3, 121-138.

American Council on Higher Education. (2001). "Percentage Plan" for college admissions. Washington, DC: Center for Policy Analysis.

American Psychological Association. (1996). Affirmative action: Who benefits? Washington, DC: Author.

Andrews, R. J., Ranchhod, V., \& Sathy, V. (2009). Estimating the responsiveness of college applications to the likelihood of acceptance and financial assistance: Evidence from Texas. doi:10.1016/j.econedurev.2009.04.004

Antonio, A. L. (2004). When does race matter in college friendships? Review of Higher Education, 27, 553-575.

Asagba, J. O., \& Antwi-Boasiako, K. B. (2004). A preliminary analysis of African American college students' perceptions of racial preferences and affirmative action in making admissions decisions at a predominantly White university. Journal of Instructional Psychology, 31, 269-279.

Association of American Medical Colleges. (n.d.). Underrepresented in medicine: Definition. Retrieved from http://www.aamc.org

Berg, B. L. (2007). Focus group interviewing. In B. L. Berg (Ed.), Qualitative research methods for the social sciences (6th ed.; pp. 144-170). Boston, MA: Pearson. 
Bergmann, B. R. (1999). The continuing need for affirmative action. Quarterly Review of Economics and Finance, 39, 757-768.

Bickel, R. D. (2008). The non-discrimination principle and American higher education: Judicial failure to recognize the present effects of past discrimination. Education and the Law, 20(1), 1-24.

Board of Education of Piscataway v. Taxman, 91 F.3d 1547 (3d Cir. 1996).

Bowen, W. G., \& Bok, D. (1998). The shape of the river: Long-term consequences of considering race in college and university admissions. Princeton, NJ: Princeton University Press.

Brest, P., \& Oshige, M. (1995). Affirmative action for whom? Stanford Law Review, 47, 855-900.

Brezina, T., \& Winder, K. (2003). Special issue: Race, racism, and discrimination. Social Psychology Quarterly, 66, 402-418.

Brooks, M. (2003). A review of recent court cases: Affirmative action must be narrowly tailored. Principal Leadership, 4(1), 79.

Brown, C. M., \& Patterson, F. D. (2004). Collegiate desegregation as progenitor and progeny of Brown v. Board of Education: The forgotten role of postsecondary litigation, 1908-1990. Journal of Negro Education, 73, 342-349.

Brown v. Board of Education of Topeka, 347 U.S. 483 (1954).

Button, J. W., \& Rienzo, B. A. (2003). The impact of affirmative action: Black employment in six southern cities. Social Science Quarterly, 84(1), 1-14. 
Cabrera, A. F., \& La Nasa, S. M. (2002). Understanding the college-choice process. In A. F. Cabrera \& S. M. L. Nasa (Eds.), Understanding the college choice of disadvantaged students (pp. 5-22). San Francisco, CA: Jossey-Bass.

Chang, M. J. (2005, Winter). Reconsidering the diversity rationale. Liberal Education, pp. 6-13.

Chapa, J. (2005). Affirmative action and percent plans as alternatives for increasing successful participation of minorities in higher education. Journal of Hispanic Higher Education, 4, 181-188.

Chavez, L. (1998). The color bind: California's battle to end affirmative action. Berkeley, CA: University of California Press.

Clarke, C. (1996). Affirmative action in higher education: A case for clarity. Community Review, 14, 59-66.

Cole, S., \& Barber, E. (2003). Increasing faculty diversity. Cambridge, MA: Harvard University Press.

Coleman, A. L., Palmer, S. R., \& Winnick, S. Y. (2008). Race-neutral policies in higher education: From theory to practice. New York, NY: The College Board.

Corbin, J., \& Strauss, A. (1990). Grounded theory research: Procedures, canons, and evaluative criteria. Qualitative Sociology, 13(1), 3-21.

Corbin, J., \& Strauss, A. (2008). Basics of qualitative research (3rd ed.). Thousand Oaks, CA: Sage.

Creswell, J. W. (1998). Qualitative inquiry and research design: The five traditions. Thousand Oaks, CA: Sage. 
Creswell, J. W. (2007). Qualitative inquiry and research design: Choosing among five approaches (2nd ed.). Thousand Oaks, CA: Sage.

Creswell, J. W. (2009). Research design: Qualitative, quantitative and mixed methods approaches (3rd ed.). Thousand Oaks, CA: Sage.

Crosby, F. J., \& Clayton, S. (2001). Affirmative action: Psychological contributions to policy. Analyses of Social Issues and Public Policy, 1, 71-87.

Crosby, F. J, \& Cordova, D. I. (1996). Words worth of wisdom: Toward an understanding of affirmative action. Journal of Social Issues, 52(4), 33-49.

Crosby, F. J., Iyer, A., Clayton, S., \& Downing, R. A. (2003, February). Affirmative action: Psychological data and the policy debates. American Psychologist, 93-115.

Crosby, F. J., lyer, A., \& Sincharoen, S. (2006). Understanding affirmative action. Annual Review of Psychology, 57, 585-611.

Cushner, K. H., McClelland, A., \& Safford, P. (2006). Human diversity in education: An integrative approach. Retrieved from http://highered.mcgraw-hill.com/sites/ 0072486694/student_view0/glossary.htm

Davis, L. R. (2002). Racial diversity in higher education: Ingredients for success and failure. Journal of Applied Behavioral Science, 38(2), 137-155.

Delgado, R., \& Stefancic, J. ( 2001). Critical race theory. New York, NY: New York University Press.

Denzin, N. K. (1989). Interpretive interactionism. Newbury Park, CA: Sage.

Dickson, L. M. (2006). Does ending affirmative action in college admissions lower the percentage of minority students applying to college? Economics of Education Review, 25, 109-119. 
Downing, R. A., Lubensky, M. E., Sincharoen, S., Gurin, P., Crosby, F. J., Queirolo, S., \& Franco, J. (2002). Affirmative action in education. Diversity Factor, 10(2), 1520.

Duncan, A. C. (2010). Cultural capital, habitus, and schemes: A case study of African American student engagement in a secondary classroom (doctoral dissertation). Los Angeles, CA: University of California, Irvine and California State University, Los Angeles.

Ely, M., Anzul, M., Friedman, T., Garner, D., \& Steinmetz, A. M. (1991). Doing qualitative research: Circles within circles. New York, NY: Falmer.

Equal Justice Society. (2009). Compliance manual, Appendix 4: Race-neutral policies. Retrieved from http://www.equaljusticesociety.org/compliancemanual/ Appendix 4_Race_Neutral_\%20Policies.pdf

Etter-Lewis, G. (1993). My soul is my own: Oral narratives of African American women in the professions. New York, NY: Routledge.

Fine, B. (1973). Southern educators study the implications of Supreme Court rulings on segregation. In J. Cass (Ed.), Education U.S.A. (pp. 212-215). New York, NY: Arno Press.

Fischer, M. J., \& Massey, D. S. (2006). The effects of affirmative action in higher education. Social Science Research, 36, 531-549.

Fish, S. (1997). Reverse racism, or how the pot got to call the kettle black. In F. J. Beckwith \& T. E Jones (Eds.), Affirmative action: Social justice or reverse discrimination? (pp. 142-151). Amherst, NY: Prometheus Books. 
Flores, A., \& Rodriguez, C. M. (2006). University faculty attitudes on affirmative action principles toward faculty and students. Equity and Excellence in Education, 39, 303-312.

Florida. (1999). Executive Order 99-281. Retrieved from http://dms.myflorida.com/ media/general_counsel_files/one_florida_executive_order_pdf

Forsythe, K. (2003). Racial preference and affirmative action in law school admissions: Reactions from Minnesota law schools and ramifications for higher education in the wake of Grutter v. Bollinger. Hamline Journal of Public Law \& Policy, 25(1), 157-199.

Fu, Q. (2006). A theory of affirmative action in college admissions. Economic Inquiry, $44,420-428$.

Glaser, B., \& Strauss, S. (1967). The discovery of grounded theory. Chicago, IL: Aldine.

Glesne, C. (2006). Becoming qualitative researchers: An introduction (3rd ed.). New York, NY: Longman.

Gnagey, L. T. (2003). Percent-plan alternatives not the answer, U-M leaders say. Retrieved from http://www.ur.umich.edu/0203/Feb03_03/06.shtml

Gratz v. Bollinger, 539 U.S. 244 (2003).

Grodsky, E., \& Kalogrides, D. (2008). The declining significance of race in college admissions decisions. American Journal of Education, 115, 1-33.

Grutter v. Bollinger, 539 U.S. 306 (2003).

Gurin, P., Nagda, B. A., \& Lopez, G. E. (2004). The benefits of diversity in education for democratic citizenship. Journal of Social Issues, 60, 17-34. 
Hanna, C. (1988). The organizational context for affirmative action for women faculty. Journal of Higher Education, 59, 390-411.

Harper, S., \& Reskin, B. (2005). Affirmative action at school and on the job. Annual Review of Sociology, 31, 357-379.

Hebel, S. (2001, February 16). University of Georgia settles affirmative action suit. Chronicle of Higher Education, p. 30.

Herrnstein, R. J., \& Murray, C. (1994). The bell curve: Intelligence and class structure in American life. New York, NY: Free Press.

Holsti, O. R. (1969). Content analysis for the social sciences and humanities. Reading, MA: Addison-Wesley.

Hopwood v. Texas, 78 F. 3rd 932 (5th Cir. 1996).

Horn, C. L., Flores, S. M., \& Orfield, G. (2003). Percentage plans in college admissions: A comparative analysis of three states' experiences. Cambridge, MA: The Civil Rights Project at Harvard University.

Hossler, D., Braxton, J., \& Coopersmith, G. (1989). Understanding student college choice. In J. C. Smart (Ed.), Higher education: Handbook of theory and research (Vol. 5, pp. 231-288). New York: Agathon Press.

Hossler, D., \& Gallagher, K. S. (1987, Spring). Studying student college choice: A threephase model and the implication for policymakers. College and University, 207221. 
Hurtado, S. (2002). Linking diversity and educational purpose: How diversity affects the classroom environment and student development. In Harvard Education Publish Group (Eds.), Diversity challenged: Evidence on the impact of affirmative action. Cambridge (pp. 187-203). Cambridge, MA: Harvard University Press. (ERIC Document Reproduction Service No. ED 034 365)

Hurtado, S., Inkelas, K. K., Briggs, C., \& Rhee, B. (1997). Differences in college access and choice among racial/ethnic groups: Identifying continuing barriers. Research in Higher Education, 38, 43-75

Hyer, P. (1985). Affirmative action for women faculty: Case studies of three successful institutions. Journal of Higher Education, 56, 282-299.

Iyer, A., Leach, C. W., \& Crosby, F. J. (2003). White guilt and racial compensation: The benefits and limits of self-focus. Personality and Social Psychology Bulletin, 29(1), 117-129.

Johnson, L. B. (1965). To fulfill these rights: Commencement address at Howard University. In F. J. Beckwith \& T. E. Jones (Eds.), Affirmative action: Social justice or reverse discrimination? Amherst, NY: Prometheus Books.

Judkins, B. M., \& LaHurd, R. (1999). Building community from diversity. American Behavioral Scientist, 42, 786-799.

Kain, J. F., O’Brien, D. M., \& Jargowsky, P.A. (2005). Hopwood and the Top 10\% Law: How they have affected the college enrollment decisions of Texas high school graduates. Philadelphia, PA: Andrew W. Mellon Foundation. 
Kidder, D. L., Lankau, M., Chrobot-Mason, D., Mollica, K., \& Friedman. R. A. (2004). Toward diversity initiatives: Examining the impact of diversity program justification, personal, and group outcomes. International Journal of Conflict Management, 15, 61-94.

Kidder, W. C. (2003). The struggle for access from Sweatt to Grutter: A history of African American, Latino, and American Indian law school admissions, 19502000. Harvard BlackLetter Law Journal, 19, 1-42.

Klineberg, S. L., \& Kravitz, D. A. (2003). Ethnic differences in predictor of support for municipal affirmative action contracting. Social Science Quarterly, 84, 425-440.

Knight, J. L., \& Hebl, M. R. (2005). Affirmative reaction: The influence of type of justification on nonbeneficiary attitudes toward affirmative action plans in higher education. Journal of Social Issues, 61, 547-568.

Koffman, D., \& Tienda, M. (2008, March). Missing in application: The Texas Top 10\% Law and campus socioeconomic diversity. Paper presented at the 2008 meting of the American Educational Research Association, New York City.

Kravitz, D. A., \& Klineberg, S. L. (2000). Reactions to two versions of affirmative action among Whites, Blacks, and Hispanics. Journal of Applied Psychology, 85, 597 611.

LegalView. (n.d.). Legal dictionary. Retrieved from http://www.legalview .info/Legal-Dictionary/Affirmative_action/Default.aspx

Lincoln, Y. S., \& Guba, E. G. (1985). Naturalistic inquiry. Beverly Hills, CA: Sage.

Litosseliti, L. (2003). Using focus groups in research. London, UK: Continuum. 
Lloyd, K. M., Leicht, K. T., \& Sullivan, T. A. (2008). Minority college aspiration, expectations and applications under the Texas Top 10\% Law. Social Forces, 86 , 1105-1137.

Long, B. T. (2003). Diversity by any other name: Are there viable alternatives to affirmative action in higher education? Western Journal of Black Studies, 27(1), 30-34.

Long, M. C., \& Tienda, M. (2008). Winners and losers: Changes in Texas university admissions post-Hopwood. Educational Evaluation and Policy Analysis, 30, 255 280.

Long, M. C., \& Tienda, M. (2009). Changes in Texas universities' applicant pools after the Hopwood decision. Social Science Research Policy, 25(1), 157-199. doi:10.1016/j.ssresearch.2009.06.004

Maccabe, A. T. (2004). Affirmative action in college admissions: The case for diversity. Journal of Veterinary Medicine, 31(4), 421-424.

Malos, S. B. (2000). The new affirmative action: Socioeconomic preference criteria in college admissions. Journal of Applied Behavioral Science, 36, 5-22.

McDonough, P.M. (1997). Choosing colleges: How social class and schools structure opportunity. Albany, NY: State University of New York Press.

McDonough, P. M., Antonio, A. L., \& Trent, J. W. (1997). Black students, Black colleges: An African American college choice model. Journal for a Just and Caring Education, 3, 9-36.

Merriam, S. B. (1998). Qualitative research and case study applications in education. San Francisco, CA: Jossey-Bass. 
Milem, J. F., \& Umbach, P. D. (2003). The influence of precollege factors on students' predispositions regarding diversity activities in college. Journal of College Student Development, 44, 611-624.

Miles, M. B., \& Huberman, A. B. (1994). Qualitative data analysis. Thousand Oaks, CA: Sage.

Moore, J. (2005). Race and college admissions: A case for affirmative action. Jefferson, NC: McFarland \& Company, Inc.

Moses, M. S., \& Chang, M. J. (2006). Toward a deeper understanding of the diversity rationale. Educational Researcher, 35(1), 6-11.

Nacoste, R. W., \& Lehman, D. (1987). Procedural stigma. Representative Research in Social Psychology, 17(1), 25-38.

National Center for Education Statistics. (2004). Digest of education statistics 2003. Washington, DC: Author.

Nebeker, K. C. (1998). Critical race theory: A White graduate student's struggle with this growing area of scholarship. Qualitative Studies In Education, 11(1), 25-41.

Newcombe, J. P. (1980). A theory of prescribed academic change: The case of Title IX. Doctoral dissertation, College of William and Mary.

Niemann, Y. F., \& Maruyama, G. (2005). Inequities in higher education: Issues and promising practices in a world ambivalent about affirmative action. Journal of Social Issues, 61, 407-426.

Niu, S. X., Sullivan, T., \& Tienda, M. (2008). Minority talent loss and the Texas Top 10 Percent Law. Social Science Quarterly, 89, 831-845. 
Niu, S. X., \& Tienda, M. (2010). The impact of the Texas Top 10\% Law on college enrollment: A regression discontinuity approach. Journal of Policy analysis and Management, 29(1), 84-110.

Office for Civil Rights Evaluation. (2002). Beyond percentage plans: The challenge of equal opportunity in higher education. Washington, DC: Author.

Olivia, M. (2008). Latino access to college: Actualizing the promise and potential of K16 partnerships. Journal of Hispanic Higher Education, 7(2), 119-130.

Orfield, G. (1998). Campus resegregation and its alternatives. In G. Orfield \& E. Miller (Eds.), Chilling admissions: The affirmative action crisis and the search for alternatives (pp. 1-16). Cambridge, MA: Harvard Education Press.

Orfield, G., \& Whitla, D. (2001). Diversity and legal education: Student experiences in leading law schools. In G. Orfield \& M. Kurlaender (Eds.), Diversity challenged: The evidence on the impact of affirmative action (pp. 143-174). Cambridge, MA: Harvard Education Publishing Group.

Parker, L. (1998). Race is . . race ain't: An exploration of the utility of critical race theory in qualitative research in education. Qualitative Studies in Education, $11(1), 43-55$.

Patton, M. Q. (1990). Qualitative evaluation and research methods (2nd ed.).. Newbury Park, CA: Sage.

Perna, L. W. (2000). Differences in the decision to attend college among African American, Hispanics, and Whites. Journal of Higher Education, 71(2), 117-141. 
Perna, L. W. (2006). Studying college access and choice: A proposed conceptual model. In J. C. Smart (Ed.), Higher education: Handbook of theory and research (Vol. 21, pp. 99-157). The Hague, The Netherlands: Springer.

Peterson, M. R., Kowolik, J. E., Coleman, G., Dietrich, S., Mascarenhas, A. K., McCunniff, M., \& Taylor, G. (2004). Perspectives on affirmative action in academic dental institutions: The U.S. Supreme Court rulings in the University of Michigan cases. Journal of Dental Education, 68, 932-937.

Plessy v. Ferguson, 163 U.S. 537 (1896).

Podberesky v. Kirwan, 38 F.3d 147; 1994 U.S. App. (1995)

Pusser, B. (2001). The contemporary politics of access policy: California after Proposition 209. In D. E. Heller (Ed.), The states and public higher education policy: Affordability, access, and accountability (pp. 121-152). Baltimore, MD: Johns Hopkins University Press.

Randall, V. (2006). University of Michigan Law School affirmative action case. Retrieved from http://academic.udayton.edu/race/04needs/affirm14.htm Regents of the University of California v. Bakke, 438 U.S. 265 (1978).

Reyna, C., Tucker, A., Korfmacher, W., \& Henry, P. J. (2005). Searching for common ground between supporters and opponents of affirmative action. Political Psychology, 26, 667-682.

Riessman, C. K. (1999). Narrative analysis. Newbury Park, CA: Sage.

Roebuch, J. B., \& Murty, K. S. (1993). Historical Black colleges and universities: Their place in American higher education. Westport, CT: Praeger. 
Rotthoff, K. W. (2008). Could affirmative action be efficient in higher education? Science Directions, 99, 574-576.

Russo, C. J., \& Mawdsley, R. D. (2003). American update: The Supreme Court and affirmative action. Education and the Law, 15, 263-274.

Schumaker, P., \& Kelly, M. (1999). Affirmative action, principles of justice, and the evolution of the urban theory. Urban Affairs Review, 34, 619-640.

Sher, G. (1997). Justifying reverse discrimination in employment. In F. J. Beckwith \& T. E. Jones (Eds.), Affirmative action: Social justice or reverse discrimination? (pp. 227-238). Amherst, NY: Prometheus Books.

Shushok, F. (2001). Percentage plans for college admissions. Washington, DC: American Council on Education, Center for Policy Analysis.

Slaughter, J. B. (2007, February). After Michigan, what? Next steps for affirmative action. Policy Perspectives, pp. 1-14.

Smith-Maddox, R., \& Solorzano, D. G. (2002). Using critical race theory, Paulo Freire's problem-posing method, and case study research to confront race and racism in education. Qualitative Inquiry, 8(1), 66-84.

Solorzano, D., Ceja, M., \& Yosso, T. (2000a). Knocking at freedom's door: Race, equity, and affirmative action in U.S. higher education. Journal of Negro Education, $69(1 / 2), 60-73$.

Solorzano, D., Ceja, M., \& Yosso, T. (200b). Critical race theory, racial microaggression, and campus racial climate: The experiences of African American college students. Journal of Negro Education, 69(1/2), 60-73. 
Sowell, T. (2004). Affirmative action around the world: An empirical study. New Haven,

CT: Yale University Press.

Springer, L., Palmer, B., Terenzini, P. T., Pascarella, E. T., \& Nora, A. (1996). Attitudes toward campus diversity: Participation in a racial or cultural awareness workshop. Review of Higher Education, 20(1), 53-68.

Stefkovich, J. A., \& Leas, T. (1994). A legal history of desegregation in higher education. Journal of Negro Education, 63, 406-420.

Sterrett, W. M. (2005, Spring). Current issues involving affirmative action and higher education. NACAC Journal, 22-28.

Strauss, A., \& Corbin, J. (1990). Basics of qualitative research: Grounded theory procedures and techniques. Newbury Park, CA: Sage.

Sweatt v. Painter, 339 U.S. 629 (1950).

Swim, J. K., \& Miller, D. L. (1999). White guilt: Its antecedents and consequences for attitudes toward affirmative action. Personality and Social Psychology Bulletin, $25,500-514$.

Teranishi, R. T.., \& Brisco, K. (2006). Social capital and the racial stratification of college opportunity. In J. C. Smart (Ed.), Higher education: Handbook of theory and research (Vol. 21, pp. 591-614). New York, NY: Agathon Press..

Teranishi, R. T., \& Briscoe, K. (2008). Contextualizing race: African American college choice in an evolving affirmative action era. Journal of Negro Education, 77(1), 43-65.

Thelin, J. R. (2004). A history of American higher education. Baltimore, MD: Johns Hopkins University Press. 
Thernstrom, S., \& Thernstrom, A. M. (1999a). America in Black and White: One nation indivisible. New York, NY: Simon \& Schuster.

Thernstrom, S., \& Thernstrom, A. M. (1999b). Reflections on the shape of the river. UCLA Law Review, 46,1583-1631.

Tienda, M. (2006). Harnessing diversity in higher education: Lessons from Texas. In M. Devlin (Ed.), Ford Policy Forum, 2006: Exploring the economics of higher education (pp. 7-14). Washington, DC: NACUBO and the Forum for the Future of Higher Education.

Tienda, M., Alon, S. \& Niu, S.X. (2008). Affirmative action and the Texas Top 10\% Percent Admission Law: Balancing equity and access to higher education. Retrieved from http://theop.princeton.edu/reports/wp/AffirmativeAction _TopTen.pdf

Tienda, M., Cortes, K., \& Niu, S. (2003, October). College attendance and the Texas Top 10 Percent law: Permanent contagion or transitory promise. Paper presented at the Conference on Expanding Opportunity in Higher Education, Sacramento, CA.

Tienda, M., Leicht, K. T., Sullivan, T., Maltese, M., \& Lloyd, K. (2003). Closing the gap: Admissions and enrollments at the Texas public flagships before and after affirmative action. Princeton, NJ: Princeton University Press.

Tienda, M., \& Niu, S. X. (2006a). Capitalizing on segregation, pretending Neutrality: College admissions and the Texas Top 10\% Law. American Law and Economics Review, 8, 312-346.

Tienda, M., \& Niu, S. X. (2006b). Flagships, feeders, and the Texas Top 10\% Law: A test of the "brain drain" hypothesis. Journal of Higher Education, 77, 712-739. 
Tuckman, B. (1965). Developmental sequence in small groups. Psychological Bulletin $63,384-399$.

U.S. Census Bureau. (2002). Census 2000 urban and rural classification. Retrieved from http://www.census.gov/geo/www/ua/ua_2k.html

U.S. Census Bureau. (2005). Texas becomes nation's newest "majority-minority" state. Retrieved from http://www.census.gov/Press-Release/www/releases/archives/ population/005514.html

U.S. Commission on Civil Rights. (2002). Beyond percentage plans: The challenge of equal opportunity in higher education. Washington, DC: Office of Civil Rights Evaluation.

Watson, J. (2007). Ted Shaw and other diversity proponents retool while Ward Connerly gloats. Diverse Issues in Higher Education, 24(14), 24-26.

West, C. (1997). Nihilism in Black America. In F. J. Beckwith \& T. E Jones (Eds.), Affirmative action: Social justice or reverse discrimination? (pp. 121-131). Amherst, NY: Prometheus Books.

Yin, R. K. (1994). Case study research: Design and methods (2nd ed.). Thousand Oaks, CA: Sage.

Yin, R. K. (2003). Applications of case study research. Thousand Oaks, CA: Sage.

Yin, R. K. (2009). Case study research: Design and methods (4th ed.). Thousand Oaks, CA: Sage.

Zamani-Gallaher, E. M. (2007). The confluence of race, gender, and class among community college students: Assessing attitudes toward affirmative action in college admissions. Equity \& Excellence in Education, 40, 241-251. 
APPENDIX A

\section{LEGISLATIVE DOCUMENTS REVIEWED}


I certify that H.B. No. 588 was passed by the House on April 16, 1997, by a non-record vote.

\author{
Chief Clerk of the House
}

I certify that H.B. No. 588 was passed by the Senate on May 8, 1997, by a viva-voce vote.

Secretary of the Senate

APPROVED:

Date

Governor 


\section{AN ACT}

relating to uniform admission and reporting procedures for institutions of higher education.

BE IT ENACTED BY THE LEGISLATURE OF THE STATE OF TEXAS:

SECTION 1. Chapter 51, Education Code, is amended by adding Subchapter $S$ to read as follows:

\section{SUBCHAPTER S. UNIFORM ADMISSION POLICY}

Sec. 51.801. DEFINITLONS. In this subchapter. "general academic teaching institution" "governing board," "medical and dental unit," and "university system" have the meanings assigned by Section 61.003 .

Sec. 51.802. UNIFORM ADMISSION SYSTEM. A general academic teaching institution shall admit first-time freshman students for each semester under the provisions of this subchapter.

Sec. 51.803. AUTOMATIC ADMISSION: ALL NSTITUTIONS. (a) Each general academic teaching institution shall admit an applicant for admission to the institution as an undergraduate student if the applicant graduated in one of the two school years preceding the academic year for which the applicant is applying for admission from a public or private high school in this state accredited by a generally recognized accrediting organization with a grade point average in the top 10 percent of the student's high school graduating class. To qualify for admission under this section, an applicant must submit an application before the expiration of any application filing deadline established by the institution.

(b) After admitting an applicant under this section, the institution shall review the applicant's record and any other factor the institution considers appropriate to determine whether the applicant may require additional preparation for college-level work or would benefit from inclusion in a retention program. The institution may require a student so identified to enroll 
during the summer immediately after the student is admitted under this section to participate in appropriate enrichment courses and orientation programs. This section does not prohibit a student who is not determined to need additional preparation for college-leyel work from enrolling, if the student chooses, during the summer immediately after the student is admitted under this section.

Sec. 51.804. ADDITIONAL AUTOMATIC ADMISSIONS: SELECTED INSTITUTIONS. For each academic year, the governing board of each general academic teaching institution shall determine whether to adopt an admissions policy under which an applicant to the institution as a first-lime freshman student, other than an applicant eligible for admission under Section 51.803 , shall be admitted to the institution if the applicant graduated from a public or private high school in this state accredited by a generally recognized accrediting organization with a grade point average in the top 25 percent of the applicant's high school graduating class.

Sec. 51.805. OTHER ADMISSIONS. (a) A graduating student who does not qualify for admission under Section 51.803 or 51.804 may apply to any general academic teaching institution.

(b) The general academic teaching institution, after admitting students under Sections 51.803 and 51.804, shall admit other applicants for admission as undergraduate students. It is the intent of the legislature that all institutions of higher education pursue academic excellence by considering students' academic achievements in decisions related to wdmissions. Because of changing demographic trends, diversity, and population increases in the state, each general academic teaching institution shall also consider all of any of, or a combination of the following socioeconomic indicators or factors in making first-time froshman admissions decisions:

(1) the applicant's academic record;

(2) the socioeconomic background of the applicant. including the percentage by which the applicant's family is above or below any recognized measure of poverty, the applicant's household income, and the applicant's parents' level of education: 
(3) whether the applicant would be the first generation of the applicant's family to attend or graduate from an institution of higher education;

(4) whether the applicant has bilingual proficiency;

(5) the financial status of the applicant's school district:

(6) the performance level of the applicant's school as determined by the school accountability criteria used by the Texas Education Agency;

(7) the applicant's responsibilities while attending school, including whether the applicant has been employed, whether the applicant has helped to raise children, or other similar factors:

(8) the applicant's region of residence;

(9) whether the applicant is a resident of a rural or urban area or a resident of a central city or suburban area in the state:

(10) the applicant's performance on standardized tests:

11) the applicant's perfornance on standardized tests in comparison with that of other students from similar socioeconomic backgrounds:

(12) whether the applicant attended any school while the school was under a court-ordered desegregation plan;

(13) the applicant's involvement in community activities:

114) the applicant's extracurricular activities:

(15) the applicant's commitment to a particular field of study:

(16) the applicant's personal interview:

(17) the applicant's admission to a comparable accredited out-of-state institution; and

(18) any other consideration the institution considers necessary to accomplish the institution's stated mission.

(c) A general academic teaching institution may review other factors in making an admissions decision. 
(d) Not later than one year before the date that applications for admission are first considered under this section, each general academic teaching institution shall publish in the institution's catalog a description of the factors considered by the institution in making admission decisions and shall make the information available to the public.

(e) This section does not apply to an institution that has an open enrollment policy.

Sec. 51.806. REPORT TO COORDINATING BOARD. Each general academic teaching institution shall provide a report annually to the Texas Higher Education Coordinating Board describing the composition of the entering class of students admitted under this subchapter. The report shall include a demographic breakdown, including a breakdown by race, ethnicity, and economic status, of the students admitted under Sections $51.803,51.804$, and 51.805 .

Scc. 51.807. RULEMAKING. The Texas Higher Education Coordinating Board may adopt rules relating to the operation of admissions programs under this subchapter, including rules relating to the identification of eligible students and the reporting requircments of Section 51.806.

SEC. 51.808. APPLICATION OF ADMISSION CRITERIA TO OTHER PROGRAMS. (a) Each general academic teaching institution or medical and dental unit that offers admissions to undergraduate transfer students or admissions to a graduate, postgraduate, or professional program shall also adopt a written admission policy applicable to those programs.

(b) The policy shall be published in the institution's or unit's catalog and made available to the public.

Sec. 51.809. SCHOLARSHIP AND FELLOWSHIP AWARDS. (a) A general academic teachiag institution or a medical and dental unit that offers competitive scholarship or fellowship awards shall adopt a written policy describing the factors to be used by the institution or unit in making an award.

(b) A policy adopted under this section shall be published in the institution's or unit's catalog and shall be made available to the public in advance of any deadline for the submission of an application for a competitive scholarship or fellowship to which the policy applies. 
SECTION 2. (a) The change in law made by this Act applies beginning with admissions and scholarships for the fall term or semester in 1998.

(b) The Texas Higher Education Coordinating Board, each general academic teaching institution, and each medical and dental unit shall adopt rules or policies relating to the admission of students under Subchapter S, Chapter 51, Education Code, as added by this Act, not later than January 1, 1998.

SECTION 3. The importance of this legislation and the crowded condition of the calendars in both houses create an emergency and an imperative public necessity that the constitutional rale requiring bills to be read on three several days in each house be suspended, and this rule is hereby suspended. 
HB 588

House Research Organization

page 7

vague criteria as an "applicant's academic record," schools could portray almost any admissions policy as compliant with the bill's provisions.

NOTES: $\quad$ The committee substitute added a statement of legislative intent to foster academic excellence in all higher education institutions and address demographic trends by considering certain socioeconomic factors in admissions decisions.

The substitute added to the list of alternative criteria the income and performance level of the applicant's high school, an applicant's performance on standardized tests in comparison with other students from similar socioeconomic backgrounds, the applicant's region of residence and type of neighborhood; the applicant's personal interview; the applicant's admission to a comparable out-of-state school; and any other factors an institution considered necessary to accomplish its mission. It also added the provision that schools could annually decide whether to automatically admit the top 25 percent of high school graduating classes, specified that the provisions applied only to first-time freshman students, exempted universities with open enrollment, and required that schools adopt and publicize a written policy on admissions and scholarship decisions.

The substitute deleted the requirement that schools publish the weights given various factors used to decide admissions.

HB 858 by Goolsby, requiring higher education institutions to admit one percent of their freshmen class under an open enrollment policy, passed the House on second reading yesterday. 
SUBJECT: $\quad$ Statewide higher education admissions policy

COMMITTEE: Higher Education - committee substitute recommended

VOTE: $\quad 8$ ayes - Rangel, Solis, Bailey, Cuellar, Dunnam, Kamel, Rabuck, E.

Reyna

0 nays

1 absent - Rodriguez

WITNESSES: $\quad$ For - Miguel Bedolla; Robert Goad; Al Kauffman, Mexican American Legal Defense Fund; Thomas Larralde; Bobby I. Martinez and Alfonso Menchaca, Mexican American Physicians Association; David Montejano; Ricardo Romo; Oscar de la Torre; Gerald Torres

Against - None

On - William H. Cunningham; Leo Sayaverda

DIGEST:

CSHB 588 would establish uniform admission and reporting procedures for the state's general academic colleges and universities considering admission applications of first-time freshman students. The bill would require that each institution admit applicants who graduated in one of the two preceding school years from accredited public or private high schools and whose grade point average placed them in the top 10 percent of their graduating class.

The institutions would review the files of the admitted applicants to determine which applicants would benefit from additional preparation for college-level work or participation in a retention program. Students requiring such work could be required to enroll during the summer following their admission to begin enrichment courses and orientation programs. Students not selected for additional preparation could enroll for the summer term.

Each academic year, an institution's governing board would have to decide whether to extend the scope of automatic admissions to include students from the top 25 percent of high school graduating classes.

-1 - 
HB 588

House Research Organization

page 2

After admitting either the top 10 or top 25 percent of high school graduating classes, schools would consider other applicants for admission. Students whose GPA did not afford them automatic admission would be permitted to apply to any general academic institution.

CSHB 588 would establish legislative intent that all institutions of higher education pursue academic excellence by considering academic achievement as well as other indicators of performance. In making first-time freshman admissions decisions, schools could consider all or any of a number of other factors, including:

- the applicant's academic recotd, socioeconomic background, income level, family educational history, and bilingual proficiency;

- the financial status of the applicant's school district and the performance level of the applicant's school, as determined by the school accountability criteria used by the Texas Education Agency;

- the applicant's responsibilities while attending school, including ' whether the applicant was employed or helped to raise children;

- the applicant's place of residence, whether rural or urban, central city or suburban area, and region;

- the applicant's performance on standardized tests, both isolated and in comparison to other students from similar socioeconomic backgrounds;

- whether the applicant attended any school under a court-ordered desegregation plan or had been admitted to a comparable out-of-state institution;

- the applicant's involvement in community activities and extracurricular activities and commitment to a particular field of study;

- results of a personal interview with the applicant; and 
HiB 588

House Research Organization

page 3

- any other consideration the institution considers necessary to accomplish its stated mission.

The provisions of CSHB 588 would not apply to institutions with open enrollment policies.

At least one year before the date that applications would be considered under these conditions, schools would have to publish in the catalogues a description of the factors they considered in admissions decisions and make the information available to the public. Each school would have to report annually to the Higher Education Coordinating Board on its freshman class, including a demographic breakdown by race, ethnicity, and economic status.

General academic institutions and medical and dental schools that admitted undergraduate transfer students or graduate, postgraduate, or professional students would also be required to adopt a written admissions policy. The policy would have to be published in the institution's catalog and made available to the public. These institutions would have to adopt and publicize a similar written policy on awarding competitive scholarship or fellowship awards.

The coordinating board could adopt nulcs for reporting requirements and identifying students eligible for admissions.

The changes proposed by CSHB 588 would apply to applications for admissions and scholarship for the 1998 fall term or semester. The Higher Education Coordinating Board and each affected institution would be required to adopt rules or policies on admission of students by January 1 , 1988.

SUPPORTERS CSHB 588 would be a bold step to adapt admissions policies at Texas SAY: institutions of higher education to the changing needs of the state's changing population, allowing all students the opportunity to continue their education. Studies have shown that innate intellectual ability is distributed evenly throughout the population, occurring with equal regularity among all racial, ethnic, and socioeconomic groups. The under-representation, therefore, of certain groups in Texas colleges and universities does not indicate these students are unable to succeed in a university setting. Rather, 
HB 588

House Research Organization

page 4

it shows that these individuals have not been given an opportunity to show what they can do. CSHB 588 would establish a fair, race-neutral admissions structure providing students from all backgrounds and parts of the state an opportunity to continue their educations.

Admitting the top 10 percent of high school classes would ensure a highly qualified pool of students each year in the state's higher educational system. There is no better predictor of future success than past performance, and all students in the top 10 percent of their classes have shown themselves able to meet the highest standards of scholarship. The group admitted under CSHB 588 would be not only talented, but diverse: about two-thirds of graduating seniors in 1996 represented minority groups.

Automatically admitting the top 10 percent of graduating classes is a common element of higher education admissions policy, currently practiced by schools such as Southwest Texas State University and previously by the University of Texas at Austin. This provision would guarantee universities a high caliber of student while ensuring students who have been successful in high school a place in Texas higher education. The bill would specify that accredited high schools only would be considered; students who have excelled in these schools would be capsble students at any college or university in the state.

CSHB 588 would not overinflate college enrollments. For example, only one third of the top 10 percent students even applied to UT Austin in 1996. UT admitted 93 percent of thesc students, but over half of those students chose not to attend. Admitted students would attend colleges throughout the state and many would go out-of-state, preventing any one university from being flooded with students.

The bill would not harm students from high schools with rigorous academic programs. Schools would be free to admit students not in the top 10 percent of their class by considering other factors that make these students valuable, including the rigor of their high school curriculum.

Many regions of the state, school districts, and high schools in Texas are still predominantly composed of people from a single racial or ethnic group. Because of the persistence of this segregation, admitting the top 10 percent 
of all high schools would provide a diverse population and ensure that a large, well qualified pool of minority students was admitted to Texas universities.

The educational achievement level of a student's parents and their socioeconomic status still continue to be among the foremost predictors of academic achievement. CSHB $\$ 88$ would help break this cycle, allowing students to achieve greater things than the generation before them did. This strategy would not only assist minority students to whom affirmative action programs were previously targeted but also similarly deserving Anglo students.

CSHB 588 would allow schools to consider "all or any" of the socioeconomic criteria described, providing schools with guidance on reforming admissions policies but allowing them flexibility to comply in the way that best met their individual needs. Furthermore, the bill's reporting requirements would let students know exactly by what criteria they were being judged. These requirements also would keep the coordinating board informed about how admissions screenings were affecting the population of students in Texas' colleges and universities and generally provide an accurate, cohesive picture of whether admissions policies were working across the state.

Even though some colleges and universities currently employ policies that admit the top 10 percent of students and encourage the consideration of socioeconomic factors in the admission of students, many do not. And with higher education admissions procedurcs contested in the courts and on the federal level, it is prudent to establish a statewide admissions policy that would be clear, legally defensible, and most importantly, fair to all Texas' students.

OPPONENTS SAY:
CSHB 588 would decree statewide admissions policies that could actually harm institutions that are facing important decisions regarding admissions policies. In the past, the Legislature has wisely left decisions on admissions policies up to the individual schools. Universities should retain the authority to make such decisions and implement policies that best suit their individual needs and that will best help them meet their goals and educate their student bodies. 
HB 588

House Research Organization

page 6

Most schools already have policies in place that allow students to demonstrate that grade point average or standardized test scores do not accurately measure their qualifications for admission. UT Austin has freshman admission criteria that provide for consideration of "socioeconomic hardship," "special circumstances," and "related factors you tell us about in writing." At Texas A\&M, the admissions policy allows students to submit a written statement describing any special circumstances and requesting a more extensive file review.

Most schools have responded quickly and diligently to the recent changes affecting admissions throughout the Texas system of higher education. The University of Houston, for example, is now granting full file review to about two-thirds of the applications, up from 30 percent. Texas institutions of higher education institutions have proved themselves responsible in the past, and should be allowed to continue determining their own admissions policies.

CSHB 588 would not solve the problems created when the Fifth U.S. higher education. The employment of race-neutral criteria would not address the reason that affirmative was originally initiated: to overcome prejudice and discrimination and their effects on the educational, professional, and socioeconomic achievements of minorities.

The 1994 disparity study conducted by the General Services Commission indicated that discrimination still affects minorities in this state and that it would be ineffective to try to remedy this problem through race-neutral measures. The Higher Education Coordinating Board also studied the issue, and found that employing race-neutral criteria to increase minority participation in higher education would reach only about half of the minority students that could be reached through race-based policies.

CSHB 588 would do little to change the nature of higher education admissions. The top 10 percent of high school classes would normally be accepted to most schools, even without such a mandate. Furthermore, the list of socioeconomic criteria contained in the bill is preceded by a statement that schools could adopt "all or any" of them. Because the list includes such 
5. Levine, A. Why Innovations Fail. Albany: State University of New York Press, 1980.

6. Levine, D. O. The Condition of Women in Higher Education: A Decade of Progress, An Uncertain Future. ERIC Document ED 184 447, 1979.

7. Lindquist, J. Strategies for Change. Berkeley: Pacific Soundings Press, 1978.

8. National Research Council. Climbing the Ladder: An Update on the Status of Doctoral Women Scientists and Engineers. Washington, D.C.: National Academy Press, 1983.

9. Newcombe, J. P. "A Theory of Prescribed Acadernic Change: The Case of Title IX." Ph.D. dissertation, College of William and Mary, 1980.

10. —, and C. F. Conrad. "A Theory of Mandated Academic Change." Joumal of Higher Education, 52 (November/December 1981), 555-77.

11. Nordvall, R. C. The Process of Change in Higher Education Institutions. AAHEERIC/Higher Education Research Report No. 7. Washington, D.C.: American Association for Higher Education, 1982.

12. Peterson, M, W, et al. Black Students on White Campuses: The Impacts of Increased Black Enrollments. Ann Arbor: Institute for Social Research, University of Michigan, 1978.

13. Taylor, M. L. "The Role of the Staff Specialist in the Policy Implementation Process," Ph.D. dissertation, Harvard University, 1979.

14. - "Implementing Affirmative Action: Impetus and Enabling Factors in Five Organizations." Research in Corparate Performance and Policy, 3 (1981), 43-69. 
APPENDIX B

FOCUS GROUP INTERVIEW PROTOCOL 


\section{Interview Protocol - Focus Group}

Date

Location

Time

1. Affirmative Action has been used by agencies and institutions that receive government funds to ensure equity and access in the workplace. Prior to Hopwood, race based admissions was a common practice used by higher education institutions to ensure Affirmative Action standards were met. The Hopwood v. Texas case systemically banned the use of race in admissions in Texas. As an alternative to AA, Texas public colleges and institutions, instituted "race neutral" policies. What is your understanding and perception of "race neutral" policies in higher education admissions?

2. Can you think of any instances during your senior year in high school where the Top $10 \%$ law was explained to you? Was the purpose and history of the Top 10\% explained? If so, explain your reactions or feelings?

3. Admissions standards are based on pre-established criteria set by colleges and institutions. What standards were most important to you as you sought admissions to Texas colleges and universities? Did you think of your race or ethnicity as a possible advantage or disadvantage?

4. What influence did the Top $10 \%$ Law have on your application and selection to attend Texas A\&M University? Was money the main factor?

5. Do you consider your high school to be academically elite, competitive, satisfactory or marginal and what evidence supports your answers?

6. What has been your experience with classmates who have not been accepted into Texas A\&M because they were not Top $10 \%$ ?

7. Discuss your thoughts about being more qualified, less qualified, or about the same as other students who are not Top $10 \%$ ? What evidence supports your thoughts?

8. Do you think Top $10 \%$ underrepresented minority students are viewed different than majority students? Describe any situations or events that have occurred - positive or negative - that you feel are related to the Top $10 \%$ status?

9. Do you feel the Top $10 \%$ Law is a fair admissions policy and adequately provides equal access and opportunity to all students?

10. If the Top $10 \%$ law was abolished or reduced to $5 \%$, how do think that would have affected you and your admissions to Texas A\&M?

11. Tell me about your overall feelings of race neutral admissions and its utility to ensure fairness, equity, and access to top tier colleges and institutions?

12. Do you consider your socio-economic status an advantage you had over other students who may not have had the same familial or financial resources to prepare for college?

13. Is there anything you would like to add or comment on that I did not ask? 


\section{CURRICULUM VITAE}

NAME:

C. J. Woods

ADDRESS:

325 Mojave Canyon Drive, College Station TX 77845

EDUCATION

B.S., University of Southern Mississippi, 1993

\& TRAINING:

M.E., George Mason University, 1995

PROFESSIONAL

SOCIETIES:

Association for Student Conduct Administrators

Southern Association of College Student Administrators

College Student Educators International (ACPA)

Association for the Study of Higher Education

Association of Fraternity/Sorority Advisors

PROFESSIONAL

SERVICE:

Assistant Vice President, Division of Student Affairs

Texas A\&M University (2009-present)

Director, Multicultural Services

Texas A\&M University (2006-2009)

Director, Diversity Programs

Western Kentucky University (1998-2006)

Coordinator, Judicial Affairs

Western Kentucky University (2002-2006) 